\title{
International Emigrant Selection on Occupational Skills
}

\author{
Alexander Patt, Jens Ruhose, Simon Wiederhold, and \\ Miguel Flores \\ CID Research Fellow and Graduate Student \\ Working Paper No. 84 \\ June 2017
}

(c) Copyright 2017 Patt, Alexander; Ruhose, Jens; Wiederhold, Simon; Flores, Miguel; and the President and Fellows of Harvard College
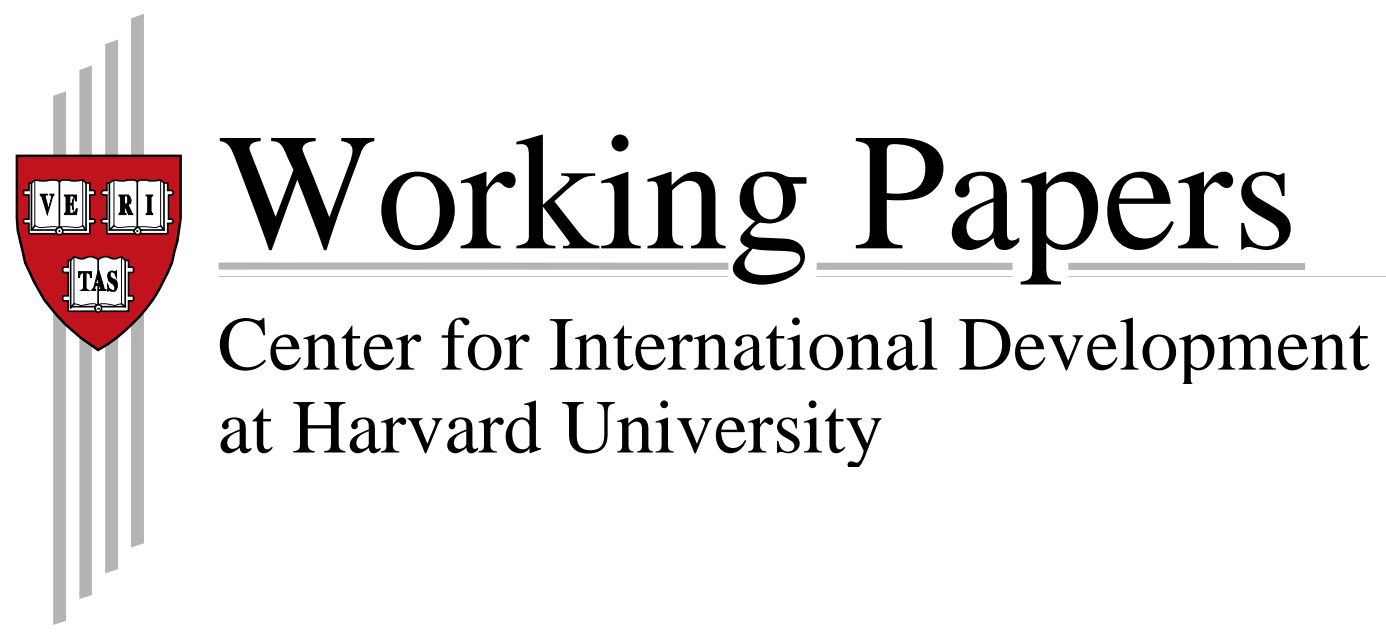


\title{
International Emigrant Selection on Occupational Skills
}

\author{
Alexander Patt, Jens Ruhose, Simon Wiederhold, and Miguel Flores*
}

\begin{abstract}
We present the first evidence that international emigrant selection on education and earnings materializes through occupational skills. Combining novel data from a representative Mexican task survey with rich individual-level worker data, we find that Mexican migrants to the United States have higher manual skills and lower cognitive skills than non-migrants. Conditional on occupational skills, education and earnings no longer predict migration decisions. Differential labor-market returns to occupational skills explain the observed selection pattern and significantly outperform previously used returns-to-skills measures in predicting migration. Results are persistent over time and hold within narrowly defined regional, sectoral, and occupational labor markets. (JEL F22, O15, J61, J24)
\end{abstract}

*Patt: KU Eichstätt-Ingolstadt, Auf der Schanz 49, D-85049 Ingolstadt, Germany (e-mail: alexander.patt@ ku.de); Ruhose: Leibniz Universität Hannover, Königsworther Platz 1, D-30167 Hannover, Germany (e-mail: ruhose@wipol.uni-hannover.de); Wiederhold: KU Eichstätt-Ingolstadt (Auf der Schanz 49, D-85049 Ingolstadt, Germany), ifo Institute, and CESifo (e-mail: simon.wiederhold@ku.de); Flores: Tecnologico de Monterrey, Escuela de Gobierno y Transformación Pública, Eugenio Garza Laguera y Rufino Tamayo, San Pedro Garza Garcia, 66269, Mexico (e-mail: miguelflores@itesm.mx). We thank George J. Borjas, Benjamin Elsner, Jesús Fernández-Huertas Moraga, David Figlio, Lawrence Kahn, Marc Piopiunik, Andreas Steinmayr, seminar participants at the University of Trier, and participants at the 2016 meeting of the American Economic Association in San Francisco, the 13th IZA Annual Migration Meeting in Bonn, the 2016 meeting of the German Economic Association in Augsburg, and the 2017 meeting of the standing field committee "Education Economics" of the German Economic Association in Hanover for helpful comments. We are also grateful to Jesús Fernández-Huertas Moraga for sharing his code for cleaning the ENET data. Patt, Wiederhold, and Flores are thankful for the hospitality provided by the Center for International Development at Harvard University, with special thanks to Ricardo Hausmann, Ljubica Nedelkoska, and Frank Neffke. Wiederhold gratefully acknowledges the receipt of a scholarship from the Fritz Thyssen Foundation for financing the research stay at Harvard University. Patt and Wiederhold also gratefully acknowledge financial support from the European Union's (Grant agreement no. 290683) FP7 through the LLLight'in'Europe project. 


\section{Introduction}

The worldwide stock of international migrants amounts to 244 million people (equivalent to $3.3 \%$ of the world population), having increased by almost $60 \%$ over the last 25 years (United Nations, 2015). International migration is often directed toward developed countries. Between 1990 and 2015, the population share of international migrants in developed countries has increased from $7.2 \%$ to $11.2 \%$. Because international migrants make up a sizeable fraction of the labor force in many countries, knowing the skill structure of the migrant flow-and the factors determining it-yield important information for labor-market and immigration policies. For the receiving country, the skills of immigrants determine how easily they can be integrated into the labor force and how they will affect natives' earnings and employment opportunities (among others, Borjas, 1994; Dustmann et al., 2016; Peri, 2016). For the sending country, the characteristics of emigrants have implications for domestic income levels and growth opportunities (e.g., due to absent productive household members, remittances, and knowledge transfer back to the home country).

Given the social and economic implications of migration, it is not surprising that an abundant literature deals with the selectivity of migrants (see Section II.). The most widely studied dimensions of selection are educational attainment and earnings as proxies for migrants' productive capacity (or skills). These proxies, however, have important limitations for understanding migrant selection. For instance, although educational attainment tends to be a good predictor of labor-market success, it is typically fixed after labor-market entry and is therefore uninformative regarding skill developments during the career. Earnings, as a broad summary measure of skills that presumably reflects all sorts of observed and unobserved inputs (e.g., ability, family background, school quality, on-the-job training, etc.), cannot explain the mechanism behind the selection pattern. ${ }^{1}$

Our paper is the first to look at the selection of emigrants on occupational skills, that is, human capital acquired through performing tasks associated with the job. Occupational skills are a more direct measure of the knowledge and capabilities relevant in the labor market than educational attainment and-because several skill dimensions can be considered-are a more detailed measure of migrants' productive capacity than are earnings. Going beyond education and earnings in describing migrants' skills is also important because many moves across borders are work related. ${ }^{2}$ Thus, using occupational information should yield important new insights into how and why people choose to migrate.

\footnotetext{
${ }^{1}$ In fact, previous studies have found a non-monotonic pattern in the probability of migration as a function of residual wages, which cannot be explained by a uni-dimensional skill measure (Gould and Moav, 2016). Parey et al. (2017) is one of the few exceptions that systematically investigates the components of predicted earnings and how they relate to emigrant selection.

${ }^{2}$ Recent estimates suggest that one-half of all migration movements to OECD countries are for work-related reasons (OECD, 2016). This counts migration within free movement areas (e.g., the European Union) as being workrelated, since having a job in the destination country is a typical requirement to establish residence in another member state.
} 
We use the case of migration from Mexico to the United States to study the role of occupational skills in emigrant selection. Mexican migrants constitute by far the largest foreign-born population in the United States; almost one-third of all foreigners in that country are Mexican-born immigrants (Hanson and McIntosh, 2010). Using novel data from CONOCER, a large-scale survey of Mexican workers designed to be similar to the U.S. O*NET, we characterize occupations by their skill content in terms of two dimensions, manual skills and cognitive skills. ${ }^{3}$ Manual skills are related to, for example, physical strength and using machinery and tools. Cognitive skills capture skills that are related to, for example, problem solving, proactivity, and creativity. For our analyses, it is useful to construct skill measures that are directly comparable between Mexico and the United States. We thus combine the results from a principal component analysis of the O*NET data with the responses to the questions from CONOCER that were asked in the same fashion as in $\mathrm{O}^{*} \mathrm{NET}$ to calculate our Mexican skill measures. ${ }^{4}$ The resulting measures allow us to interpret the skills of Mexican workers within the skill distribution of U.S. workers.

We merge these skill measures at the detailed occupational level with individual-level Mexican worker data from the National Survey of Occupation and Employment (ENOE), the Quarterly National Labor Survey (ENET), the Mexican Migration Project (MMP), and the Mexican Family Life Survey (MxFLS). ${ }^{5}$ These datasets allow identifying migrants from Mexico to the United States and additionally contain rich pre-migration information on worker characteristics (including labormarket history, earnings, age, education, gender, and marital status). Due to the longitudinal nature of the worker data, our measures of cognitive and manual occupational skills are based on several pre-migration occupations. This allows us to account for the possibility that the last pre-migration occupation is endogenous to the migration decision, for instance, because a negative labor-market shock forces workers to enter a less desirable occupation and pushes them to migrate. We can also consider individuals with unemployment spells before migration, who, typically, are ignored when the selection on earnings is investigated. Throughout, we focus our attention on the migration decisions of Mexican males because of females' low labor-market participation rates (Kaestner and Malamud, 2014).

Comparing the occupational skills of migrants and non-migrants, we document that Mexican migrants to the United States are positively selected on manual skills, that is, migrants have higher manual skills than non-migrants, and are negatively selected on cognitive skills, that is, migrants have lower cognitive skills than non-migrants. The same selection pattern appears in estimations that simultaneously include both skill measures and condition on age, educational attainment, and

\footnotetext{
${ }^{3}$ The survey was conducted by the Consejo Nacional de Normalización y Certificación de Competencias Naturales.

${ }^{4}$ We find similar results performing the principal component analysis on the CONOCER data, making us confident that $\mathrm{O} * \mathrm{NET}$ and CONOCER capture comparable skill concepts.

${ }^{5}$ Below, we devote considerable attention to discuss the implications of assigning Mexican workers the average skills in their occupation (see Sections III.A. and IV.B.).
} 
earnings. In these models, educational attainment and earnings are no longer important predictors of migration. This suggests that the negative selection on education and earnings found in other studies materializes to a large extent through the selection on occupational skills. In terms of magnitude, we find a $16 \%$ drop in the migration propensity for a one-decile increase in cognitive skills (e.g., corresponding to the cognitive-skill distance from a shoemaker to a medical technician). In contrast, migration propensity increases by $18 \%$ for a one-decile increase in manual skills (e.g., from a cook to a carpenter).

These results also hold within narrowly defined regional and sectoral labor markets and when conditioning on detailed occupational categories (up to the three-digit level). Thus, the observed selection pattern does not merely reflect that workers in certain occupational groups (e.g., agriculture) or from certain segments of the labor market (e.g., labor-intensive economic sectors) are more likely to migrate. We also address potential endogenous occupational choice by exploiting information on the individual's occupation at the start of the labor-market career in an instrumentalvariable analysis. These models strongly confirm the baseline results, which supports the idea that a worker's occupation does contain relevant information on his set of skills. Furthermore, we show in various ways that skill mismatch between a worker's skill endowment and the job requirements is unlikely to affect our conclusions. Finally, we investigate the long-run dynamics of selection on occupational skills of Mexico-to-U.S. migrants. Exploiting the fact that our worker data reach back to the 1950 s, we find that the selection pattern remained highly persistent over periods of sharp increases in net migration and periods where net migration has plummeted. ${ }^{6}$

We rationalize our findings in a Roy/Borjas-type selection model (Roy, 1951; Borjas, 1987) with two related skills ${ }^{7}$ by showing that the returns to manual skills for Mexicans are higher in the United States than in Mexico, while the opposite holds for the returns to cognitive skills. Intuitively, as in the Roy/Borjas model, individuals self-select into migration if they receive a higher reward for their skills in the foreign country than they do in the home country. The comparison of skill returns between Mexico and the United States is possible because we construct skill measures that are directly comparable across borders.

Recent studies document that Mexican emigrants are strongly negatively selected on earnings and argue that this pattern can be explained by the fact that the benefits of migration are negatively correlated with earnings (i.e., those with the highest earnings in Mexico profit the least from migration) (Ambrosini and Peri, 2012; Kaestner and Malamud, 2014). Supporting the notion that migrant selection on earnings materializes through occupational skills, we show that adjusting for differential returns to occupational skills between Mexico and the United States substantially al-

\footnotetext{
${ }^{6}$ See Hanson and McIntosh (2010) for details on the various emigration waves that Mexico has experienced during the last 70 years.

${ }^{7}$ Dustmann et al. (2011) develop a Roy/Borjas model with two skills in the context of return migration.
} 
ters the pattern of migrant selection on earnings. ${ }^{8}$ In fact, when accounting for these differential returns, the selection on earnings almost entirely disappears. We also observe that differential returns to occupational skills are themselves highly predictive for Mexican emigration and clearly outperform previously used differential-return measures (based on worker's socioeconomic characteristics, such as education, age, and marital status) in explaining both migration out of Mexico and the selection on earnings. These results underscore that occupational skills are more important than education and other observed determinants of earnings in predicting migration, and that it is sufficient to study emigrant selection on occupational skills to understand selection on earnings.

Our work contributes to the large stream of literature describing the allocation of human capital across countries due to migration (see Section II.). In terms of methodology, Abramitzky et al. (2012) is perhaps most closely related to our paper. They investigate the selection of migrants from Norway to the United States in the late nineteenth century, and show that the selection pattern is (at least partly) consistent with the one-dimensional Roy/Borjas model. Lacking individual earnings information, they assign individuals the average earnings for their occupation. Our approach infers individual skill endowment from the average cognitive and manual skills in an occupation. This allows us to study selection along two skill dimensions highly relevant in the labor market and to investigate the implications of selection on occupational skills for the selection on other proxies for migrant skills (i.e., earnings and education). In addition, the labor flows we study are of immediate interest for policy today.

Our paper also adds to the growing stream of literature that considers the occupation in which a worker is employed as an important proxy for human capital. While earlier analysis of worker mobility after job displacement has argued that human capital is specific to firms (e.g., Jacobson et al., 1993), industries (e.g., Neal, 1995; Parent, 2000), or occupations (Kambourov and Manovskii, 2009), more recent evidence shows that human capital is rather specific to the basic tasks performed in occupations (e.g., Gibbons and Waldman, 2004; Poletaev and Robinson, 2008; Gathmann and Schönberg, 2010; Nedelkoska et al., 2017). This latter literature was highly influenced by the work of Autor et al. (2003), Ingram and Neumann (2006), and Spitz-Oener (2006) that uses job task surveys to describe each occupation in terms of the skill set required to accomplish the job tasks. ${ }^{9}$ In our paper, we explore the implications of occupational skills for migrant selection. Because a number of countries have already made efforts to collect detailed information about the tasks performed on the job, the selection of migrants with respect to occupational skills can be investigated for a wide range of migration flows (both domestically and internationally). ${ }^{10}$

\footnotetext{
${ }^{8}$ To take into account the bundling of skill requirements within occupations (e.g., Heckman and Scheinkman, 1987; Autor and Handel, 2013), we construct returns to occupational skills by partitioning the skill distribution into four-by-four manual-by-cognitive skill cells.

${ }^{9}$ See Acemoglu and Autor (2011) for a formal task-based framework.

${ }^{10}$ In particular, job task surveys have been conducted in countries known for sending or receiving large numbers of migrants, for instance, in Germany (Qualification and Career Survey), Mexico (CONOCER), the United Kingdom
} 
The remainder of the paper is structured as follows. Section II. provides an overview of the migration selection literature, both in general and specifically for Mexico-U.S. migration. Section III. introduces the data. Section IV. develops a Roy/Borjas selection model with two related skills, derives the model predictions, and tests them empirically for Mexican emigrants to the United States. Section V. explains our strategy for estimating the selection on occupational skills and Section VI. presents the results. Section VII. provides evidence for the importance of differential returns to occupational skills between Mexico and the United States in explaining the selection on earnings. Section VIII. discusses the robustness of our findings and investigates how selection on occupational skills changes over time. Section IX. concludes.

\section{Related Literature}

There is an abundant literature dealing with the selection of international migrants (Table A1 in the Appendix). Three observations stand out. First, ever since Borjas (1987), this field of research has expanded rapidly. Second, most of the studies use either educational attainment or some measure of earnings to measure productivity and skills of individuals. Notable exceptions are Abramitzky et al. (2012), who use occupational information to impute individual earnings by the average earnings in the occupation, and Ramos (1992), who constructs predicted earnings from occupational information. Both papers acknowledge that occupations contain information that is important in determining individual labor-market productivity. Third, previous work has not consistently shown that the observed selection pattern is compatible with the basic Roy/Borjas model predicting that workers migrate when returns to their skills are lower in their home country than abroad. One reason for these mixed results could be that the observed skill measure does not fully reflect migrants' labor-market skills (as may be the case for educational attainment) and that broader measures of migrant skills, such as actual or predicted earnings, are more appropriate in evaluating the selection of migrants (Parey et al., 2017). However, aggregate summary measures of migrants' productive capacity are uninformative regarding the mechanism behind the observed selection pattern.

The literature that specifically deals with Mexican migration to the United States (Table A2 in the Appendix) yields similar insights. A highly influential paper by Chiquiar and Hanson (2005) uses the U.S. Census to identify Mexican migrants and computes predicted earnings for migrants and non-migrants based on education, age, gender, and marriage status in Mexico from the Mexican Census. Comparing predicted earnings of migrants and non-migrants, Chiquiar and Hanson (2005) find that Mexican migrants are drawn from the middle of the predicted earnings distribution in Mexico. They also find intermediate selection on educational attainment. ${ }^{11}$ However, intermediate

(British Skills Survey), and the United States (e.g., Dictionary of Occupational Titles and its successor O*NET). See Section III. and Autor (2013) for overviews.

${ }^{11}$ Using the same approach of comparing Mexican migrants in the U.S. Census to Mexican non-migrants in the 
selection is not consistent with the predictions of the basic Roy/Borjas model; because returns to education are higher in Mexico than in the United States (e.g., Fernández-Huertas Moraga, 2013), the Roy/Borjas model predicts that Mexican migrants should be negatively selected. In line with this prediction, Ibarraran and Lubotsky (2007) observe that Mexican migrants are negatively selected when comparing migrants in the U.S. Census and return migrants in the Mexican Census to non-migrants in the Mexican Census. They explain this difference from the results of Chiquiar and Hanson (2005) by the fact that low-skilled and undocumented migrants are underreported in the U.S. Census (see also Hanson, 2006).

Due to these problems in U.S. Census data, more recent papers use longitudinal Mexican data with rich pre-migration characteristics to study the selection of Mexican emigrants. For instance, drawing on data from the Quarterly National Labor Survey (ENET), Fernández-Huertas Moraga (2011) finds that migrants are in fact negatively selected on actual earnings and educational attainment. Using data from the Mexican Family Life Survey (MxFLS), which tracks Mexicans in the United States, Ambrosini and Peri (2012) and Kaestner and Malamud (2014) also document that migrants are negatively selected on actual earnings. Rendall and Parker (2014) combine different datasets to investigate educational selection over time and consistently find that Mexican migrants are negatively selected. However, other work that uses longitudinal migrant data from the Mexican Migration Project (MMP) finds intermediate educational selection (Orrenius and Zavodny, 2005).

In sum, the literature on the selection of migrants is inconclusive as to whether the basic Roy/Borjas model can predict migration patterns. The main reasons for these mixed results are the use of different measures to proxy the productive capacity of migrants and the different sampling frames of the migration data.

\section{Data and Construction of Occupational Skill Measures}

This study's primary innovation is its use of detailed information on the skill structure of Mexican occupations provided by the Mexican CONOCER survey. In this section, we describe the CONOCER data and our construction of the occupational skill measures based on these data. To investigate the selection on occupational skills of Mexican emigrants, we link these measures to rich Mexican micro-level datasets that allow us to identify migrants to the United States. These datasets are also described below.

Mexican Census, Mishra (2007) and Feliciano (2008) argue that Mexican migrants are better educated on average than their peers staying in Mexico. 


\section{A. Measuring Occupational Skills in Mexico}

In 2012, the Mexican government fielded the CONOCER survey to collect comprehensive information about the competencies required in the universe of occupations in Mexico. CONOCER is a representative worker survey of 17,250 respondents in 443 occupations (four-digit level). The median number of respondents per four-digit occupation is 30 , with only $3 \%$ of occupations having fewer respondents. ${ }^{12}$ The survey captures an exceptionally large set of job content aspects, grouped into seven domains (responsibility, knowledge, tools, abilities, social skills, traits, and physical skills) with more than 100 questions in total, thus providing detailed information about the nature of jobs that is directly comparable across all occupations.

CONOCER was designed to be comparable to the U.S. O*NET, which has been used extensively in prior research (e.g., Acemoglu and Autor, 2011; Firpo et al., 2011; Autor and Dorn, 2013; Kok and ter Weel, 2014). ${ }^{13}$ Similar to O*NET, CONOCER contains information about how important a particular job aspect is, ranging from 1 ("dispensable") to 5 ("essential"). ${ }^{14}$ We aggregate the survey information from the individual to the occupational level by using occupational averages at the four-digit level (for a similar aggregation with German task data, see Gathmann and Schönberg, 2010), which gives us a representative measure of the average skill content in each detailed Mexican occupation.

We construct occupational skill measures that are directly comparable across borders. ${ }^{15}$ First, we map CONOCER domains to corresponding domains in O*NET. In each domain, we choose a subset of questions from both surveys that are worded similarly, ${ }^{16}$ organize all matching questions into four major groups (i.e., use of tools, physical skills, cognitive \& social skills, and use of office equipment), and apply principal component analysis (PCA) separately on each group to reduce the dimensionality of the data. ${ }^{17}$ Because the first principal components capture $50-95 \%$ of the

\footnotetext{
${ }^{12}$ Excluding occupations with fewer than 30 observations in the CONOCER survey from our main estimation sample does not affect the results.

${ }^{13}$ The Occupational Information Network (O*NET), developed under the sponsorship of the U.S. Department of Labor, is an ongoing data collection program that surveys employees and occupational experts in the United States. Ever since the O*NET replaced the DOT in 1998, it has been the primary source of information about job content in the United States. O*NET is designed according to the content model, which explicitly distinguishes between fixed characteristics of employees (e.g., physical and cognitive abilities, values and work style preferences), acquired characteristics (knowledge and different categories of skills), and experience. Specifically, O*NET has 52 variables related to abilities, 35 to skills, 41 to generalized work activities, and 16 to work styles.

${ }^{14}$ The importance scales in $\mathrm{O}^{*} \mathrm{NET}$ use the same range of values and are worded similarly.

${ }^{15}$ Section B in the Appendix explains the construction of the measures in detail. Our analysis uses O*NET database version 19, released in July 2014, which describes 699 jobs classified in a generally consistent way with the Standard Occupational Classification (SOC).

${ }^{16}$ These questions come from the CONOCER domains of use of tools, social skills, personal traits, and physical abilities. Matching questions from $\mathrm{O}^{*} \mathrm{NET}$ come from the domains of work activities, work styles, and abilities.

${ }^{17}$ Ingram and Neumann (2006) use a related data reduction technique, factor analysis, in constructing measures of skills from 53 variables on tasks collected in the Dictionary of Occupational Titles, the predecessor to O*NET. Yamaguchi (2012) and Autor and Handel (2013) employ PCA to create similarly constructed measures of tasks.
} 
variation in each group, they provide an efficient summary of the group data. As a measure of manual skills, we take the first principal component of the reduced variables for use of tools and physical skills. As a measure of cognitive skills, we take the first principal component of the reduced variables for cognitive \& social skills and use of office equipment. ${ }^{18}$ Based on the PCA analysis of $\mathrm{O}^{*} \mathrm{NET}$, we calculate manual and cognitive skill scores for each Mexican occupation by taking the rotations corresponding to the variables from each domain and applying them to the responses in CONOCER. ${ }^{19}$ The resulting skill scores allow us to interpret the skills of Mexican workers within the skill distribution of U.S. workers. To facilitate interpretation, we convert the raw scores to a percentile scale based on the distribution of the scores in the 2010 U.S. Census.

Table 1 shows the six top and six bottom Mexican occupations in terms of cognitive and manual skill content. Occupations like managers/coordinators, municipal authorities, hotel managers, specialists in HR, secondary school teachers, and professors score high on cognitive skills, while operators of agricultural machinery, farm managers and foremen, support workers in agriculture, miners, and loggers have high manual skills. Log splitters, cattle breeders, workers in certain crops, garbage collectors, and workers in maize/beans have the lowest cognitive skills. Software developers, photographers, fiber weavers, and street vendors have the lowest manual skills. Three observations emerge from this table. First, PCA seems to yield a sensible classification of jobs along the two skill dimensions. Second, cognitive and manual skills are negatively correlated (at the occupational level: $\rho=-0.19$ ), but neither one is the mirror image of the other; the top-six cognitive skill occupations do not overlap with the bottom-six manual skill occupations or vice versa. Third, even within the top-six and bottom-six occupations, there is some variation in the skills of the other skill dimension. For example, within the bottom-six manual skill occupations are street vendors who need very little cognitive skill for their jobs and software developers who need very high cognitive skills.

Figure 1 demonstrates the variation in cognitive and manual occupational skills and the ranking of occupations along both dimensions in the 2010 Mexican Census. For example, a street vendor is at the 37th percentile of the U.S. manual skill distribution and at the 5th percentile of the U.S. cognitive skill distribution. In contrast, an engineer has both higher manual skills (75th percentile) and higher cognitive skills (91st percentile) than a street vendor. An architect has even higher cognitive skills than an engineer (95th percentile), but somewhat lower manual skills (70th percentile). We again observe the negative correlation between the two types of skills (weighted by number of individuals: $\rho=-0.56$ ), but we also see plenty of variation in the other skill for a given level of

\footnotetext{
${ }^{18}$ Because we use only a subset of questions from both surveys, we do not take into account all available information. However, alternative skill measures based on the full set of CONOCER questions provide scores highly correlated with those constructed from the subset of questions $(\rho>0.86)$.

${ }^{19}$ Reassuringly, we find that all rotations belonging to the same group have the same sign and are usually numerically close to their counterpart in the other survey (Appendix Table B2). This suggests that the domains in both surveys measure similar skill dimensions.
} 
cognitive or manual skills.

The figure also illustrates that the average Mexican worker, relative to his peers in the United States, has high manual skills and low cognitive skills (indicated by the red lines). Moreover, while the distribution of cognitive skills in Mexico covers the entire U.S. skill range, the distribution of manual skills is compressed and ranges mainly between the 33rd and 84th percentile of the U.S. manual skill distribution. ${ }^{20}$ There are several potential reasons for the compressed manual skill distribution in Mexico. First, the skill-biased employment structure in the United States could have led to the creation of (labor-intensive) jobs that are not available in Mexico. For example, the high opportunity cost of skilled workers in the United States to perform simple tasks results in a market for services that are close substitutes for home production activities (e.g., personal care services, housekeeping, etc.) (Cortés and Tessada, 2011; Mazzolari and Ragusa, 2013). Second, but related to the first argument, task specialization among natives and migrants leads to an expansion of occupations with high cognitive skill intensity among natives and high manual skill intensity among migrants (Peri and Sparber, 2009; Peri, 2012), increasing the variance in occupational skills. ${ }^{21}$ Third, countries with a higher GDP per capita usually have a more diverse set of products and services (Cadot et al., 2011; Imbs and Wacziarg, 2003), which could translate into a higher variance in occupational skills.

Because we assign workers the average skills for their occupation, our results throughout the paper rely on between-occupational variation in skills. This unavoidable limitation has implications for the analysis of migrant selection on occupational skills (see also Abramitzky et al., 2012, for a discussion in the context of migrant selection based on average occupational earnings). ${ }^{22}$ Positive migrant selection, for instance, could be generated either by high migration rates among Mexicans from occupations with high average occupational skills or by high migration rates among Mexicans at the top percentiles of the occupational skill distribution within their occupation. Of course, an analogous argument holds for negative selection. However, since the selection pattern is very similar within broader occupational groups (see Section VIII.A.), we are confident that inferring a worker's actual skill level (which is unobservable to us) from the average skill level in her occupation is no first-order concern.

\footnotetext{
${ }^{20}$ Overall percentile ranges of occupational skills in the Mexican worker surveys (described below) are very similar.

${ }^{21}$ For example, using the U.S. Census 2000, we find that agricultural workers and construction workers have manual scores above the 90th percentile; these occupations have manual scores around the 70th percentile in Mexico. Even though it is difficult to compare occupations across borders because they differ in their specific contents and requirements, this could mean that Mexican migrants have higher manual skills than the average worker in their previous occupation in Mexico and/or that migrants work in occupations in the United States that require higher manual skills than the occupation previously held in Mexico. We discuss the implications of skill mismatch and partial skill transferability in Section IV.

${ }^{22}$ To the best of our knowledge, there are no data sources that would allow us to measure the occupational skill level of migrants within an occupation.
} 


\section{B. Identifying Mexican Emigrants}

\section{Mexican Labor Force Survey (ENET/ENOE)}

Our main source of worker data is the Mexican Quarterly Labor Force Survey, which has been used extensively to study the selection of Mexican emigrants to the United States (see, e.g., FernándezHuertas Moraga, 2011, 2013; Rendall and Parker, 2014). From 2000 to 2004, the Instituto Nacional de Estadística, Geografía e Informática (INEGI) conducted the Quarterly National Labor Survey (Encuesta Nacional de Empleo Trimestral-ENET). After 2004, the survey was replaced by the National Survey of Occupation and Employment (Encuesta Nacional de Ocupación y EmpleoENOE). Our main specifications are based on ENOE because it is more recent and covers a wider range of years than ENET. We use ENOE data from Q1/2005-Q3/2014 and draw on ENET for robustness tests.

The structure of the survey is similar to the Current Population Survey (CPS) in the United States; households are surveyed for five consecutive quarters and the survey reports sociodemographic variables, such as age, gender, educational attainment, occupation, and earnings of (documented and undocumented) migrants and non-migrants. The panel structure of the survey allows the identification of emigrant characteristics before the move.

In all specifications based on the Mexican Labor Force Survey, migrants are defined as males between 16 and 65 years of age, who lived in Mexico in quarter $t$ and who left for the United States in quarter $t+1$. Mexican residents, on the other hand, are those living in Mexico in both quarter $t$ and quarter $t+1$. We restrict our analysis to males because of Mexican women's high rates of nonparticipation in the labor market (Kaestner and Malamud, 2014).

The main advantage of the Mexican Labor Force Survey (compared to the other surveys described below) is that it is nationally representative and reports occupational information at a very detailed (i.e., four-digit) level, which is key to our approach. ${ }^{23}$

\section{Mexican Migration Project (MMP)}

The MMP is a bi-national study based at the University of Guadalajara and the University of Pennsylvania. It surveys Mexican households in Mexican communities that are known for sending a large number of migrants to the United States. Thus, the MMP is representative for immigrantsending communities, providing a sample of mainly urban communities with relatively high emigration propensities. Areas sampled in the MMP are identified by surveying Mexican migrants

\footnotetext{
${ }^{23}$ In Q2/2012, a new occupational classification system (Sistema Nacional de Clasificación de OcupacionesSINCO) was introduced, replacing the Mexican Classification of Occupations (Clasificación Mexicana de Ocupaciones-CMO). We use crosswalks between occupational codes to make the coding comparable over time. Details are provided in Section C in the Appendix.
} 
in the United States and then surveying their home community in Mexico. ${ }^{24}$ The survey started in 1982 and has been conducted annually since 1987. We use the MMP143 database with 143 communities, released in 2013. At each interview, a retrospective life history of the household head is gathered. This includes, among other things, migration experience, work history (including occupational information at the three-digit level), and marriage behavior.

Since one main aim of the MMP is to gather accurate data on (documented and undocumented) Mexican migration to the United States, respondents answer detailed questions on their migration episodes. In the analyses using MMP data, we define migrants as males aged 16 to 65 years who lived in Mexico at year $t$ and left for the United States the year after. Mexican residents are those who lived in Mexico in years $t$ and $t+1 .^{25}$ We again focus on males and restrict the analysis to household heads because they most likely make the decision about whether or not to migrate.

A unique feature of the survey is that it contains occupational information over a worker's whole career, allowing us to test the robustness of our results with respect to the occupation that best proxies a worker's skills (e.g., first occupation, last pre-migration occupation, rolling average over all pre-migration occupations, etc.). Extensive information on workers' occupational histories also provides the opportunity to investigate path dependencies of occupational choices and their implications for migrant selection. The MMP also includes information about whether migrants to the United States returned to Mexico and whether they left again for the United States. This allows us to investigate whether the pattern of selection on occupational skills is different for people with several Mexico-to-U.S. migration episodes.

\section{Mexican Family Life Survey (MxFLS)}

The MxFLS is a nationally representative household panel that follows individuals and households over time. The first round, in which about 8,000 households in Mexico were surveyed, took place in 2002. The second and third rounds took place in 2005 and 2009, respectively. A unique feature of the survey is that respondents are followed even to the United States, with re-contact rates for migrants and non-migrants as high as $90 \%$.

The main advantage of the survey is that it is representative of the Mexican population and also covers entire households that emigrated to the United States. Thus, it avoids the potential sample selection problem of missing households in the Mexican data (Steinmayr, 2014). Because the survey does not rely on retrospective information, the problem of recall bias is also reduced. However, the main disadvantages of the survey in the context of our study are the relatively small sample size of the migrant population and, more importantly, that information on occupations is provided only at the two-digit level (in total, only 18 occupations). Due to the coarse occupational information,

\footnotetext{
${ }^{24}$ Due to this sampling design, these areas have a migration propensity above the Mexican average.

${ }^{25}$ We drop years before 1950 because there was very little migration in the first half of the 20th century.
} 
the MxFLS-based measures of cognitive and manual skills will likely yield considerable measurement error. Despite these limitations of the MxFLS data, we use the survey to show that our results are robust to different sampling frames.

\section{Descriptive Statistics}

Table A3 in the Appendix provides summary statistics on migration rates, occupational skills, and main control variables for ENOE, ENET, MMP, and MxFLS surveys. Due to the different sampling frames, migration rates vary substantially across datasets, from $0.3 \%$ (per quarter) in ENOE to $2.5 \%$ (per year) in the MxFLS. However, the observed occupational skills are strikingly similar. Consistently across datasets, the average Mexican worker has relatively high manual skills and relatively low cognitive skills compared to his U.S. peer. The percentile ranks are very similar to those in the Mexican Census data (see Figure 1). ${ }^{26}$

We find substantial variation in skills within broader occupational groups (see Table A4 in the Appendix). Using ENOE, the skill range (difference between maximum skills and minimum skills) within one-digit occupations is 48 percentiles for manual skills and 66 percentiles for cognitive skills. At the two-digit level (43 occupations), we find a skill range of 34 percentiles for manual skills and 43 percentiles for cognitive skills. Even at the three-digit level (144 occupations), there is substantial variation in skills (17 percentiles for manual skills and 21 percentiles for cognitive skills). These large skill differences within occupational groups make a strong case for using our measures to categorize and rank occupations, because we can take into account both the large skill heterogeneity within broader occupational groups and skill similarities across occupational borders.

Strikingly, the ENOE data show that during the four pre-migration quarters $53 \%$ of individuals change their one-digit occupation at least once, suggesting a large degree of occupational mobility. However, if we look at the associated change in occupational scores, we find that workers tend to switch to occupations requiring similar skills. For manual skills, the median (mean) skill range is only 3 percentiles (9 percentiles) (i.e., 7\% (18\%) of the full skill range within one-digit occupations). For cognitive skills, the median (mean) skill range is 6 percentiles (16 percentiles) (i.e., $9 \%$ (24\%) of the full skill range). ${ }^{27}$ This analysis of the (skill) mobility of workers provides support for the idea that our occupation-level skill measures are a meaningful summary of individual's actual skills.

\footnotetext{
${ }^{26}$ See Section VII. for the construction and interpretation of the returns measures in Table A3.

${ }^{27}$ This result is consistent with recent evidence from the United States and Germany showing that individuals try to move to skill-related occupations to avoid the loss of specific human capital (Robinson, 2011; Nedelkoska et al., 2017).
} 


\section{Theory of Emigrant Selection}

\section{A. A Selection Model with Two Related Skills}

In this section, we develop a variant of the Roy/Borjas model (Roy, 1951; Borjas, 1987) of international migrant selection that accommodates two related skills. ${ }^{28}$ All workers are characterized by two skills labeled $z_{1}$ and $z_{2}$, for example, cognitive skills and manual skills, which are drawn from the bivariate normal distribution with the mean vector $\boldsymbol{\mu}$ and the covariance matrix $\Sigma$ :

$$
\mathbf{z} \sim N(\boldsymbol{\mu}, \Sigma), \quad \boldsymbol{\mu}=\left(\begin{array}{c}
\mu_{1} \\
\mu_{2}
\end{array}\right), \quad \Sigma=\left(\begin{array}{cc}
\sigma_{1}^{2} & \rho \sigma_{1} \sigma_{2} \\
\rho \sigma_{1} \sigma_{2} & \sigma_{2}^{2}
\end{array}\right) .
$$

Skills may be correlated, so $\rho \neq 0$ in general.

Occupations in the economy are represented by ordered pairs of task intensities $\mathbf{x}=\left(x_{1}, x_{2}\right) \in$ $\mathbb{R}^{2}$ with $x_{i}$ as the intensity of task $i$. Achieving maximum throughput in task $i$ with intensity $x_{i}$ requires supplying a skill input of the same type and quantity $x_{i}$. Every worker with a skill endowment $\mathbf{z}$ chooses an occupation $\mathbf{x}$ by minimizing the skill mismatch $\|\mathbf{z}-\mathbf{x}\|{ }^{29}$ Labor demand is perfectly elastic for any value of $\mathrm{x}$. In this setting, workers are perfectly matched ${ }^{30}$ and occupations, tasks, and skills are interchangeable. ${ }^{31}$

As in Roy (1951), we assume that productivity is log-normally distributed. We further assume that the log marginal product of labor is a linear function of skills and tasks (Welch, 1969; Dustmann et al., 2011). Together these assumptions imply that the earning capacity $w$ in a location $j$ is given by:

$$
\log w^{j}=\frac{1}{2} \mathbf{p}^{j} \cdot(\mathbf{z}+\mathbf{x})+\varepsilon, \quad j \in\{\text { abroad, origin }\},
$$

where $\mathbf{p}^{j}$ is a vector of returns to skills or returns to tasks (equivalently, skill or task prices) ${ }^{32}$ and $\varepsilon$ is an independently distributed disturbance term specific to every individual. ${ }^{33}$ From this

\footnotetext{
${ }^{28}$ See Dustmann et al. (2011) for a Roy/Borjas model with two skills in the context of return migration. Dahl (2002) and Kennan and Walker (2011) develop models of internal migration and show the importance of expected returns for the migration decision.

${ }^{29}$ Alternatively, skills and tasks are combined in a Leontief production function, which yields the same implications regarding the choice of occupations.

${ }^{30}$ In the empirical part, we explore potential mismatch between a worker's skill endowment $\mathbf{z}$ and the occupational skill requirement $\mathbf{x}$ due to demand side labor-market frictions (Section VIII.A.) and due to skill-specific labor-market shocks or imperfect job matches early in the career (Section VIII.B.). The analysis shows that skill mismatch is unlikely to affect our results.

${ }^{31}$ Thus, unlike the case with a finite number of job types, skills are always fully utilized in the optimum. See also Acemoglu and Autor (2011) and Robinson (2011) for a discussion of the differences between skills and tasks.

${ }^{32}$ We refer to $p_{i}$ simply as the "return to skill" for skill $i$. It does not, however, correspond to a rate of return calculation, not only because of the general arguments in Heckman et al. (2006), but also because we have no indication of the cost of achieving any given level of skill.

${ }^{33}$ Autor and Handel (2013) consider a more general model of earnings with occupation-specific task returns. They
} 
specification of the earnings equation, it follows that workers in more task-intensive occupations earn more, as do more skilled workers in general. Returns to skills may differ across locations, due to, for example, differences in labor productivity and local labor-market conditions. In the baseline version of the model, we assume that migrants suffer no penalty for transferring skills across borders, so they will choose the same job in both locations. We discuss changes in the model predictions when relaxing the assumption of perfect skill transferability below.

Every worker decides whether to stay in the location of origin or to migrate by comparing earning capacity between both locations (Sjaastad, 1962; Borjas, 1987). Migration takes place when earnings abroad net of migration costs $\kappa$ exceed earnings in the location of origin. Migration costs are the same for all migrants. Equation (3) summarizes the migration decision.

$$
\text { Migrate }= \begin{cases}1 & \text { if } \log w^{\text {abroad }}-\kappa>\log w^{\text {origin }} \Leftrightarrow\left(\mathbf{p}^{\text {abroad }}-\mathbf{p}^{\text {origin }}\right) \cdot \mathbf{z}-\kappa>0 \\ 0 & \text { otherwise }\end{cases}
$$

To simplify the notation, we define $\lambda_{i} \equiv \Delta p_{i} \equiv p_{i}^{\text {abroad }}-p_{i}^{\text {origin }}$ as the difference in returns to skill $i$ between the location abroad and the location of origin.

Migrants are positively selected on skill $i$ whenever $\mathbb{E}\left[z_{i} \mid\right.$ Migrate $\left.=1\right]>\mu_{i}$, implying that the average skill level of migrants is higher than the average skill level of non-migrants. Migrants are negatively selected on skill $i$ whenever $\mathbb{E}\left[z_{i} \mid\right.$ Migrate $\left.=1\right]<\mu_{i}$, implying that the average skill level of migrants is lower than the average skill level of non-migrants. If conditional and unconditional means are equal, then there is no selection.

Given the assumptions above, the mean of skill 1 for migrants equals

$$
\mathbb{E}\left(z_{1} \mid \text { Migrate }=1\right)=\mu_{1}+\left(\lambda_{1}+\lambda_{2} \beta_{2,1}\right) \frac{\sigma_{1}^{2}}{\sigma} \frac{\phi(d)}{1-\Phi(d)},
$$

where $\beta_{2,1}=\operatorname{Cov}\left(z_{1}, z_{2}\right) / \operatorname{Var}\left(z_{1}\right)$ is the slope of a least squares regression of skill 2 on skill 1, $d=\left(\kappa-\lambda_{1} \mu_{1}-\lambda_{2} \mu_{2}\right) / \sigma, \sigma^{2}=\operatorname{Var}\left(\lambda_{1} z_{1}+\lambda_{2} z_{2}\right)$, and $\phi(d) /[1-\Phi(d)]$ is the inverse Mills ratio. ${ }^{34}$ The corresponding equation for skill 2 can be obtained by symmetry, thus

$$
\mathbb{E}\left(z_{2} \mid \text { Migrate }=1\right)=\mu_{2}+\left(\lambda_{2}+\lambda_{1} \beta_{1,2}\right) \frac{\sigma_{2}^{2}}{\sigma} \frac{\phi(d)}{1-\Phi(d)}
$$

argue that returns to tasks and multi-dimensional skills are conceptually different to returns to uni-dimensional skill measures such as education because tasks are usually represented by bundles of activities requiring a set of skills to be carried out (for a similar argument, see Heckman and Scheinkman, 1987). Because tasks that a worker performs on the job are an application of that worker's skill endowment to a bundle of activities, it is difficult to evaluate the returns to a specific task or skill empirically. We discuss the estimation of returns to skills in Sections IV.B. and VII.

${ }^{34}$ The conditional mean equation is equivalent to the formulation in Borjas (1987) in the special case when log $w=$ $z_{1}, \lambda_{1}=1$ and $\lambda_{2}=-1$. 
From Equation (4), it follows that the selection of migrants on skill 1 is determined by the sign of the expression $\lambda_{1}+\lambda_{2} \beta_{2,1}$. Intuitively, this can be interpreted as the predicted benefit from relocating one unit of skill 1 abroad. Analogously, from Equation (5), the selection of migrants on skill 2 is determined by the sign of the expression $\lambda_{2}+\lambda_{1} \beta_{1,2}$, showing the predicted benefit of relocating one unit of skill 2 abroad.

To illustrate the model predictions with respect to migrant selection, we start with the simplest case of uncorrelated skills, that is, $\rho=0$ (and hence $\beta_{2,1}=0$ ). Here, the selection pattern for each skill $i$ is completely determined by the differential returns between both locations, $\lambda_{i}$. For $\lambda_{i}>0$, individuals with higher endowments of skill $i$ tend to relocate their skills abroad, and therefore the model predicts positive selection on skill $i$. In Figure 2a, there is positive selection on skill 1 in the two RHS quadrants and positive selection on skill 2 in the upper two quadrants. In contrast, for $\lambda_{i}<0$, a worker receives a wage penalty from relocating skill $i$ abroad, so the model predicts negative selection on skill $i$ as those with higher endowments of skill $i$ tend to remain in the location of origin. In Figure 2a, there is negative selection on skill 1 (skill 2) in the two LHS (bottom) quadrants. ${ }^{35}$ For $\lambda_{i}=0$, the reward for skill $i$ is the same at home and abroad and there is no selection on skill $i$-this situation occurs along the ordinate for skill 1 and along the abscissa for skill 2.

For correlated skills $(\rho \neq 0)$, the selection pattern is not only affected by the differential returns to skills, but also by the correlation between skill 1 and skill 2 . The general configuration of regions of selection, however, is similar to the case of $\rho=0$. Figure $2 \mathrm{~b}$ depicts the model's predictions for negatively correlated skills (i.e., $\rho<0$ and therefore $\beta_{2,1}<0$ ). ${ }^{36}$ In region A, negative selection on skill 2 prevails despite $\lambda_{2}$ being positive. The reason is that the contribution of skill 1 to the earnings differential is so large that it is more attractive to migrate for individuals with a high endowment of skill 1 - and therefore on average with low endowments of skill 2. In region D, due to the negative $\lambda_{2}$ it becomes attractive to migrate for individuals with lower endowments of skill 2-and therefore on average with higher endowments of skill $1-$ despite $\lambda_{1}$ being negative. Similarly, in region B, $\lambda_{2}$ is such that its contribution to the selection pattern outweighs the contribution of $\lambda_{1}$; and in region $\mathrm{C}$, the contribution of the negative $\lambda_{1}$ dominates the contribution of $\lambda_{2}$.

The model's predictions for positively correlated skills (i.e., $\rho>0$ and therefore $\beta_{2,1}>0$ ) are shown in Figure 2c. In region A, positive selection on skill 2 prevails despite $\lambda_{2}<0$ because $\lambda_{1}$ is such that individuals with a high endowment of skill 1 -and therefore on average also with a high

\footnotetext{
${ }^{35}$ In the bottom-left quadrant, skill price differentials are negative for both skills. From Equation (3), in this situation only individuals with skills from the left tail of the normal distribution migrate, so negative selection on both skills prevails. This result is in line with other models arguing that negative selection occurs because individuals with low productivity can insure themselves against low returns by migrating to countries with a more compressed wage distribution and/or high baseline wages (Borjas, 1987; Fernández-Huertas Moraga, 2011).

${ }^{36}$ This is the case of interest in this paper because the empirically observed correlation between cognitive and manual skills is negative (see Section III.).
} 
endowment of skill 2-tend to migrate. By the same logic, in region $\mathrm{B}, \lambda_{1}<0$ is outweighed by a positive $\lambda_{2}$ such that individuals with a high endowment of skill 2 - and therefore on average also of skill 1 - find it attractive to migrate. Analogously, in regions $\mathrm{C}$ and $\mathrm{D}$ there are new combinations of $\left(\lambda_{1}, \lambda_{2}\right)$ such that negative selection prevails for skill 2 despite $\lambda_{2}>0$ (region C) and for skill 1 despite $\lambda_{1}>0$ (region $\left.\mathrm{D}\right)$.

The model sketched above assumes that skills are valued the same in both locations. However, suppose that migrants can only partially utilize their skills abroad, for example, due to a low degree of foreign-language proficiency (Friedberg, 2000; Bazzi et al., 2016). This would lead to skill downgrading abroad (Dustmann and Preston, 2012; Dustmann et al., 2013, 2016), implying that, for instance, a medical doctor would be employed as a nurse after migrating abroad. We can accommodate this possibility by letting $z_{i}^{\text {abroad }}=a_{i} z_{i}^{\text {origin }}$, with $0<a_{i}<1$, where $a_{i}$ is a parameter that captures the extent of human capital transferability for skill $i$ across borders. Potential migrants will use the same decision rule as in Equation (3), albeit with returns abroad replaced by effective returns $\tilde{p}_{i}^{\text {abroad }}=a_{i} p_{i}^{\text {abroad }}$. Hence, we can use Equations (4) and (5) with appropriately defined differential returns to predict the selection pattern. Note that if migrants are not aware that they can only partially transfer their skills abroad, Equation (3) with the original differential returns applies. However, given that migration networks and relatives abroad are strong predictors of migration (McKenzie and Rapoport, 2010; Kaestner and Malamud, 2014), it seems likely that individuals in Mexico base their migration decision on observed effective returns to skills, incorporating partial skill transferability. Indeed, we show below that observed differential returns to skills are a strong predictor of emigration (see Section VII.).

\section{B. Model Predictions for Mexican Migration to the United States}

The extended Roy/Borjas model specified in Section IV.A. shows that the main determinant of emigrant selection are differential returns to occupational skills. To illustrate this general mechanism and to guide intuition what to expect in the empirical analysis of selection on occupational skills of Mexican emigrants, we estimate the returns to cognitive and manual skills for Mexican residents and for recent Mexican migrants in the United States (immigrated 10 years prior to the survey year). ${ }^{37}$ We here follow Ambrosini and Peri (2012) and Kaestner and Malamud (2014) in assuming that potential Mexican migrants form expectations about their earnings abroad based on observable characteristics of such recent migrants. ${ }^{38}$

We find that the returns to manual skills (skill 1) of Mexicans are higher in the United States than in Mexico (see Tables D1 and D2 in the Appendix). This seems plausible given the high supply of

\footnotetext{
${ }^{37}$ See Section D in the Appendix for details on the estimation strategy and results.

${ }^{38}$ Ambrosini and Peri (2012), among others, compare the earnings of Mexican residents with the earnings of future Mexican migrants to the United States. Results are similar if we use the earnings of future Mexican migrants to estimate returns to occupational skills in the United States.
} 
manual skills in Mexico (see Figure 1). In contrast, cognitive skills (skill 2) of Mexicans are better rewarded in Mexico than in the United States. Relatively low returns to cognitive skills for Mexican workers in the United States are consistent with cognitive skills facing lower demand or being less transferable than manual skills due to their large communication and language component. Given these differences in the returns and the fact that cognitive and manual skills are negatively correlated (see Section III.), the theoretical model predicts that Mexican migrants are positively selected on manual skills and negatively selected on cognitive skills (region +- in Figure $2 b$ ).

One further remark deserves attention. Our estimates cannot be interpreted as causal returns to skills, that is, we neither identify the returns that a random Mexican resident would receive in the United States, nor do we identify the causal returns of Mexican residents in Mexico. However, as long as prospective Mexican migrants are not aware of the selection bias, we can expect that migrants form expectations about their potential earning prospects based on observable returns of former Mexican migrants (Kaestner and Malamud, 2014). We return to this issue in Section VII.

\section{Empirical Strategy}

The model specified in Section IV.A. provides clear predictions regarding the selection on occupational skills of Mexican emigrants to the United States. We should observe that Mexican emigrants have higher manual skills and lower cognitive skills than Mexican residents. We start to test the model by comparing the distributions of occupational skills of migrants prior to moving to the United States to the distribution of occupational skills of non-migrants in Mexico (Section VI.A.). Because the probability of Mexicans moving to the United States differs substantially across time (due to different migration waves) and across datasets (due to different sampling frames), we scale the migration indicator by the average migration rate to make effect sizes comparable. This results in the following expression for the migration propensity of individual $i$ at time $t$ :

$$
\text { migprop }_{i t}=\frac{I(\text { migration })_{i, t+1}}{\text { migration rate }_{t+1}},
$$

where $I$ (migration $)_{i, t+1}$ is equal to 1 if individual $i$ migrates in period $t+1$ ( 0 otherwise) and

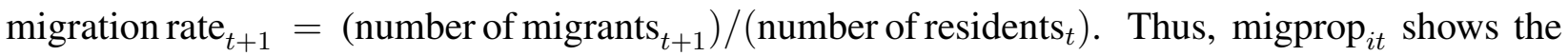
probability of migrating as a percentage of the average migration rate. ${ }^{39}$

Descriptive statistics, however, do not reveal whether individuals' occupational skills coincide with other personal characteristics, such as education or earnings. Both are likely to be correlated with occupational skills because occupational choices are a function of education and expected earnings. To investigate the selection pattern conditional on worker characteristics, we estimate

\footnotetext{
${ }^{39}$ All results hold when using an unscaled migration indicator.
} 
variants of the following linear probability model:

$$
\operatorname{migprop}_{i t}=\alpha_{0}+\alpha_{1} z_{c, i t}+\alpha_{2} z_{m, i t}+\alpha_{3} z_{c, i t} \times z_{m, i t}+\mathbf{X}_{i t}^{\prime} \gamma+\zeta_{t}+\epsilon_{i t}
$$

with $z_{c}$ denoting our measure of cognitive skills and $z_{m}$ denoting our measure of manual skills. From Figure 1, it follows that there are occupations with similar levels of cognitive skills, but with very different levels of manual skills (and vice versa). We also include the interaction between cognitive and manual skills, $z_{c} \times z_{m}$, to allow for a nonlinear relation of skills with migration propensity. ${ }^{40}$ In addition to education (and in some specifications also earnings), the vector $\mathbf{X}$ contains the worker's age to account for changes in the propensity to migrate over the lifecycle. We estimate the model as a pooled cross-section and include time fixed effects, $\zeta_{t}$, which account for temporal migration shocks.

Our measures of cognitive and manual skills use all occupational information available in the data, that is, they incorporate the full observed pre-migration worker history. In ENOE and ENET, where we have at most four pre-migration quarters, we use average occupational skills over all available quarters prior to migration to measure migrant skills. In MMP, where we have information on an individual's complete job history, we take the average of occupational skills over the entire pre-migration history to construct the skill measures. In MxFLS, we take the average of the current job, the job five years prior to the survey, and the first job. ${ }^{41}$

In addition to using all available occupational information, constructing cumulative skill measures has several other advantages. First and foremost, it is not immediately clear which occupation is most appropriate for measuring occupational skills. The last pre-migration occupation is endogenous to the migration move if individuals regard it as particularly suitable for emigration (e.g., for visa considerations). Similarly, a negative labor-market shock (e.g., job displacement) may push workers into a less desirable occupation, and they therefore decide to migrate. Using the first occupation at labor-market entry, although likely unaffected by the (future) migration decision, has the problem that occupational skills are not fully developed at this stage and that there is the potential for imperfect job matches (e.g., Jovanovic, 1979; Altonji and Pierret, 2001; Hanushek et al., 2015). Using an average over all observed occupations seems to be an appropriate way of capturing a worker's true occupational skills and, at the same time, of alleviating concerns about the endogeneity of the pre-migration occupation. Second, using a cumulative skill measure allows us to consider individuals who are unemployed in the current period. ${ }^{42}$ This is a major advantage over considering

\footnotetext{
${ }^{40}$ In Table A5 in the Appendix, we replace the interaction between cognitive and manual skills with a sixth-order polynomial or with decile fixed effects of the respective skill to control very flexibly for the impact of the other occupational skill on the propensity to migrate. The selection pattern is very similar to that of the baseline model.

${ }^{41}$ We show below that our results hold for various definitions of the relevant occupation (i.e., first occupation, last pre-migration occupation, occupations several periods before migration).

${ }^{42}$ We ignore skill depreciation due to unemployment because it is unclear how fast occupational skills depreciate
} 
actual earnings because unemployed individuals (with missing earning information) may migrate because of their unemployment status.

\section{Evidence on Emigrant Selection on Occupational Skills}

\section{A. Descriptive Evidence}

This section compares the occupational skills of Mexican migrants to the United States to nonmigrants. Table 2 reports the migration propensity at different points of the skill distribution for male Mexicans across the four worker-level datasets described above. In our main dataset, ENOE, we find that workers are $76.6 \%$ more likely to emigrate when they belong to the bottom tertile of the cognitive skill distribution compared to having average cognitive skills. Conversely, workers are $55.3 \%$ less likely to migrate when belonging to the top tertile of the cognitive skills distribution than when having average skills. We find the opposite pattern for manual skills. Compared to the average, workers are $48.3 \%$ less likely to migrate when coming from the bottom tertile of the manual skill distribution and $56.7 \%$ more likely to migrate when coming from the top tertile. This indicates that Mexican emigrants to the United States are positively selected in terms of manual skills and negatively selected in terms of cognitive skills.

Strikingly, the pattern of selection is very similar in the other three datasets in terms of both the general pattern of selection and the differences in migration propensities at different points in the skill distribution. For comparison, we also consider the educational selection of emigrants. Here, we confirm previous findings that Mexican emigrants come mostly from the middle of the educational distribution, suggesting intermediate educational selection.

These results are corroborated by plots of cumulative distribution functions (CDFs) and population density functions (PDFs) of cognitive and manual skills by migrant status (Figure 3). We observe that the CDF of cognitive skills for migrants is to the left of the CDF for non-migrants. ${ }^{43}$ This shows that migrants are negatively selected on cognitive skills along the entire skill distribution. For manual skills, we find that the CDF of migrants is to the right of the CDF of non-migrants, indicating positive selection. These results are confirmed by the PDFs, showing that the mass of density for Mexican migrants is at the bottom (top) of the cognitive (manual) skill distribution. ${ }^{44}$ This selection pattern is robust to omitting agricultural workers (Figure A1 in the Appendix), ${ }^{45}$ and

when individuals are not working.

${ }^{43}$ Kolmogorov-Smirnov tests indicate that the CDFs for both cognitive and manual skills are significantly different from each other throughout.

${ }^{44}$ In fact, the PDFs for manual skills suggest a bimodal distribution, with peaks occurring somewhat below the median and the 75th percentile of the manual skill distribution. However, these spikes are not generated by a single (large) occupation, since the selection pattern is robust to omitting one one-digit occupation at a time (results not shown).

${ }^{45}$ The largest occupation in Mexico is agriculture, constituting $12.6 \%$ of the entire sample in ENOE (see also 
is very similar using the ENET data (Figure A2 in the Appendix). ${ }^{46}$

\section{B. Multivariate Analysis}

We now estimate linear probability models to predict migration propensity to the United States (Table 3). ${ }^{47}$ The model shows that, on average, migration propensity is negatively associated with cognitive skills and positively associated with manual skills (Column 1). We then add the interaction between cognitive and manual skills, which turns out to be negative but does not affect the selection pattern (Column 2). To facilitate interpretation and comparison across specifications, we de-mean cognitive and manual skills in the interacted models. In Column 3, we add socioeconomic characteristics (education and age) that are likely correlated with both the migration decision and occupational skills. In particular, educational attainment is strongly positively correlated with cognitive skills $(r=0.64)$ and strongly negatively correlated with manual skills $(r=-0.47)$. However, including these variables has no impact on the selection pattern. ${ }^{48}$

In terms of magnitude, an increase in cognitive skills by one decile, ceteris paribus, is associated with a $16 \%$ drop in the propensity to migrate. This is equivalent to comparing the migration propensities of a shoemaker (at the mean of the cognitive skill distribution) and a medical technician $(+1$ decile in cognitive skills). Similarly, when manual skills increase by one decile, the propensity to migrate increases by $18 \%$. This is equivalent to comparing the migration propensities of a cook (at the mean of the manual skill distribution) and a carpenter $(+1$ decile in manual skills). These results indicate that selection on cognitive and manual skills is also economically significant. ${ }^{49}$

Many studies stress that migrant selection is not uniform across regions within Mexico. ${ }^{50}$ To assess the potential importance of a rural-urban divide in migrant selection, we estimate our base-

Figure 1). Agricultural workers are also the the population group that are most likely to migrate for seasonal work. For instance, the H-2A visa program is set up solely to handle temporary agricultural workers.

${ }^{46}$ There is less scope for investigating the selection pattern along the entire distribution of cognitive and manual skills in MMP and MxFLS because skills are measured at a coarser occupational level in these data.

${ }^{47}$ We discuss results based on the MMP below. See Tables A6 and A7 in the Appendix for the results using data from ENET and MxFLS. In general, results are consistent for different time periods and sampling frames.

${ }^{48}$ These results hold across a range of robustness specifications (results not shown). First, we include education (five categories) and age (six categories) as categorical variables. Second, we control for the distance to the U.S. border as a proxy for the cost of migration. Third, we drop the largest Mexican occupation, agricultural workers, or even the three largest three-digit occupations (which constitute one-quarter of the sample). Fourth, we estimate probit models yielding coefficients very similar to those from the linear probability model.

${ }^{49}$ For comparison, using a binary migration indicator as the dependent variable yields coefficients of -0.00054 (0.000025) for cognitive skills, $0.00057(0.000042)$ for manual skills, and $-0.00024(0.000014)$ for the interaction term.

${ }^{50}$ Using different Mexican data, McKenzie and Rapoport (2010) and Fernández-Huertas Moraga (2013) show that selection on education and earnings is likely to be negative in urban areas and areas with strong networks, both of which are characterized by large emigration propensities. Specifically, large networks decrease migration costs as low-skilled individuals profit from low-cost information flows. On the other hand, positive selection prevails in rural areas and areas with weak networks. There, high migration costs prevent low-skilled individuals from migrating. 
line model separately for urban and rural areas (Columns 4 and 5 of Table 3 ). We find that the selection pattern is qualitatively similar for migrants from both area types, but is more pronounced in rural areas. ${ }^{51}$

Finally, we test whether earnings, as a comprehensive productivity measure that reflects skills learned both on the job and off the job, provide information over and above occupational skills for explaining emigration. ${ }^{52}$ Column 7 of Table 3 shows a very similar selection pattern on occupational skills as was the case without the earnings control (Column 6 reports the results of the baseline model including only workers with positive earnings), while there is no selection whatsoever on earnings. It is important to note that without conditioning on occupational skills, we confirm previous findings of negative selection on both earnings (with a coefficient of -0.152 and a standard error of 0.031) and education (with a coefficient of -0.053 and a standard error of 0.005) in terms of mean differences. This suggests that the impact of earnings and educational attainment on migration materializes to a large extent through job choice. Put differently, holding the occupational skills constant, people with higher earnings or better education are not less likely to migrate.

Because they contain information on migrants' entire work history, the MMP data allow us to check whether the ENOE results are specific to recent migration episodes and whether the limited time coverage (e.g., left-censored occupational histories) potentially confounds the results. Table A8 in the Appendix reports the results for the MMP-based analysis. Columns 1 to 3 replicate the baseline models from Table 3, but use workers' full pre-migration occupational history to construct cognitive and manual skills. Corroborating the descriptive results in Table 2, the selection pattern is remarkably similar in MMP and ENOE. The pattern is also robust to a number of additional analyses exploiting specific features of the MMP data. In Column 4, we keep only spells of migrants before their first move to the United States, that is, we drop observations of Mexican emigrants who return to their home country. In Column 5, our measures of cognitive and manual skills are constructed using only the last pre-migration occupation instead of using the job content of all occupations held prior to migration. Column 6 additionally controls for a full set of state-ofbirth fixed effects to capture different migration trends across Mexican states that are potentially correlated with the occupational structure in these states. The pattern of selection on occupational skills also holds in both rural and urban areas (results not shown). ${ }^{53}$

\footnotetext{
${ }^{51}$ In Section VII., we document that rural areas have a higher fraction of manual-intensive workers and a lower fraction of cognitive-intensive workers. As Mexican emigration is responsive to differential returns to skills, especially workers from rural areas are pushed out of Mexico.

${ }^{52}$ Following Chiquiar and Hanson (2005) and Fernández-Huertas Moraga (2011), hourly earnings are obtained by dividing monthly earnings by $4.5 \times$ hours worked per week. Earning observations are dropped for persons who are unemployed, not in the labor force, not working in Mexico, and who work less than 20 or more than 84 hours per week. The top and bottom $0.5 \%$ of earning observations are dropped. Earnings are converted into PPP-adjusted U.S. dollars using OECD PPP-adjusted exchange rates and then denoted in real 2010 U.S. dollars using U.S. CPI data.

${ }^{53}$ Unfortunately, earnings in the MMP data are not continuously reported but refer to specific points in the career (e.g., earnings at first/last U.S. trip). This precludes an investigation of earnings selection with the MMP data.
} 


\section{Selection on Earnings and Differential Returns to Occupational Skills}

In the previous section, we provided evidence that there is no selection on mean earnings conditional on occupational skills. We now study selection along the entire earnings distribution and show that differential returns to occupational skills between Mexico and the United States explain both the decision to migrate and selection on earnings.

We first show that migrants in the ENOE data predominantly come from the lower earnings quintiles, confirming previous findings by Fernández-Huertas Moraga (2011) (based on the ENET data) and by Kaestner and Malamud (2014) (based on the MxFLS data). In fact, individuals in the top quintile are about $72 \%$ less likely to migrate compared to individuals in the bottom quintile (Table 4, Column 1). As discussed by Kaestner and Malamud (2014), this pattern might be explained by a negative correlation between the benefits of migration and earnings (i.e., those with the highest earnings in Mexico profit the least from migration) and/or a positive correlation between migration costs and earnings (i.e., those with the highest migration costs are those with the highest earnings). Consistent with the Roy/Borjas model, Ambrosini and Peri (2012) and Kaestner and Malamud (2014) document the importance of the benefits of migration by showing that differential labor-market returns to basic worker characteristics (essentially education, age, and martial status) between recent Mexican migrants in the United States and Mexican residents can to some extent explain the negative selection on earnings. In contrast, there is little evidence that migration costs can explain selection on earnings (Kaestner and Malamud, 2014). ${ }^{54}$

Given the strong selection on occupational skills, we expect that differential returns to occupational skills are also relevant in explaining the selection on earnings and-given that educational attainment and earnings no longer predict migration once we account for occupational skills-are potentially even more important than differential returns based on basic worker characteristics. To construct differential labor market returns, we follow Kaestner and Malamud (2014) in estimating Mincer-type regressions for Mexican residents in the 2000 Mexican Census and recent Mexican migrants in the United States (migrated to the United States between 1990 and 2000) in the 2000 U.S. Census. ${ }^{55}$ We estimate two sets of returns: basic returns and occupational returns. Basic returns are predicted from a Mincer-type regression with a full set of interactions between age (six categories), education (five categories), and marital status (two categories). Occupational returns are predicted from a Mincer-type regression with a full set of interactions between cognitive skills (four categories) and manual skills (four categories). This cell approach to construct returns to skills ad-

\footnotetext{
${ }^{54}$ Kaestner and Malamud (2014) measure migration costs by whether a person has a relative in United States, whether a person has access to credit, and whether a person has significant assets.

${ }^{55}$ Tables A9, A10, and A11 in the Appendix show that results are robust to using the differential returns based on the $2010 \mathrm{ACS}$, and that the results are also robust to using different comparison groups for calculating differential returns, such as all Mexican migrants, Spanish-speaking migrants from Central and South America (excluding Mexico), and U.S.-born individuals with Mexican ethnicity.
} 
dresses the issue that skills should be evaluated as skill bundles (Heckman and Scheinkman, 1987; Autor and Handel, 2013).

Columns 2-6 of Table 4 assess the contribution of basic versus occupational returns-to-skill measures in explaining earnings selection. In Column 2, we observe that basic returns are a highly significant predictor of the migration decision, supporting the finding by Kaestner and Malamud (2014). ${ }^{56}$ Increasing differential basic returns by 1, i.e., 100 percentage points, increases migration propensity by $71 \%$ of the average migration rate. ${ }^{57}$ Notably, we also find that the coefficients on all earning quintiles decrease in absolute size compared to the specification without differential returns. For example, migration propensity drops from $72 \%$ to $38 \%$ for the highest quintile versus the lowest quintile.

However, including differential occupational returns instead of basic returns shows an impact on migration propensity that is more than twice as large as the effect from differential basic returns (Column 3). Additionally, the coefficients on the earnings quintiles are reduced to almost zero (e.g., from $72 \%$ to $18 \%$ for the highest quintile vs. the lowest quintile). In Column 4 , we simultaneously include basic and occupational returns to assess the relative importance of each type of returns. We find the coefficient on differential occupational returns to be significantly larger than the respective coefficient on basic returns $(p<0.0001)$. Strikingly, adding the respective other returns measure hardly affects occupational returns, but substantially decreases basic returns (from 0.713 to 0.210 ). The selection with respect to earnings also remains very similar as in the specification with occupational returns alone.

In Columns 5 and 6 of Table 4, we add the travel distance to the U.S. border as a proxy for the cost of migration. Confirming results from previous literature, including migration cost measures leads to slightly more pronounced selection on earnings (Column 5), indicating that migration costs are negatively correlated with earnings in Mexico. However, including the travel distance leaves the results regarding the impact of differential occupational returns (vis-à-vis basic returns) on the pattern of earnings selection almost unchanged (Column 6).

It is important to note that we do not claim that our estimated differential returns are causal. Tackling endogeneity in the returns estimation is extremely challenging because many papersincluding this one-document that Mexican migrants to the United States are selected. However, our results are unlikely to be explained by migrant selectivity for a number of reasons. First, following Kaestner and Malamud (2014), we use Heckman's 1979 two step estimator to address selective sample selection in the earnings regression of Mexican migrants in the United States.

\footnotetext{
${ }^{56}$ The earnings selection in Kaestner and Malamud (2014) is generally somewhat weaker than indicated by our results. The most likely explanation for this difference is that Kaestner and Malamud (2014) use the MxFLS data, which have a different sampling design and a much smaller sample size than ENOE.

${ }^{57}$ This is close to the $66 \%$ found by Kaestner and Malamud (2014, p. 86).
} 
Results are robust in this approach (see Table A12 in the Appendix). ${ }^{58}$ Second, as already discussed above, we do not expect that Mexican migrants are necessarily aware of the selection bias, but rather form their earnings expectations based on observed differential returns to skills. And third, we are mostly interested in the relative contribution of basic versus occupational return measures in explaining the negative selection of migrants with respect to earnings, so any selection bias that is common for both return measures does not affect our conclusions.

We conduct two complementary analyses that further emphasize the importance of differential returns to occupational skills for understanding emigrant selection. First, in Table 5, we estimate the models from Table 4 using the ENET data. We find that occupational returns even increase in importance relative to basic returns in explaining migration. In fact, once we condition on occupational returns, the negative selection on earnings vanishes entirely. This suggests that our occupational return measures, which are based on the 2000 Mexican Census and the 2000 U.S. Census, are somewhat more appropriate for proxying the expected returns of potential Mexican migrants in the ENET data (conducted from 2000 to 2004) than in the ENOE data (conducted from 2005 onward).

Second, we show that occupational returns can explain why the pattern of selection on occupational skills is particularly pronounced in rural Mexico (Columns 4 and 5 of Table 3). Given that the average level of manual skills is much higher in rural areas (70th percentile) than in urban areas (58th percentile), the Roy/Borjas model predicts that the selection pattern in rural areas is stronger because the average rural worker can gain more from relocating her skills abroad. Table 6 shows that, while occupational returns are significantly related to Mexican emigration in both urban and rural areas, this relation is indeed substantially stronger in rural areas (Column 5). In fact, in the full specification that also contains basic returns, occupational returns are almost twice as predictive for emigration in rural areas than in urban areas (Column 6). We also find that allowing occupational returns to affect migration differently in rural and urban areas almost entirely explains selection on earnings. In contrast, basic returns do not have stronger predictive power for emigration in rural areas than in urban areas (Columns 3 and 6).

Together with the evidence presented in Section VI., two main insights emerge from this section. First, after adjusting for differential returns to occupational skills, there is very little selection of migrants with respect to earnings. Second, differential returns based on occupational skills clearly outperform differential returns based on basic characteristics in explaining Mexican emigration and selection on earnings. These results underscore that our occupational skill measures

\footnotetext{
${ }^{58}$ Specifically, we estimate two probit models predicting emigration to the United States to construct inverse Mills ratios that we include in the earnings regressions based on the sample of Mexican migrants in the United States. For the basic returns earnings regression, we include age and education categories as well as marital status as covariates. For the occupational returns earnings regression, we use cognitive and manual skill quartile categories as covariates. In both models, we include number of children in the household (defined as persons aged below 18 years) in the first stage probit model, but exclude the variable in the second stage model.
} 
do indeed capture labor-market-relevant skills and that these skills are important for understanding migration decisions. Our findings complement earlier results on the role of returns to worker characteristics in explaining earning selection because occupational choices and the skills acquired in these occupations are a function of basic characteristics. However, what appears to matter for the migration decision are primarily the returns to occupational skills and, to a much lesser extent, the returns to the more basic characteristics that may have led to choosing the occupation in the first place.

\section{Further Results on Emigrant Selection on Occupational Skills}

We have established that there is a systematic relationship between emigration and occupational skills. We have also shown that occupational skills are important for understanding and explaining selection on earnings. We now provide additional robustness checks and investigate the persistence of selection on occupational skills.

\section{A. Regional and Sectoral Labor Markets}

Selection on occupational skills might depend on the available occupations from which individuals can choose, for instance, due to the local industry structure. Table 7 considers different labor-market definitions to show that the selection pattern also holds in rather homogeneous labor markets with similar job opportunities in the labor market. In Columns 2-4 of Table 7, we include fixed effects for the state of birth, the current state of residence, and birth-by-residence state. We find that selection within these regional labor markets (defined by state boundaries) is very similar as in the baseline model (shown in Column 1). In Column 5, we identify only from within-municipality variation by including 1,499 municipality fixed effects. Coefficients on the occupational skill measures become slightly smaller (in absolute terms) in this demanding specification, but the qualitative results are unchanged.

We can also define labor markets in terms of economic sectors and broader occupational categories. Column 6 of Table 7 shows that the results are not just driven by differences in the job content of coarse occupational categories, say, agriculture and services. In fact, we can control for occupation fixed effects at the three-digit level and observe a qualitatively similar selection pattern as in the baseline. Results are also robust to controlling for the economic sector (Column 7). Finally, Column 8 tests whether results are different within residence state-by-economic sector cells, again showing a qualitatively similar selection pattern as before. In general, selection within regional labor markets leads to very similar results as in the baseline, while selection within sectoral labor markets tends to be slightly weaker. However, the economic sector and broader occupational category are simultaneously determined with the current occupation. Thus, adding occupation or 
sector fixed effects ignores a considerable part of the variation that we would like to use for identification. ${ }^{59}$

\section{B. Skill-Specific Labor-Market Shocks}

One potential concern is that those who decide to migrate received a negative labor-market shock right before the migration move (e.g., job displacement), pushing them to low-cognitive, highmanual jobs. To check whether negative labor-market shocks shortly before migration may explain the pattern of negative selection on cognitive skills and positive selection on manual skills, we investigate occupational changes during the four quarters preceding the migration move. Figure A3 in the Appendix shows that the selection pattern is always very similar when we use the occupation held four, three, two, or one quarter before migration to measure occupational skills. Thus, imperfect job matches due to skill-specific labor-market shocks are unlikely to affect our results. ${ }^{60}$

However, employment shocks might also have a long-lasting effect on occupational choices, that is, individuals being forced by a labor-market shock to move to a worse occupation may have problems to make the reverse switch later in the career. ${ }^{61}$ In the MMP data, we have the opportunity to exploit long-run dynamics of occupational choices by relating an individual's first occupation to his current occupation. The first occupation is likely not affected by labor-market shocks and plausibly orthogonal to migration decisions later in life. Moreover, plenty of evidence suggests that occupational careers are affected by early job choices. ${ }^{62}$

We use occupational skills from the first occupation to instrument current occupational skills in a two-stage least squares (2SLS) model. In the second stage (Equation (8)), we use predicted skills that are obtained from first-stage regressions where "current" cognitive and manual skills (calculated based on the current occupation) as well as their interaction are regressed on "first" cognitive and manual skills (calculated based on the occupation at labor-market entry) and their

\footnotetext{
${ }^{59}$ Table A13 in the Appendix replicates the analysis with ENET. Results are very similar, in terms of both coefficient magnitude and statistical significance.

${ }^{60}$ There is also reason to suspect that skill mismatch systematically varies over the career, as early-career workers are more likely to experience skill mismatch than higher-tenured workers (e.g., Jovanovic, 1979; Hanushek et al., 2015). We therefore estimate our baseline model for persons at different ages (using data from ENOE and MMP) and occupational-tenure cutoffs (using data from MMP). Results are highly robust in these restricted samples (see Tables A14 and A15 in the Appendix).

${ }^{61}$ Nedelkoska et al. (2017) find that German workers frequently switch to less demanding jobs after displacement and that a considerable share of these moves is persistent.

${ }^{62}$ For instance, it is well established in the empirical labor-market literature that the probability of job change generally declines with tenure. For instance, Topel and Ward (1992) find that for men, two-thirds of all job changes happen in the first 10 years after entering the labor market. Farber (1994) shows that the job hazard rate peaks after three months of employment, and declines afterward. Abraham and Farber (1987) estimate a Weibull hazard model for job change transitions, finding that the hazard declines sharply with tenure.
} 
interaction (Equation (9)):

$$
\operatorname{migprop}_{i t}=\alpha_{0}+\alpha_{1} \widehat{z_{c, i t}^{\text {current }}}+\alpha_{2} \widehat{z_{m, i t}^{\text {current }}}+\alpha_{3} z_{c, i t}^{\text {current } \times z_{m, i t}^{\text {current }}}+\mathbf{X}_{\mathbf{i t}}^{\prime} \gamma+\zeta_{t}+\epsilon_{i t}
$$

Hence, for each $k=\left\{z_{c, i t}^{\text {current }}, z_{m, i t}^{\text {current }}, z_{c, i t}^{\text {current }} \times z_{m, i t}^{\text {current }}\right\}$, we have the following first stages:

$$
k=\pi_{0}+\pi_{1} z_{c, i t}^{\text {first }}+\pi_{2} z_{m, i t}^{\text {first }}+\pi_{3} z_{c, i t}^{\text {first }} \times z_{m, i t}^{\text {first }}+\mathbf{X}_{\mathbf{i t}}^{\prime} \delta+\zeta_{t}+\nu_{i, t}
$$

Table 8 contains the results of the 2SLS regressions, which are fully in line with the selection pattern in the baseline least squares models. In Column 1 (Column 2), we instrument only cognitive (manual) skills. We find that the skills required in the first occupation are a very strong predictor of the current skill level. The coefficient is close to 0.7 and the F statistic on the excluded instrument is very large, indicating a persistent occupational pathway that is largely determined by the first occupation. Instrumenting both skills at the same time shows that current cognitive skills are predicted by cognitive skills (but not manual skills) required in the first job and that current manual skills are predicted by manual skills (but not cognitive skills) required in the first job (Column 3). Also, instrumenting the interaction between cognitive and manual skills does not alter the selection pattern (Column 4). These results show that occupational skills early in the career are a good approximation for skills at migration, suggesting that workers try to avoid switching to occupations that involve significant changes in job content. ${ }^{63}$

In light of this evidence, we consider it highly unlikely that skill-specific employment shocks prior to migration affect our results.

\section{Long-Run Dynamics of Selection on Occupational Skills}

During the last 15 years, Mexico has experienced very different emigration waves. The Mexicanborn population in the United States increased rapidly between 2000 and 2009/2010, from about 9 million at the beginning of the century to more than 12 million one decade later. Recently, however, net migration from Mexico to the United States was negative, so the Mexican-born population fell below 12 million in 2013. In light of these different emigration waves, the question arises whether the occupational skills of Mexican emigrants systematically change with the scale of migration and the size of the migrant community in the United States.

Pooling data from ENET and ENOE, the right panel of Figure 4 plots the annual migration propensities for a one-decile increase in cognitive (blue line) and manual (green line) occupational skills for the period between 2000 and 2013. ${ }^{64}$ Remarkably, we observe that Mexican emigration

\footnotetext{
${ }^{63}$ The selection pattern is also very similar when we estimate the baseline least squares models with occupational skill measures based on the occupation at labor-market entry.

${ }^{64}$ Estimates are based on the model in Column 3 of Table 3.
} 
has been positively selected on manual skills and negatively selected on cognitive skills over the entire period. Notably, this pattern also holds during the recent decline in Mexican emigration.

While there has already been a large Mexican community in the United States during the period 2000-2013, one might wonder whether the selection pattern changes when considering the less recent past when the Mexican migrant community was still small and migration rates were dramatically rising. The left panel of Figure 4 shows that even though the migrant community in the United States in the 1950s, 1960s, and most of the 1970s were very small, the pattern of selection of Mexican emigrants on occupational skills is remarkably persistent. This is also true for the period from 1970 to 2000, when the United States experienced a sharp increase in the Mexican-born population from almost zero to around 9 million. ${ }^{65}$

\section{Conclusions}

International migrants constitute a sizeable fraction of the labor force in many countries. Therefore, understanding who migrates and why is essential for informed labor market and migration policies in sending and receiving countries. In this paper, we provide the first evidence that emigrant selection on education and earnings materializes through the selection on occupational skills.

We develop measures of workers' occupational skills using data from a representative Mexican worker survey — similar to the U.S. O*NET_- and combine these measures with detailed longitudinal individual-level data from two Mexican labor-force surveys. We show that Mexican emigrants are negatively selected on cognitive skills and are positively selected on manual skills, consistent with a two-dimensional Roy/Borjas model with related skills. The selection pattern is remarkably stable over time and holds within narrowly defined regional and sectoral labor markets and within detailed occupational groups. A similar selection pattern also prevails when we use other sources of Mexican data that include workers' full occupational histories, permanent migrants, return migrants, and migrating households.

Our results not only inform politicians on both sides of the border about the knowledge and capabilities of migrants directly relevant in the labor market, they also shed new light on how to interpret previous evidence from the selection literature. We find that many of the selection mechanisms studied in previous papers materialize almost entirely through the selection on occupational skills. For instance, the negative selection on education can be explained by the fact that better education enables workers to enter occupations with a higher cognitive skill content. Although it is not surprising that education and type of job are related, we show that education plays almost no role in migrant selection over and above its effect on occupational choice.

We also show that occupational skills are important in understanding the selection of migrants

\footnotetext{
${ }^{65}$ Estimates are based on MMP data. All years within a decade are pooled to increase sample size.
} 
with respect to earnings. After adjusting for differential labor-market returns to occupational skills between Mexico and the United States, the selection on earnings vanishes almost completely. The change in the pattern of selection after this adjustment suggests that differential returns to occupational skills are an important determinant of migration and the primary explanation of the negative selection of migrants with respect to earnings. It also suggests that occupational skills provide almost the same information as earnings in explaining migrant selection, although earnings are a much more comprehensive measure of the productive capacity of migrants encompassing inputs such as schooling, family background, local labor-market conditions, and peer effects. Since information on job skill requirements are becoming increasingly available across a number of countries, the selection on occupational skills can be studied for a wide range of migration flows, which provides an important building block toward better understanding emigrant selection. 


\section{References}

Abraham, K. G. and Farber, H. S. (1987). Job Duration, Seniority, and Earnings. American Economic Review, 77(3):278-297.

Abramitzky, R., Boustan, L. P., and Eriksson, K. (2012). Europe's Tired, Poor, Huddled Masses: Self-Selection and Economic Outcomes in the Age of Mass Migration. American Economic Review, 102(5):1832-1856.

Acemoglu, D. and Autor, D. H. (2011). Skills, Tasks, and Technologies: Implications for Employment and Earnings. In Ashenfelter, O. and Card, D. E., editors, Handbook of Labor Economics Volume 4, volume 4B. Amsterdam: Elsevier.

Altonji, J. G. and Pierret, C. R. (2001). Employer Learning and Statistical Discrimination. Quarterly Journal of Economics, 116(1):313-350.

Ambrosini, J. W. and Peri, G. (2012). The Determinants and the Selection of Mexico-US Migrants. World Economy, 35(2):111-151.

Autor, D. (2013). The "Task Approach" to Labor Markets: An Overview. Journal for Labour Market Research, 46(3):185-199.

Autor, D. and Dorn, D. (2013). The Growth of Low Skill Service Jobs and the Polarization of the U.S. Labor Market. American Economic Review, 103(5):1553-1597.

Autor, D. and Handel, M. (2013). Putting Tasks to the Test: Human Capital, Job Tasks, and Wages. Journal of Labor Economics, 31(2):S59-S96.

Autor, D., Levy, F., and Murnane, R. J. (2003). The Skill Content of Recent Technological Change: An Empirical Exploration. Quarterly Journal of Economics, 118(4):1279-1333.

Bazzi, S., Gaduh, A., Rothenberg, A. D., and Wong, M. (2016). Skill Transferability, Migration, and Development:Evidence from Population Resettlement in Indonesia. American Economic Review, 106(9):2658-2698.

Borjas, G. J. (1987). Self-Selection and the Earnings of Immigrants. American Economic Review, 77(4):531-553.

Borjas, G. J. (1994). The Economics of Immigration. Journal of Economic Literature, 32(4):16671717.

Cadot, O., Carrère, C., and Strauss-Kahn, V. (2011). Export Diversification: What's Behind the Hump? Review of Economics and Statistics, 93(2):590-605. 
Chiquiar, D. and Hanson, G. H. (2005). International Migration, Self-Selection, and the Distribution of Wages: Evidence from Mexico and the United States. Journal of Political Economy, 113(2):239-281.

Cortés, P. and Tessada, J. (2011). Low-Skilled Immigration and the Labor Supply of Highly Skilled Women. American Economic Journal: Applied Economics, 3(3):88-123.

Dahl, G. B. (2002). Mobility and the Return to Education: Testing a Roy Model with Multiple Markets. Econometrica, 70(6):2367-2420.

Dustmann, C., Fadlon, I., and Weiss, Y. (2011). Return Migration, Human Capital Accumulation and the Brain Drain. Journal of Development Economics, 95(1):58-67.

Dustmann, C., Frattini, T., and Preston, I. P. (2013). The Effect of Immigration Along the Distribution of Wages. Review of Economic Studies, 80(1):145-173.

Dustmann, C. and Preston, I. (2012). Comment: Estimating the Effect of Immigration on Wages. Journal of the European Economic Association, 10(1):216-223.

Dustmann, C., Schönberg, U., and Stuhler, J. (2016). The Impact of Immigration: Why Do Studies Reach Such Different Results? Journal of Economic Perspectives, 30(4):31-56.

Farber, H. S. (1994). The Analysis of Interfirm Worker Mobility. Journal of Labor Economics, 12(4):554-593.

Feliciano, C. (2008). Gendered Selectivity: U.S. Mexican Immigrants and Mexican Nonmigrants, 1960-2000. Latin American Research Review, 43(1):139-160.

Fernández-Huertas Moraga, J. (2011). New Evidence on Emigrant Selection. Review of Economics and Statistics, 93(1):72-96.

Fernández-Huertas Moraga, J. (2013). Understanding Different Migrant Selection Patterns in Rural and Urban Mexico. Journal of Development Economics, 103(1):182-201.

Firpo, S., Fortin, N., and Lemieux, T. (2011). Occupational Tasks and Changes in the Wage Structure. IZA Discussion Paper No. 5542.

Friedberg, R. M. (2000). You Can't Take It with You? Immigrant Assimilation and the Portability of Human Capital. Journal of Labor Economics, 18(2):221-251.

Gathmann, C. and Schönberg, U. (2010). How General is Human Capital? A Task-Based Approach. Journal of Labor Economics, 28:1-50. 
Gibbons, R. S. and Waldman, M. (2004). Task-Specific Human Capital. American Economic Review, 94(2):203-207.

Gould, E. D. and Moav, O. (2016). Does High Inequality Attract High Skilled Immigrants? Economic Journal, 126(593):1055-1091.

Hanson, G. H. (2006). Illegal Migration from Mexico to the United States. Journal of Economic Literature, 44(4):869-924.

Hanson, G. H. and McIntosh, C. (2010). The Great Mexican Emigration. Review of Economics and Statistics, 92(4):798-810.

Hanushek, E. A., Schwerdt, G., Wiederhold, S., and Woessmann, L. (2015). Returns to Skills Around the World: Evidence from PIAAC. European Economic Review, 73(C):103-130.

Heckman, J. J. (1979). Sample Selection Bias as a Specification Error. Econometrica, 47(1):153161.

Heckman, J. J., Lochner, L. J., and Todd, P. E. (2006). Earnings Functions, Rates of Return and Treatment Effects: The Mincer Equation and Beyond. In Hanushek, E. A. and Welch, F., editors, Handbook of the Economics of Education, volume 1, pages 307-458. Amsterdam: North Holland.

Heckman, J. J. and Scheinkman, J. (1987). The Importance of Bundling in a Gorman-Lancaster Model of Earnings. Review of Economic Studies, 54(2):243-255.

Ibarraran, P. and Lubotsky, D. (2007). Mexican Immigration and Self-Selection: New Evidence from the 2000 Mexican Census. In Borjas, G. J., editor, Mexican Immigration to the United States, chapter 5, pages 159-192. Chicago, IL: University of Chicago Press.

Imbs, J. and Wacziarg, R. (2003). Stages of Diversification. American Economic Review, 93(1):6386.

Ingram, B. F. and Neumann, G. R. (2006). The Returns to Skill. Labour Economics, 13(1):35-59.

Jacobson, L. S., LaLonde, R. J., and Sullivan, D. G. (1993). Earnings losses of displaced workers. American Economic Review, 83:685-709.

Jovanovic, B. (1979). Job Matching and the Theory of Turnover. Journal of Political Economy, 87(5):972-990.

Kaestner, R. and Malamud, O. (2014). Self-Selection and International Migration: New Evidence from Mexico. Review of Economics and Statistics, 96(1):78-91. 
Kambourov, G. and Manovskii, I. (2009). Occupational Specificity of Human Capital. International Economic Review, 50(1):63-115.

Kennan, J. and Walker, J. R. (2011). The Effect of Expected Income on Individual Migration Decisions. Econometrica, 79(1):211-251.

Kok, S. and ter Weel, B. (2014). Cities, Tasks and Skills. CPB Discussion Paper No. 269.

Mazzolari, F. and Ragusa, G. (2013). Spillovers from High-Skill Consumption to Low-Skill Labor Markets. Review of Economics and Statistics, 95(1):74-86.

McKenzie, D. and Rapoport, H. (2010). Self-Selection Patterns in Mexico-U.S. Migration: The Role of Migration Networks. Review of Economics and Statistics, 92(4):811-821.

Mishra, P. (2007). Emigration and Wages in Source Countries: Evidence from Mexico. Journal of Development Economics, 82(1):180-199.

Neal, D. (1995). Industry-Specific Human Capital: Evidence from Displaced Workers. Journal of Labor Economics, 13(4):653-677.

Nedelkoska, L., Neffke, F., and Wiederhold, S. (2017). Skill Mismatch and the Costs of Job Displacement. Mimeo.

OECD (2016). International Migration Outlook 2016. Paris: OECD Publishing. http://dx . doi.org/10.1787/migr_outlook-2016-en.

Orrenius, P. M. and Zavodny, M. (2005). Self-Selection Among Undocumented Immigrants from Mexico. Journal of Development Economics, 78(1):215-240.

Parent, D. (2000). Industry-Specific Capital and the Wage Profile: Evidence from the National Longitudinal Survey of Youth and the Panel Study of Income Dynamics. Journal of Labor Economics, 18(2):306-323.

Parey, M., Ruhose, J., Waldinger, F., and Netz, N. (2017). The Selection of High-Skilled Emigrants. Review of Economics and Statistics, forthcoming.

Peri, G. (2012). The Effect of Immigration on Productivity: Evidence from U.S. States. Review of Economics and Statistics, 94(1):348-358.

Peri, G. (2016). Immigrants, Productivity, and Labor Markets. Journal of Economic Perspectives, 30(4):3-30. 
Peri, G. and Sparber, C. (2009). Task Specialization, Immigration, and Wages. American Economic Journal: Applied Economics, 1(3):135-169.

Poletaev, M. and Robinson, C. (2008). Human Capital Specificity: Evidence from the Dictionary of Occupational Titles and Displaced Worker Surveys. Journal of Labor Economics, 26(3):387420.

Ramos, F. A. (1992). Outmigration and Return Migration of Puerto Ricans. In Borjas, G. J. and Freeman, R. B., editors, Immigration and the Workforce: Economic Consequences for the United States and Source Areas, chapter 2, pages 49-66. Chicago, IL: University of Chicago Press.

Rendall, M. S. and Parker, S. W. (2014). Two Decades of Negative Educational Selectivity of Mexican Migrants to the United States. Population and Development Review, 40(3):421-446.

Robinson, C. (2011). Occupational Mobility, Occupation Distance and Specific Human Capital. CIBC Working Paper Series No. 2011-5.

Roy, A. D. (1951). Some Thoughts on the Distribution of Earnings. Oxford Economic Papers, 3(2):135-146.

Sjaastad, L. A. (1962). The Costs and Returns of Human Migration. Journal of Political Economy, 70(5):80-93.

Spitz-Oener, A. (2006). Technical Change, Job Tasks, and Rising Educational Demands: Looking Outside the Wage Structure. Journal of Labor Economics, 24:235-270.

Steinmayr, A. (2014). When a Random Sample is Not Random. Bounds on the Effect of Migration on Children Left Behind. Kiel Working Paper No. 1975.

Topel, R. and Ward, M. (1992). Job Mobility and the Careers of Young Men. Quarterly Journal of Economics, 107(2):439-479.

United Nations (2015). Trends in International Migrant Stock: The 2015 Revision (United Nations database, POP/DB/MIG/Stock/Rev.2015).

Welch, F. (1969). Linear Synthesis of Skill Distribution. Journal of Human Resources, 4(3):311327.

Yamaguchi, S. (2012). Tasks and Heterogeneous Human Capital. Journal of Labor Economics, 30(1):1-53. 


\section{Figures and Tables}

Figure 1: Manual and Cognitive Occupational Skills in the Mexican Population

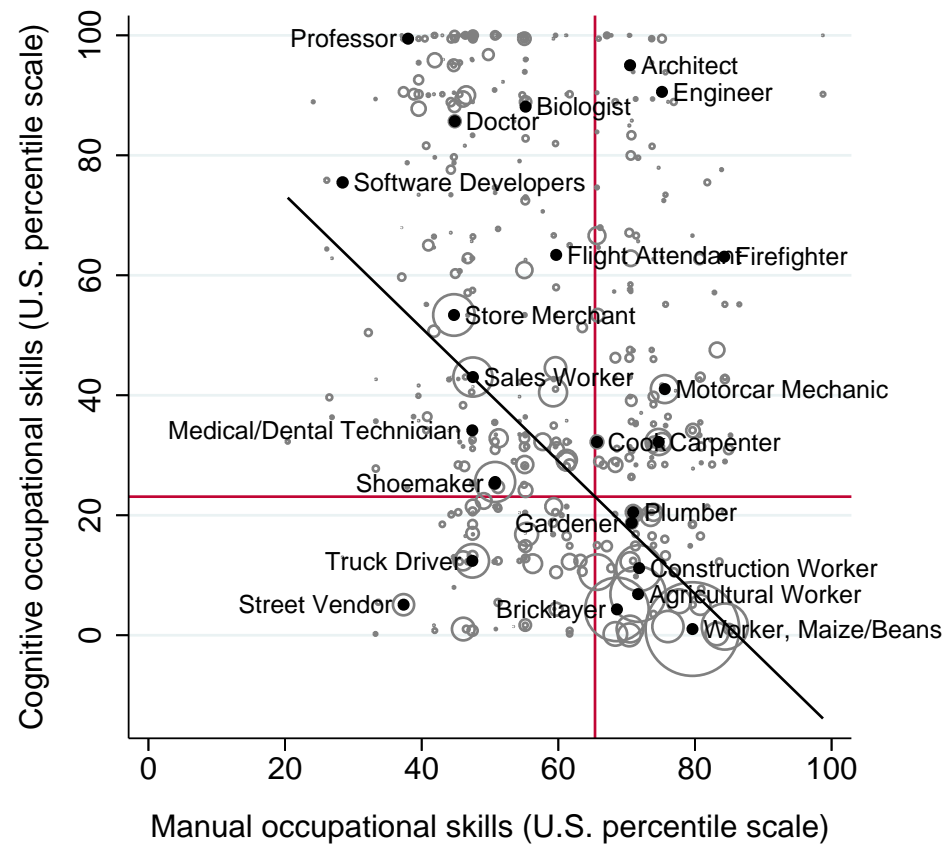

Notes: Figure plots manual and cognitive occupational skills in the Mexican population, measured in U.S. 2010 percentile ranks and weighted by the number of observations in the Mexican Census 2010. Sample restricted to male Mexicans aged 16-65. Regression line (black) is weighted by numbers of observations. Red lines show weighted averages of cognitive and manual occupational skills. The weighted correlation between the skills is $\rho=-0.56$ and the unweighted (i.e., occupation-level) correlation is $\rho=-0.19$. Data sources: CONOCER and Mexican Census 2010. 
Figure 2: Selection Patterns for Different Correlations Between Skill 1 and Skill 2

(a) Zero Correlation Between Skills

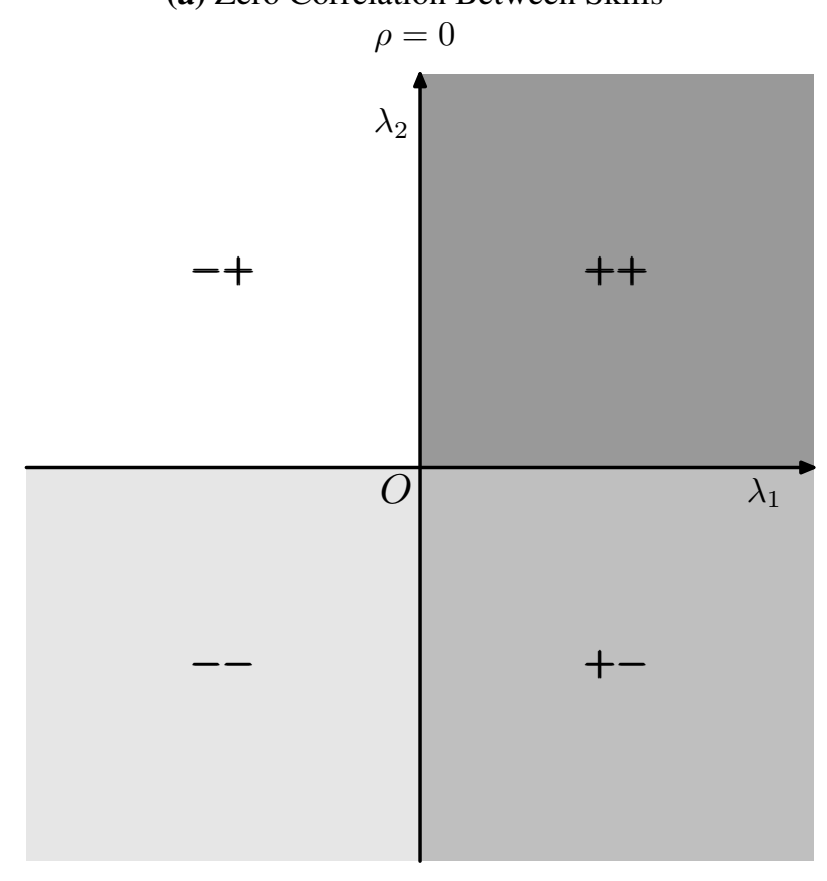

\begin{tabular}{|c|}
\hline Selection patterns \\
++ positive (skill 1), positive (skill 2) \\
+- positive (skill 1), negative (skill 2) \\
-- negative (skill 1), negative (skill 2) \\
-+ negative (skill 1), positive (skill 2) \\
\hline
\end{tabular}

(b) Negative Correlation Between Skills $\rho<0$
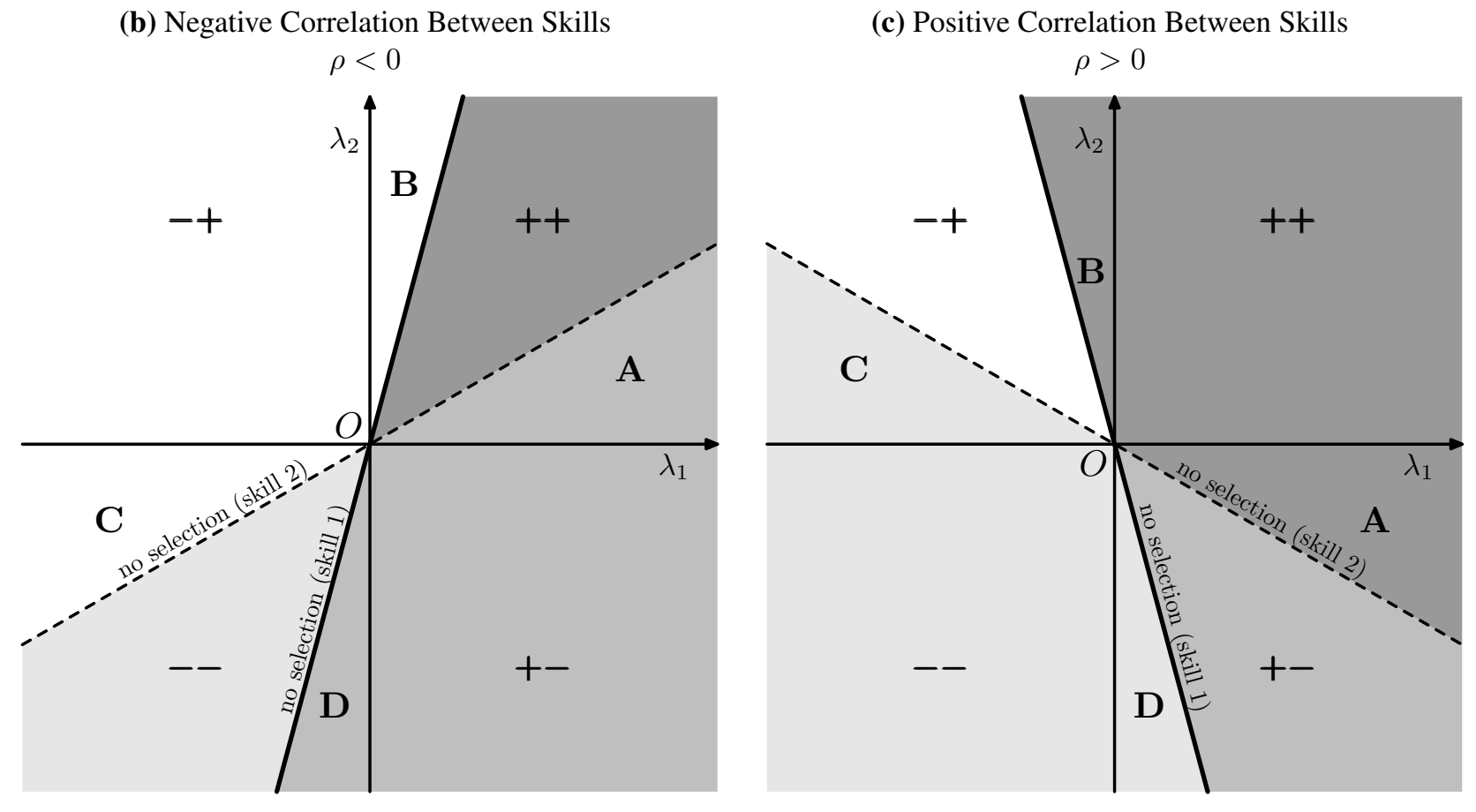

Notes: Figure shows the predictions of the two-dimensional Roy-Borjas model (Section IV.A.) when skill 1 and skill 2 are uncorrelated (Figure 2a), negatively correlated (Figure 2b), or positively correlated (Figure 2c). Regions are defined as follows: "++" for positive selection on both skills; "+-" for positive selection on skill 1 and negative selection on skill 2; "--" for negative selection on both skills; and "-+" for negative selection on skill 1 and positive selection on skill 2. See text for definitions of the areas A, B, C, and D in Figures $2 \mathrm{~b}$ and $2 \mathrm{c}$. The solid line corresponds to the knife-edge case of no selection on skill 1 when $\left(\lambda_{1}, \lambda_{2}\right)$ lie on the line $\lambda_{1}+\beta_{2,1} \lambda_{2}=0$, which divides the space into positive and negative selection half-planes. The dashed line corresponds to no selection on skill 2 . The slope of the dashed line is always smaller than the slope of the solid line. 


\section{Figure 3: Emigrant Selection on Occupational Skills}

(a) Cognitive Occupational Skills
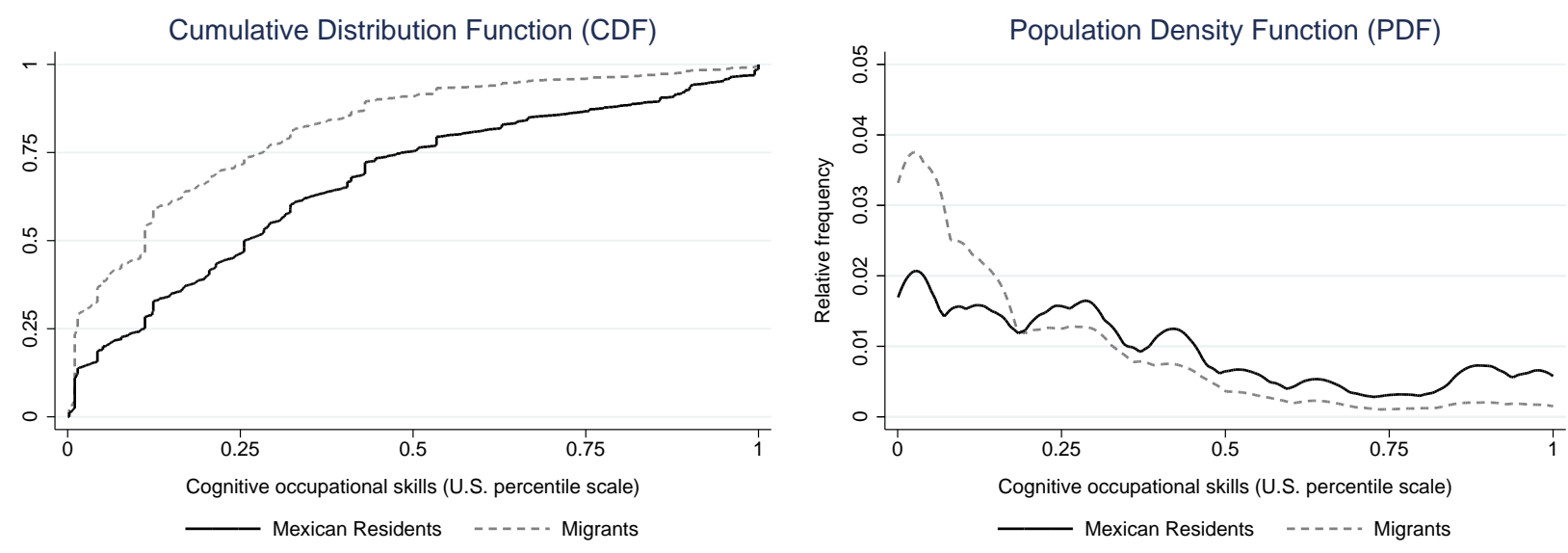

(b) Manual Occupational Skills
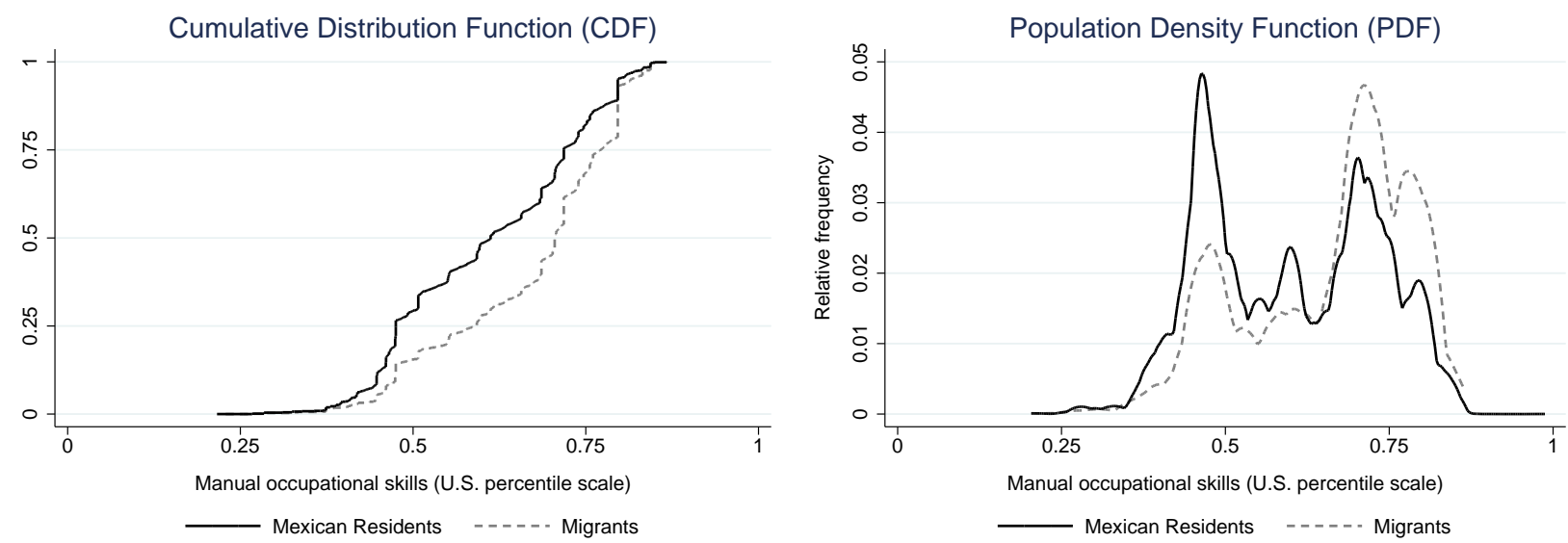

Notes: Figures show cumulative distribution functions (left panels) and population density functions (right panels) of cognitive skills (Figure 3a) and manual skills (Figure 3b) by migration status. Sample consists of male Mexicans aged 16-65. Cognitive and manual skills incorporate full observed pre-migration worker history; they are defined as (unweighted) averages of skill content of current and all previous occupations up to four pre-migration quarters. Kolmogorov-Smirnov tests on stochastic dominance indicate that differences between cumulative distribution functions are significant at the $1 \%$ level. $N=8,701$ Mexican migrants in the United States and $N=2,950,827$ Mexican residents. Data sources: CONOCER and ENOE. 
Figure 4: Emigrant Selection Over Time


Notes: Figures show the change in migration propensity for a one-decile increase in occupational skills (left scale) and the Mexican-born population in the United States (right scale). Cognitive and manual skills incorporate full observed pre-migration worker history; they are defined as (unweighted) averages of skill content of current and all previous occupations (in MMP, we can observe the entire pre-migration history; in ENET/ENOE, we can observe up to four pre-migration quarters). Data sources: CONOCER, MMP (left figure), and ENET/ENOE (right figure). 


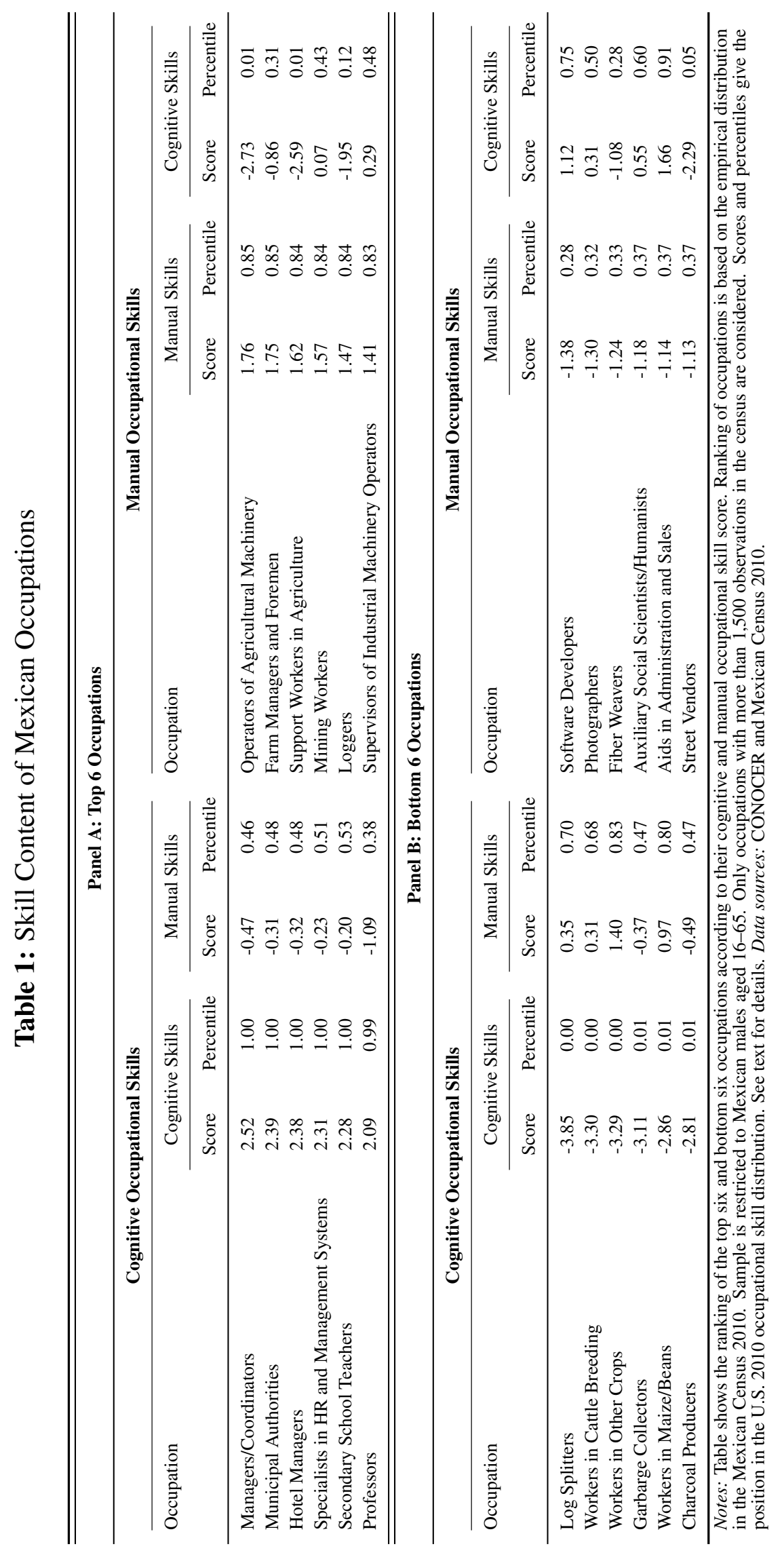


Table 2: Descriptive Statistics on Migrant Selection

\begin{tabular}{|c|c|c|c|c|c|c|c|c|}
\hline \multirow{3}{*}{ Period covered in data: } & \multicolumn{2}{|c|}{ ENOE } & \multicolumn{2}{|c|}{ ENET } & \multicolumn{2}{|c|}{ MMP } & \multicolumn{2}{|c|}{ MXFLS } \\
\hline & \multicolumn{2}{|c|}{ 2005-2014 } & \multicolumn{2}{|c|}{$2000-2004$} & \multicolumn{2}{|c|}{ 1950-2011 } & \multicolumn{2}{|c|}{$2002-2006$} \\
\hline & $\begin{array}{l}\text { Migration } \\
\text { Propensity }\end{array}$ & $\begin{array}{l}\text { Diff. from } \\
\text { Reference } \\
\text { Category }\end{array}$ & $\begin{array}{l}\text { Migration } \\
\text { Propensity }\end{array}$ & $\begin{array}{l}\text { Diff. from } \\
\text { Reference } \\
\text { Category }\end{array}$ & $\begin{array}{l}\text { Migration } \\
\text { Propensity }\end{array}$ & $\begin{array}{l}\text { Diff. from } \\
\text { Reference } \\
\text { Category }\end{array}$ & $\begin{array}{l}\text { Migration } \\
\text { Propensity }\end{array}$ & $\begin{array}{l}\text { Diff. from } \\
\text { Reference } \\
\text { Category }\end{array}$ \\
\hline \multicolumn{9}{|l|}{ Cognitive occupational skills } \\
\hline 3rd (bottom) tertile & 1.766 & & 1.807 & & 1.239 & & 1.515 & \\
\hline 2nd tertile & 0.798 & $-0.968 * * *$ & 0.832 & $-0.975^{* * *}$ & 1.156 & $-0.083^{* * *}$ & 0.963 & $-0.553 * * *$ \\
\hline 1th (top) tertile & 0.447 & $-1.319 * * *$ & 0.377 & $-1.430 * * *$ & 0.608 & $-0.631 * * *$ & 0.543 & $-0.973 * * *$ \\
\hline \multicolumn{9}{|l|}{ Manual occupational skills } \\
\hline 3rd (bottom) tertile & 0.517 & & 0.461 & & 0.688 & & 0.521 & \\
\hline 2nd tertile & 0.919 & $0.402 * * *$ & 0.970 & $0.508 * * *$ & 1.150 & $0.463 * * *$ & 0.942 & $0.422 * * *$ \\
\hline 1th (top) tertile & 1.567 & $1.050 * * *$ & 1.561 & $1.100 * * *$ & 1.596 & $0.908 * * *$ & 1.535 & $1.014 * * *$ \\
\hline \multicolumn{9}{|l|}{ For comparison: education } \\
\hline $0-3$ years of schooling & 0.977 & & 1.071 & & 0.959 & & 0.735 & \\
\hline 4-6 years of schooling & 1.355 & $0.378 * * *$ & 1.389 & $0.319 * * *$ & 1.100 & $0.142 * * *$ & 1.209 & $0.474 * * *$ \\
\hline $7-9$ years of schooling & 1.226 & $0.249 * * *$ & 1.123 & $0.053^{*}$ & 1.207 & $0.248 * * *$ & 1.283 & $0.548 * * *$ \\
\hline $10-12$ years of schooling & 0.800 & $-0.177 * * *$ & 0.670 & $-0.400 * * *$ & 0.904 & -0.055 & 1.031 & 0.296 \\
\hline More than 12 years of schooling & 0.429 & $-0.548 * * *$ & 0.255 & $-0.816^{* * *}$ & 0.482 & $-0.477 * * *$ & 0.245 & $-0.490 * * *$ \\
\hline Total observations & \multicolumn{2}{|c|}{$2,959,528$} & \multicolumn{2}{|c|}{$2,069,926$} & \multicolumn{2}{|c|}{471,123} & \multicolumn{2}{|c|}{16,164} \\
\hline U.S. migrants & \multicolumn{2}{|c|}{8,701} & \multicolumn{2}{|c|}{10,200} & \multicolumn{2}{|c|}{10,464} & \multicolumn{2}{|c|}{404} \\
\hline
\end{tabular}

Table 3: Emigrant Selection on Occupational Skills: Baseline Results

\begin{tabular}{|c|c|c|c|c|c|c|c|}
\hline \multicolumn{8}{|c|}{ Dependent variable: migration propensity to the U.S. } \\
\hline & (1) & (2) & (3) & (4) & $(5)$ & $(6)$ & (7) \\
\hline & \multicolumn{3}{|c|}{ Baseline } & \multicolumn{2}{|c|}{ Urban Status } & \multicolumn{2}{|c|}{ Earnings } \\
\hline & & & & Urban & Rural & & \\
\hline Cognitive skills & $\begin{array}{c}-0.126^{* * *} \\
(0.006)\end{array}$ & $\begin{array}{c}-0.160 * * * \\
(0.007)\end{array}$ & $\begin{array}{c}-0.164 * * * \\
(0.009)\end{array}$ & $\begin{array}{c}-0.113 * * * \\
(0.009)\end{array}$ & $\begin{array}{c}-0.242 * * * \\
(0.026)\end{array}$ & $\begin{array}{c}-0.158^{* * * *} \\
(0.009)\end{array}$ & $\begin{array}{c}-0.158^{* * *} \\
(0.010)\end{array}$ \\
\hline Manual skills & $\begin{array}{c}0.205 * * * \\
(0.015)\end{array}$ & $\begin{array}{c}0.177 * * * \\
(0.014)\end{array}$ & $\begin{array}{c}0.182^{* * *} * \\
(0.014)\end{array}$ & $\begin{array}{c}0.116 * * * \\
(0.017)\end{array}$ & $\begin{array}{c}0.201 * * * \\
(0.045)\end{array}$ & $\begin{array}{c}0.152^{* * * *} \\
(0.016)\end{array}$ & $\begin{array}{c}0.152 * * * \\
(0.016)\end{array}$ \\
\hline Cognitive skills $\times$ manual skills & & $\begin{array}{c}-0.076^{* * *} \\
(0.005)\end{array}$ & $\begin{array}{c}-0.079 * * * \\
(0.005)\end{array}$ & $\begin{array}{c}-0.051^{* * *} \\
(0.006)\end{array}$ & $\begin{array}{c}-0.049 * * * \\
(0.014)\end{array}$ & $\begin{array}{c}-0.071 * * * \\
(0.006)\end{array}$ & $\begin{array}{c}-0.071 * * * \\
(0.006)\end{array}$ \\
\hline Education & & & $\begin{array}{l}0.010^{*} \\
(0.005)\end{array}$ & $\begin{array}{c}0.003 \\
(0.005)\end{array}$ & $\begin{array}{c}0.037^{* *} \\
(0.015)\end{array}$ & $\begin{array}{c}0.006 \\
(0.006)\end{array}$ & $\begin{array}{c}0.006 \\
(0.006)\end{array}$ \\
\hline Age & & & $\begin{array}{c}-0.032 * * * \\
(0.001)\end{array}$ & $\begin{array}{c}-0.020 * * * \\
(0.001)\end{array}$ & $\begin{array}{c}-0.063^{* * * *} \\
(0.004)\end{array}$ & $\begin{array}{c}-0.027 * * * \\
(0.002)\end{array}$ & $\begin{array}{c}-0.027 * * * * \\
(0.002)\end{array}$ \\
\hline Log hourly earnings & & & & & & & $\begin{array}{l}-0.001 \\
(0.031)\end{array}$ \\
\hline Observations & $2,959,528$ & $2,959,528$ & $2,959,528$ & $2,444,755$ & 514,773 & $1,950,951$ & $1,950,951$ \\
\hline $\begin{array}{l}\text { Notes: Sample includes Mexican } \\
\text { in the previous quarter. Dependen } \\
\text { migrant share. Cognitive and man } \\
\text { skill content of current and all pr } \\
\text { earnings in Column } 7 \text { are obtaine } \\
\text { who are unemployed, not in the } 1 \\
\text { bottom } 0.5 \% \text { of earning observat } \\
\text { PPP-adjusted exchange rates and } \\
\text { effects. Observations are weight } \\
\text { standard errors, shown in parenth } \\
\text { CONOCER and ENOE. }\end{array}$ & $\begin{array}{l}\text { nales aged } 16 \\
\text { variable is mi } \\
\text { al skills incor } \\
\text { ious occupat } \\
\text { by dividing } m \\
\text { bor force, not } \\
\text { ns are dropp } \\
\text { then denoted } \\
\text { l by sampling } \\
\text { es, are cluste }\end{array}$ & $\begin{array}{l}\text {; in Column } \\
\text { ant indicator } \\
\text { rate full obse } \\
\text { is up to four } 1 \\
\text { thly earnings } \\
\text { orking in Me } \\
\text { (Chiquiar an } \\
\text { real 2010 U. } \\
\text { eights. Urba } \\
\text { at the houser }\end{array}$ & $\begin{array}{l}\text { and } 7, \text { samp } \\
\text { ual to } 1 \text { if mi } \\
\text { ed pre-migrat } \\
- \text {-migration q } \\
4.5 \times \text { hours } \\
\text { o, and who v } \\
\text { Hanson, } 2005 \\
\text { dollars using } \\
\text { rural) areas } \\
\text { d level. Signi }\end{array}$ & $\begin{array}{l}\text { is restricted } \\
\text { ated to the Un } \\
\text { worker histo } \\
\text { ters. Skill me } \\
\text { orked per wee } \\
\text { rk less than } 2 \\
\text { Earnings are } \\
\text { J.S. CPI data } \\
\text { localities wit }\end{array}$ & $\begin{array}{l}\text { ndividuals wi } \\
\text { d States, and } \\
\text { they are defi } \\
\text { ures are dem } \\
\text { Earning obse } \\
\text { r more than } \\
\text { nverted into } \\
\text { All regressior } \\
\text { at least (less } \\
p<0.01 \text {, ** }\end{array}$ & $\begin{array}{l}\text { non-negative } \\
\text { therwise) sca } \\
\text { d as (unweigh } \\
\text { eed and scale } \\
\text { tions are dro } \\
\text { hours per we } \\
\text { P-adjusted U } \\
\text { contain quart } \\
\text { in) 2,500 inh }\end{array}$ & $\begin{array}{l}\text { Durly earnings } \\
\text { d by quarterly } \\
\text { d) averages of } \\
\text { oy } 10 \text {. Hourly } \\
\text { ed for persons } \\
\text { The top and } \\
\text { dollars using } \\
\text { by-year fixed } \\
\text { tants. Robust } \\
\text { Data sources: }\end{array}$ \\
\hline
\end{tabular}


Table 4: Selection on Earnings and Differential Returns

\begin{tabular}{|c|c|c|c|c|c|c|}
\hline \multicolumn{7}{|c|}{ Dependent variable: migration propensity to the U.S. } \\
\hline & (1) & (2) & (3) & (4) & (5) & (6) \\
\hline 2nd quintile & $\begin{array}{l}-0.044 \\
(0.070)\end{array}$ & $\begin{array}{l}-0.001 \\
(0.070)\end{array}$ & $\begin{array}{c}0.051 \\
(0.070)\end{array}$ & $\begin{array}{c}0.057 \\
(0.070)\end{array}$ & $\begin{array}{l}-0.057 \\
(0.070)\end{array}$ & $\begin{array}{c}0.040 \\
(0.070)\end{array}$ \\
\hline 3rd quintile & $\begin{array}{c}-0.284 * * * \\
(0.068)\end{array}$ & $\begin{array}{c}-0.208 * * * \\
(0.068)\end{array}$ & $\begin{array}{l}-0.110 \\
(0.068)\end{array}$ & $\begin{array}{l}-0.099 \\
(0.068)\end{array}$ & $\begin{array}{c}-0.301 * * * \\
(0.068)\end{array}$ & $\begin{array}{c}-0.121^{*} \\
(0.069)\end{array}$ \\
\hline 4th quintile & $\begin{array}{c}-0.491 * * * \\
(0.064)\end{array}$ & $\begin{array}{c}-0.347 * * * \\
(0.065)\end{array}$ & $\begin{array}{l}-0.197 * * * * \\
(0.065)\end{array}$ & $\begin{array}{c}-0.173 * * * \\
(0.065)\end{array}$ & $\begin{array}{c}-0.510 * * * \\
(0.064)\end{array}$ & $\begin{array}{c}-0.196 * * * \\
(0.066)\end{array}$ \\
\hline 5th quintile & $\begin{array}{c}-0.715 * * * \\
(0.059)\end{array}$ & $\begin{array}{c}-0.376^{* * *} \\
(0.066)\end{array}$ & $\begin{array}{c}-0.183 * * * * \\
(0.064)\end{array}$ & $\begin{array}{c}-0.115^{*} \\
(0.068)\end{array}$ & $\begin{array}{c}-0.733 * * * \\
(0.060)\end{array}$ & $\begin{array}{c}-0.138 * * \\
(0.068)\end{array}$ \\
\hline$\Delta$ basic returns ${ }_{M E X, 2000}^{U S, 2000}$ & & $\begin{array}{l}0.713 * * * \\
(0.058)\end{array}$ & & $\begin{array}{l}0.210 * * * \\
(0.063)\end{array}$ & & $\begin{array}{c}0.211^{* * *} \\
(0.063)\end{array}$ \\
\hline$\Delta$ occupational returns $\frac{U S, 2000}{M E X, 2000}$ & & & $\begin{array}{c}1.611^{* * *} \\
(0.092)\end{array}$ & $\begin{array}{c}1.513 * * * \\
(0.101)\end{array}$ & & $\begin{array}{c}1.518 * * * \\
(0.101)\end{array}$ \\
\hline Travel distance to U.S. border & & & & & $\begin{array}{l}-0.007 * * \\
(0.003)\end{array}$ & $\begin{array}{c}-0.009 * * * \\
(0.003)\end{array}$ \\
\hline \multicolumn{7}{|c|}{$\begin{array}{l}\text { Notes: Sample includes Mexican males aged 16-65. Dependent variable is migrant indicator (equal to } 1 \text { if migrated to the United States, and } \\
0 \text { otherwise) scaled by quarterly migrant share. Earnings quintiles depend on hourly earnings and the construction of hourly earnings follows } \\
\text { Fernández-Huertas Moraga (2011). Hourly earnings are obtained by dividing monthly earnings by } 4.5 \times \text { hours worked per week. Earnings } \\
\text { observations are dropped for persons who are unemployed, not in the labor force, not working in Mexico, and who work less than } 20 \text { or more } \\
\text { than } 84 \text { hours per week. The top and bottom } 0.5 \% \text { of earnings observations are dropped (Chiquiar and Hanson, 2005). Earnings are denoted } \\
\text { in constant } 2010 \text { U.S. dollars and adjusted for PPP. } \Delta \text { returns indicate differential returns for observable skills between the United States and } \\
\text { Mexico following Kaestner and Malamud (2014). Returns are constructed by calculating differential labor market returns for recent Mexican } \\
\text { migrants in the United States (immigrated } 10 \text { years prior to the survey with an age of } 16 \text { years or more at time of arrival) and Mexican residents in } \\
\text { the Mexican Census } 2000 \text {. Basic returns are predicted from a Mincer-type regression with a full set of interactions between age (six categories), } \\
\text { education (five categories), and marital status (two categories). Occupational returns are predicted from a Mincer-type regression with a full } \\
\text { set of interactions between cognitive skills (four categories) and manual skills (four categories). Cutoffs for the occupational skill distribution } \\
\text { are based on the Mexican population in } 2000 \text {. Travel distance to US border is the travel distance in hours to the closest border checkpoint. All } \\
\text { regressions contain quarter-by-year fixed effects. Observations are weighted by sampling weights. } N=1,950,951 \text {. Robust standard errors, } \\
\text { shown in parentheses, are clustered at the household level. Significance levels: *** p p }<0.01, * * p<0.05, * \mathrm{p}<0.1 \text {. Data sources: CONOCER, } \\
\text { ENOE, Mexican Census } 2000 \text { ( } 10.6 \% \text { sample), and U.S. Census } 2000 \text { ( } 5 \% \text { sample). }\end{array}$} \\
\hline
\end{tabular}

Table 5: Selection on Earnings and Differential Returns: Results from ENET

\begin{tabular}{|c|c|c|c|c|c|c|}
\hline \multicolumn{7}{|c|}{ Dependent variable: migration propensity to the U.S. } \\
\hline & (1) & (2) & (3) & (4) & (5) & (6) \\
\hline 2nd quintile & $\begin{array}{c}0.037 \\
(0.061)\end{array}$ & $\begin{array}{c}0.095 \\
(0.062)\end{array}$ & $\begin{array}{c}0.218 * * * \\
(0.064)\end{array}$ & $\begin{array}{c}0.225 * * * \\
(0.064)\end{array}$ & $\begin{array}{l}-0.007 \\
(0.062)\end{array}$ & $\begin{array}{c}0.181 * * * \\
(0.064)\end{array}$ \\
\hline 3rd quintile & $\begin{array}{c}-0.216^{* * *} \\
(0.058)\end{array}$ & $\begin{array}{c}-0.122 * * \\
(0.060)\end{array}$ & $\begin{array}{c}0.055 \\
(0.061)\end{array}$ & $\begin{array}{c}0.067 \\
(0.061)\end{array}$ & $\begin{array}{c}-0.282 * * * \\
(0.060)\end{array}$ & $\begin{array}{c}0.001 \\
(0.063)\end{array}$ \\
\hline 4th quintile & $\begin{array}{c}-0.474 * * * \\
(0.054)\end{array}$ & $\begin{array}{c}-0.311^{* * * *} \\
(0.057)\end{array}$ & $\begin{array}{l}-0.084 \\
(0.059)\end{array}$ & $\begin{array}{l}-0.059 \\
(0.060)\end{array}$ & $\begin{array}{c}-0.547 * * * \\
(0.056)\end{array}$ & $\begin{array}{c}-0.132^{* *} \\
(0.062)\end{array}$ \\
\hline 5th quintile & $\begin{array}{c}-0.766 * * * \\
(0.049)\end{array}$ & $\begin{array}{c}-0.402 * * * \\
(0.060)\end{array}$ & $\begin{array}{c}-0.142^{* *} \\
(0.059)\end{array}$ & $\begin{array}{l}-0.074 \\
(0.064)\end{array}$ & $\begin{array}{c}-0.838^{* * * *} \\
(0.051)\end{array}$ & $\begin{array}{c}-0.149 * * \\
(0.065)\end{array}$ \\
\hline$\Delta$ basic returns ${ }_{M E X, 2000}^{U S, 2000}$ & & $\begin{array}{c}0.669^{* * *} \\
(0.049)\end{array}$ & & $\begin{array}{c}0.184 * * * \\
(0.053)\end{array}$ & & $\begin{array}{c}0.175^{* * *} \\
(0.053)\end{array}$ \\
\hline$\Delta$ occupational returns ${ }_{M E X, 2000}^{U S, 2000}$ & & & $\begin{array}{c}1.564 * * * \\
(0.086)\end{array}$ & $\begin{array}{c}1.484 * * * \\
(0.093)\end{array}$ & & $\begin{array}{c}1.488^{* * *} * \\
(0.093)\end{array}$ \\
\hline Travel distance to U.S. border & & & & & $\begin{array}{c}-0.020 * * * \\
(0.003)\end{array}$ & $\begin{array}{c}-0.020^{* * *} \\
(0.003)\end{array}$ \\
\hline
\end{tabular}

Notes: Table shows specifications analogous to those in Table 4 using ENET data. See Table 4 for sample restrictions and variable definitions. All regressions contain quarter-by-year fixed effects. Observations are weighted by sampling weights. $N=1,564,772$. Robust standard errors, shown in parentheses, are clustered at the household level. Significance levels: $* * * \mathrm{p}<0.01, * * \mathrm{p}<0.05, * \mathrm{p}<0.1$. Data sources: CONOCER, ENET, Mexican Census 2000 (10.6\% sample), and U.S. Census 2000 (5\% sample). 
Table 6: Selection on Earnings and Differential Returns in Rural Areas

\begin{tabular}{|c|c|c|c|c|c|c|}
\hline & (1) & (2) & (3) & (4) & (5) & (6) \\
\hline 2nd quintile & $\begin{array}{l}-0.044 \\
(0.070)\end{array}$ & $\begin{array}{l}-0.001 \\
(0.070)\end{array}$ & $\begin{array}{l}0.119^{*} \\
(0.072)\end{array}$ & $\begin{array}{c}0.051 \\
(0.070)\end{array}$ & $\begin{array}{c}0.151^{* *} \\
(0.071)\end{array}$ & $\begin{array}{c}0.152^{* *} \\
(0.072)\end{array}$ \\
\hline 3rd quintile & $\begin{array}{c}-0.284^{* * * *} \\
(0.068)\end{array}$ & $\begin{array}{c}-0.208 * * * \\
(0.068)\end{array}$ & $\begin{array}{l}-0.047 \\
(0.070)\end{array}$ & $\begin{array}{l}-0.110 \\
(0.068)\end{array}$ & $\begin{array}{c}0.017 \\
(0.070)\end{array}$ & $\begin{array}{c}0.021 \\
(0.070)\end{array}$ \\
\hline 4th quintile & $\begin{array}{c}-0.491 * * * \\
(0.064)\end{array}$ & $\begin{array}{c}-0.347 * * * \\
(0.065)\end{array}$ & $\begin{array}{c}-0.169 * * \\
(0.067)\end{array}$ & $\begin{array}{c}-0.197 * * * \\
(0.065)\end{array}$ & $\begin{array}{l}-0.068 \\
(0.066)\end{array}$ & $\begin{array}{l}-0.054 \\
(0.067)\end{array}$ \\
\hline 5th quintile & $\begin{array}{c}-0.715^{* * *} \\
(0.059)\end{array}$ & $\begin{array}{c}-0.376^{* * *} \\
(0.066)\end{array}$ & $\begin{array}{c}-0.223 * * * \\
(0.068)\end{array}$ & $\begin{array}{c}-0.183^{* * *} \\
(0.064)\end{array}$ & $\begin{array}{l}-0.087 \\
(0.065)\end{array}$ & $\begin{array}{l}-0.038 \\
(0.069)\end{array}$ \\
\hline$\Delta$ basic returns $\frac{U S, 2000}{M E X, 2000}$ & & $\begin{array}{c}0.713 * * * \\
(0.058)\end{array}$ & $\begin{array}{c}0.472 * * * \\
(0.057)\end{array}$ & & & $\begin{array}{c}0.193 * * * \\
(0.064)\end{array}$ \\
\hline$\Delta$ basic returns ${ }_{M E X, 2000}^{U S, 2000} \times$ rural & & & $\begin{array}{c}0.200 \\
(0.170)\end{array}$ & & & $\begin{array}{l}-0.265 \\
(0.203)\end{array}$ \\
\hline$\Delta$ occupational returns $\begin{array}{l}U S, 2000 \\
M E X, 2000\end{array}$ & & & & $\begin{array}{c}1.611 * * * \\
(0.092)\end{array}$ & $\begin{array}{c}1.118^{* * *} \\
(0.096)\end{array}$ & $\begin{array}{c}1.018 * * * \\
(0.106)\end{array}$ \\
\hline$\Delta$ occupational returns $\underset{M E X, 2000}{U S, 2000} \times$ rural & & & & & $\begin{array}{c}0.789 * * * \\
(0.221)\end{array}$ & $\begin{array}{c}0.928 * * * \\
(0.254)\end{array}$ \\
\hline Rural status & & & $\begin{array}{c}0.883 * * * \\
(0.098)\end{array}$ & & $\begin{array}{c}0.404 * * * \\
(0.078)\end{array}$ & $\begin{array}{l}0.260^{*} \\
(0.138)\end{array}$ \\
\hline
\end{tabular}

Table 7: Robustness of Baseline Results for Different Labor Market Definitions

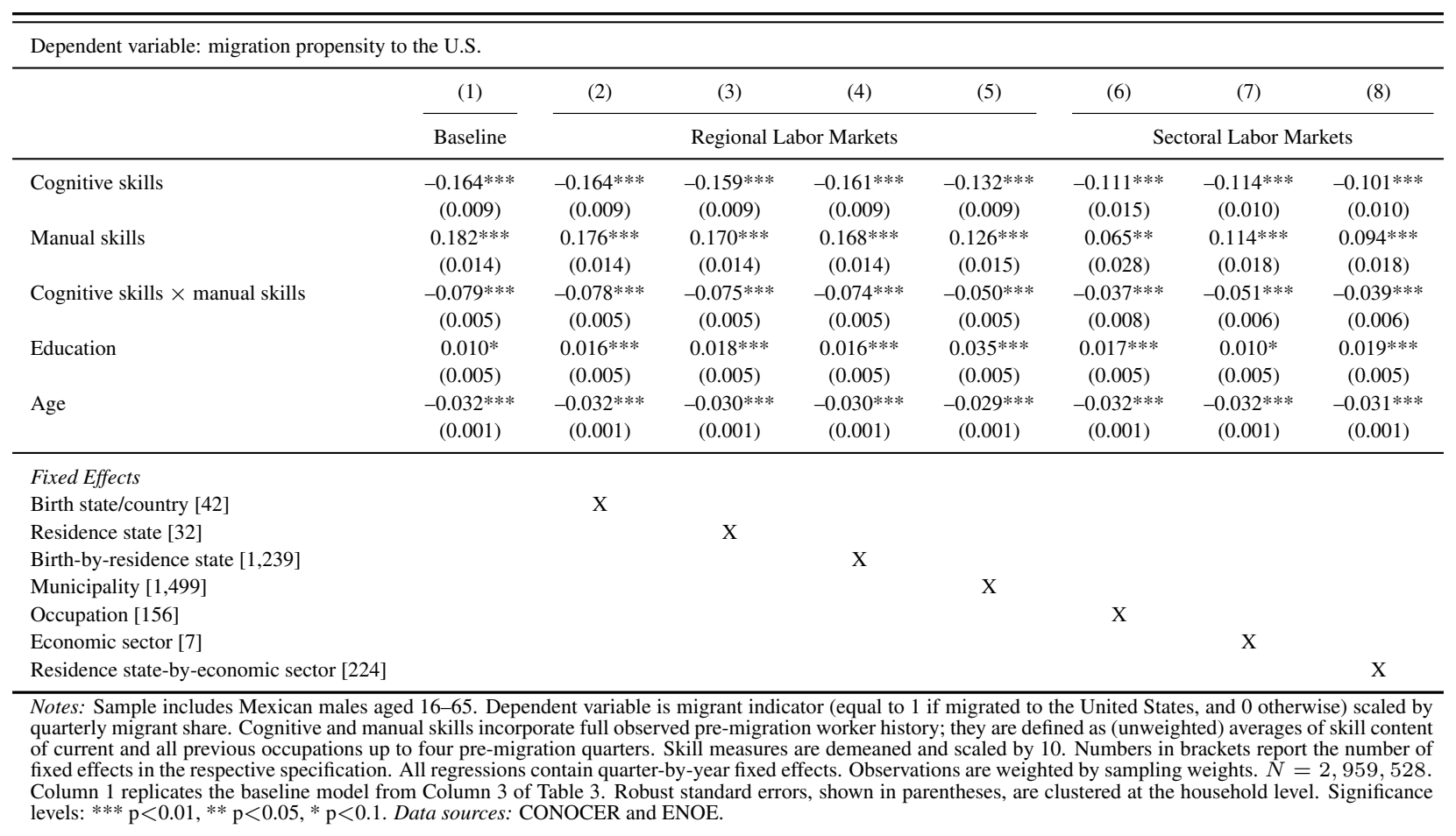


Table 8: Path Dependency in Skill Accumulation: Results from MMP

\begin{tabular}{|c|c|c|c|c|}
\hline & (1) & (2) & (3) & (4) \\
\hline \multicolumn{5}{|c|}{ Panel A: Second Stage } \\
\hline \multicolumn{5}{|l|}{ Dependent variable: migration propensity to the U.S. } \\
\hline Cognitive skills (current occupation) & $\begin{array}{c}-0.148 * * * \\
\quad(0.014)\end{array}$ & & $\begin{array}{c}-0.091 * * * \\
(0.017)\end{array}$ & $\begin{array}{c}-0.183 * * * \\
(0.023)\end{array}$ \\
\hline Manual skills (current occupation) & & $\begin{array}{l}0.239 * * * \\
(0.025)\end{array}$ & $\begin{array}{c}0.133 * * * \\
(0.031)\end{array}$ & $\begin{array}{c}0.081 * * * \\
(0.031)\end{array}$ \\
\hline Cognitive skills $\times$ manual skills (current occupation) & & & & $\begin{array}{c}-0.052 * * * \\
(0.008)\end{array}$ \\
\hline Education & $\begin{array}{l}-0.004 \\
(0.008)\end{array}$ & $\begin{array}{c}-0.024 * * * \\
(0.006)\end{array}$ & $\begin{array}{l}-0.006 \\
(0.008)\end{array}$ & $\begin{array}{l}-0.005 \\
(0.008)\end{array}$ \\
\hline Age & $\begin{array}{c}-0.039 * * * \\
(0.002)\end{array}$ & $\begin{array}{l}-0.041 * * * \\
(0.002)\end{array}$ & $\begin{array}{c}-0.039 * * * \\
(0.002)\end{array}$ & $\begin{array}{c}-0.041 * * * \\
(0.002)\end{array}$ \\
\hline \multicolumn{5}{|c|}{ Panel B: First Stage for Cognitive Skills } \\
\hline \multicolumn{5}{|l|}{ Dependent variable: cognitive skills (current occupation) } \\
\hline Cognitive skills (first occupation) & $\begin{array}{c}0.692 * * * \\
(0.010)\end{array}$ & & $\begin{array}{l}0.689 * * * \\
(0.013)\end{array}$ & $\begin{array}{c}0.645^{* * *} \\
(0.017)\end{array}$ \\
\hline Manual skills (first occupation) & & & $\begin{array}{l}-0.005 \\
(0.018)\end{array}$ & $\begin{array}{c}-0.060 * * * \\
(0.018)\end{array}$ \\
\hline Cognitive skills $\times$ manual skills (first occupation) & & & & $\begin{array}{c}-0.013 * * \\
(0.006)\end{array}$ \\
\hline Kleibergen-Paap F statistics & 4,794 & & 2,411 & 1,611 \\
\hline \multicolumn{5}{|c|}{ Panel C: First Stage for Manual Skills } \\
\hline \multicolumn{5}{|l|}{ Dependent variable: manual skills (current occupation) } \\
\hline Cognitive skills (first occupation) & & & $\begin{array}{l}-0.004 \\
(0.006)\end{array}$ & $\begin{array}{c}-0.020 * * \\
(0.009)\end{array}$ \\
\hline Manual skills (first occupation) & & $\begin{array}{c}0.694 * * * \\
(0.009)\end{array}$ & $\begin{array}{c}0.689 * * * \\
(0.011)\end{array}$ & $\begin{array}{c}0.685^{* * *} \\
(0.011)\end{array}$ \\
\hline Cognitive skills $\times$ manual skills (first occupation) & & & & $\begin{array}{c}-0.009 * * * \\
(0.003)\end{array}$ \\
\hline Kleibergen-Paap F statistics & & 6,607 & 3,336 & 2,234 \\
\hline \multicolumn{5}{|c|}{ Panel D: First Stage for Cognitive Skills $\times$ Manual Skills } \\
\hline \multicolumn{5}{|c|}{ Dependent variable: cognitive skills $\times$ manual skills (current occupation) } \\
\hline Cognitive skills (first occupation) & & & & $\begin{array}{c}0.143 * * * \\
(0.036)\end{array}$ \\
\hline Manual skills (first occupation) & & & & $\begin{array}{c}-0.306 * * * \\
(0.040)\end{array}$ \\
\hline Cognitive skills $\times$ manual skills (first occupation) & & & & $\begin{array}{c}0.737 * * * \\
(0.014)\end{array}$ \\
\hline Kleibergen-Paap F statistics & & & & 1,345 \\
\hline Individuals & 410,789 & 410,789 & 410,789 & 410,789 \\
\hline
\end{tabular}




\section{A Appendix Figures and Tables}

Figure A1: Emigrant Selection on Occupational Skills: Omitting Agricultural Workers

(a) Cognitive Occupational Skills
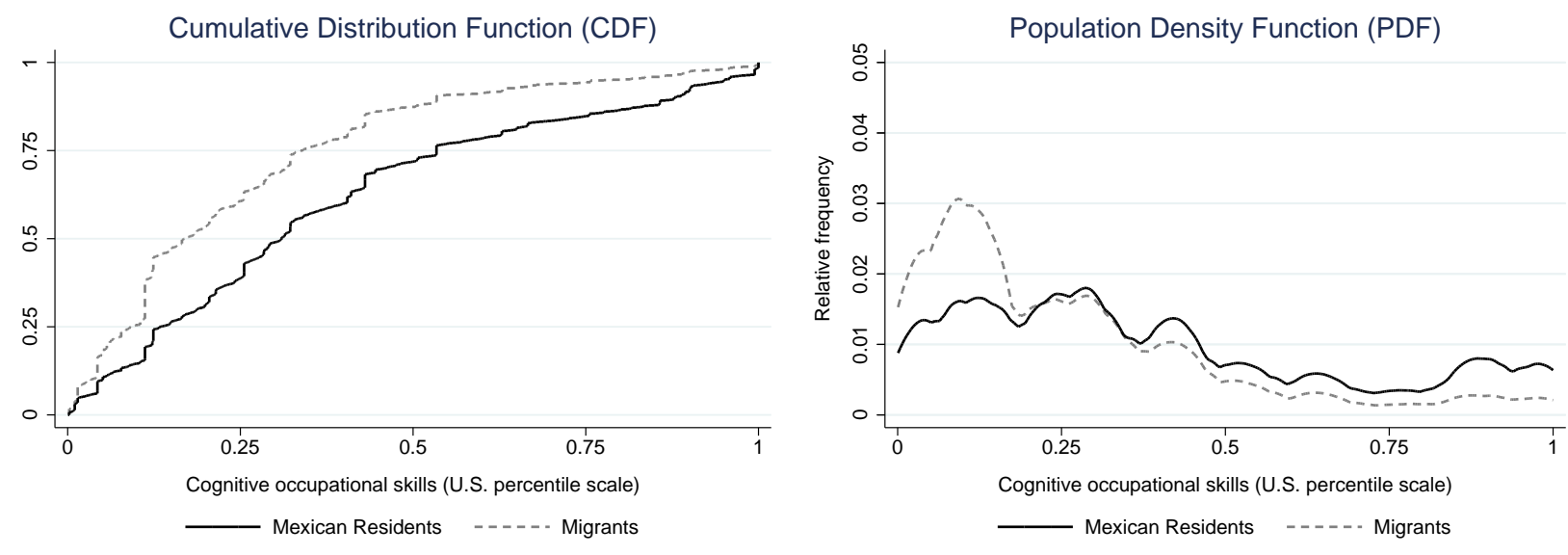

(b) Manual Occupational Skills
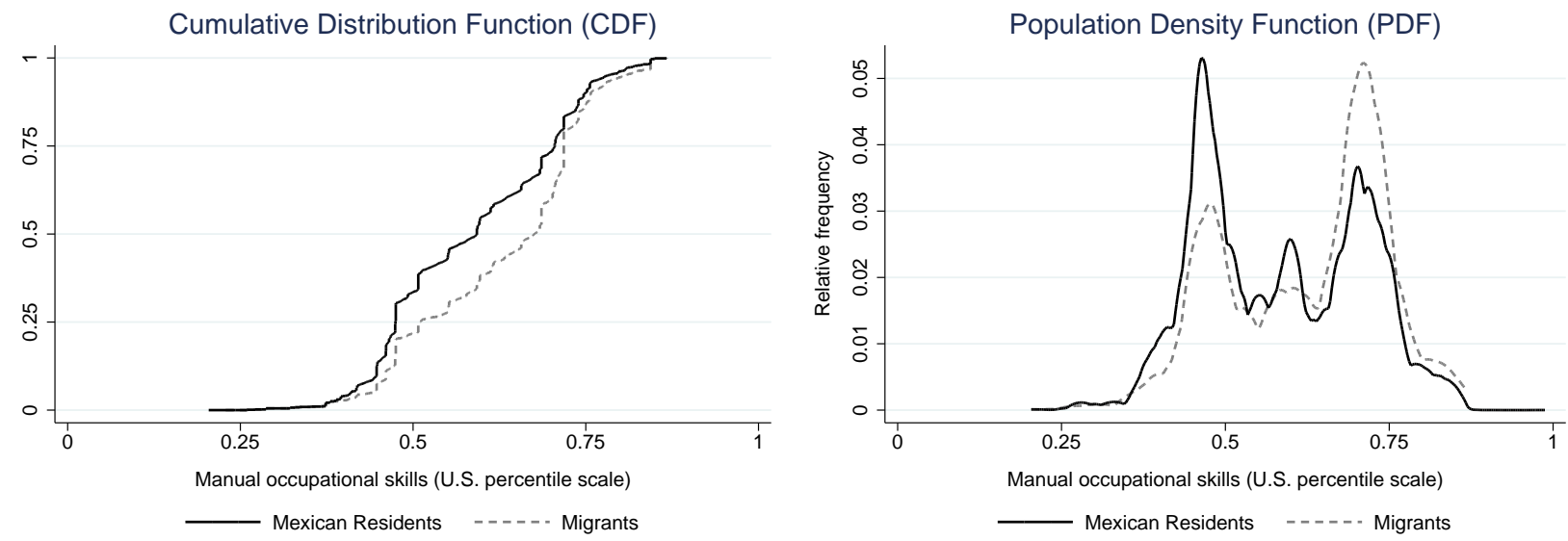

Notes: Figures show cumulative distribution functions (left panels) and population density functions (right panels) of cognitive occupational skills (Figure A1a) and manual occupational skills (Figure A1b) by migration status. Sample consists of male Mexicans aged 16-65, no agricultural workers. Cognitive and manual skills incorporate full observed pre-migration worker history; they are defined as (unweighted) averages of skill content of current and all previous occupations up to four pre-migration quarters. Kolmogorov-Smirnov tests on stochastic dominance indicate that differences between cumulative distribution functions are significant at the $1 \%$ level. $N=6,665$ Mexican migrants in the United States and $N=2,686,836$ Mexican residents. Data sources: CONOCER and ENOE. 


\section{Figure A2: Emigrant Selection on Occupational Skills: Results from ENET}

(a) Cognitive Occupational Skills
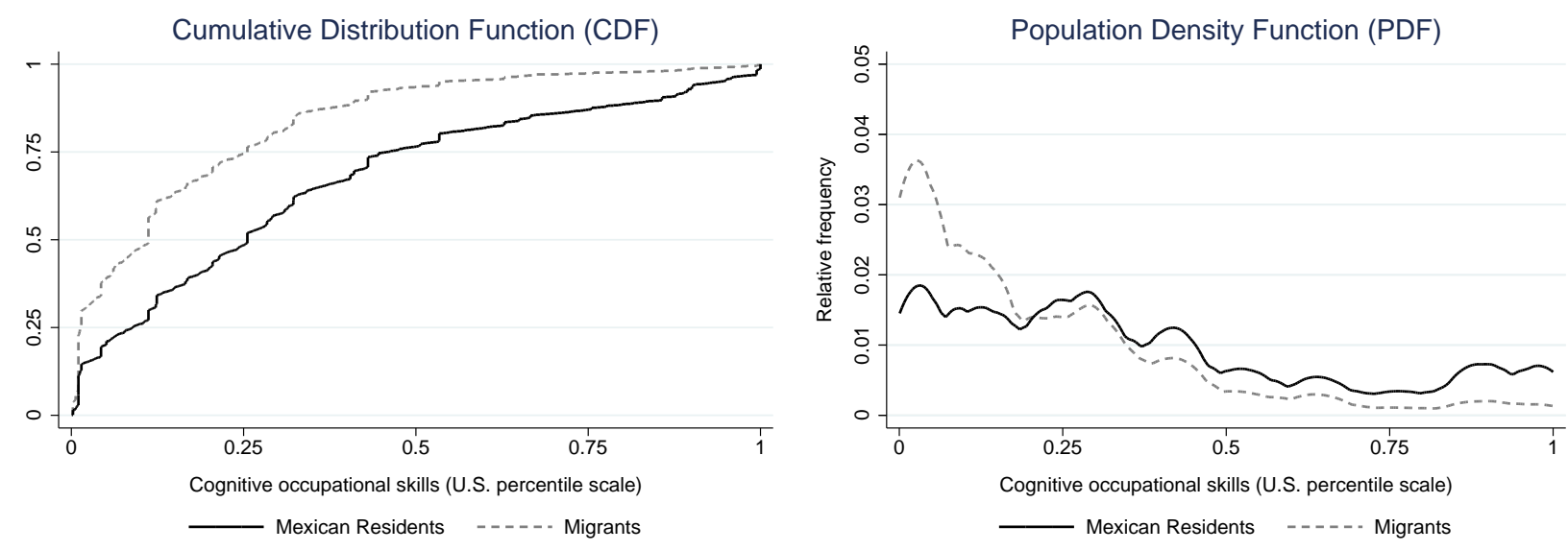

(b) Manual Occupational Skills
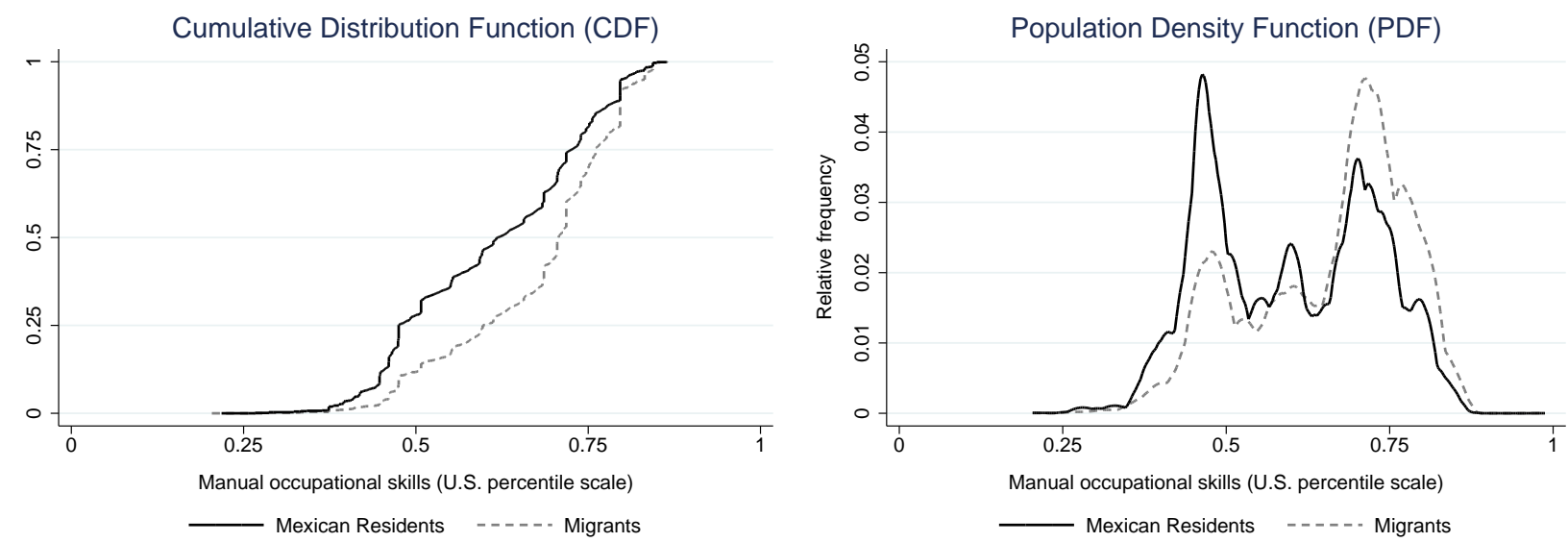

Notes: Figures show cumulative distribution functions (left panels) and population density functions (right panels) of cognitive occupational skills (Figure A2a) and manual occupational skills (Figure A2b) by migration status. Sample consists of male Mexicans aged 16-65. Cognitive and manual skills incorporate full observed pre-migration worker history; they are defined as (unweighted) averages of skill content of current and all previous occupations up to four premigration quarters. Kolmogorov-Smirnov tests on stochastic dominance indicate that differences between cumulative distribution functions are significant at the $1 \%$ level. $N=10,200$ Mexican migrants in the United States and $N=$ 2, 059, 726 Mexican residents. Data sources: CONOCER and ENET. 
Figure A3: Emigrant Selection Using Occupational Skills from Different Pre-Migration Quarters

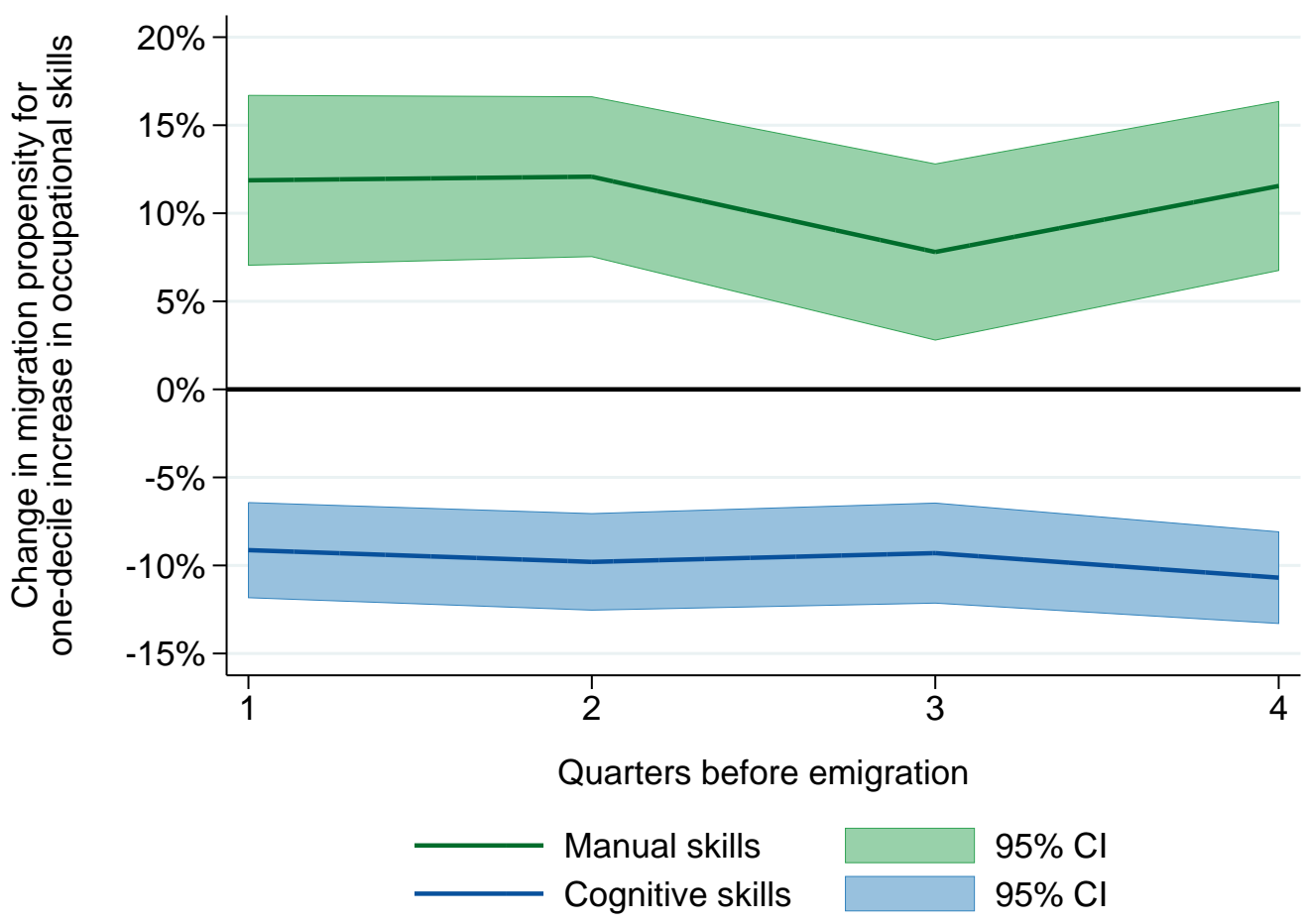

Notes: Graph shows selection on cognitive and manual skills (based on the specification in Column 3 of Table 3 ) using the occupational skills implied by the occupation four, three, two, or one quarter before migration. Sample consists of male Mexicans aged 16-65 who report an occupation in all four quarters previous to (potential) migration. Migrants are those individuals who are observed for four consecutive quarters before migrating in the fifth (one-fifth of the total sample). Data sources: CONOCER and ENOE. 
Table A1: Literature on the Selection of Migrants

\begin{tabular}{|c|c|c|c|}
\hline Paper & Skill Measure & Migration Flow & $\begin{array}{l}\text { Consistent with } \\
\text { Roy/Borjas Model }\end{array}$ \\
\hline Borjas (1987) & $\begin{array}{l}\text { entry earnings in } \\
\text { destination (U.S.) }\end{array}$ & Many $\rightarrow$ U.S. & partly \\
\hline Ramos (1992) & predicted earnings & Puerto Rico $\rightarrow$ U.S. & yes \\
\hline Feliciano (2005) & education & 32 countries $\rightarrow$ U.S. & no \\
\hline Borjas (2008) & education & Puerto Rico $\rightarrow$ U.S. & partly \\
\hline Grogger and Hanson (2011) & education & Cross country & no \\
\hline Abramitzky et al. (2012) & $\begin{array}{c}\text { father's occupation } \\
\text { own occupation }\end{array}$ & Norway $\rightarrow$ U.S. & $\begin{array}{c}\text { yes } \\
\text { partly }\end{array}$ \\
\hline Belot and Hatton (2012) & education & $\begin{array}{c}80 \text { countries } \\
\text { countries }\end{array} \rightarrow 29$ & partly \\
\hline Stolz and Baten (2012) & age heaping & $\begin{array}{l}52 \text { countries } \\
\text { countries }\end{array}$ & yes \\
\hline Borjas (2014) & $\begin{array}{l}\text { entry earnings in } \\
\text { destination (U.S.) }\end{array}$ & Many $\rightarrow$ U.S. & yes \\
\hline Borjas et al. (2015) & earnings in home country & $\begin{array}{l}\text { Denmark } \rightarrow \text { many } \\
\quad \text { countries }\end{array}$ & yes \\
\hline & residual earnings & & yes \\
\hline Gould and Moav (2016) & $\begin{array}{l}\text { education } \\
\text { residual earnings }\end{array}$ & Israel $\rightarrow$ U.S. & $\begin{array}{l}\text { yes } \\
\text { partly }\end{array}$ \\
\hline Parey et al. (2017) & predicted earnings & Germany $\rightarrow$ many & yes \\
\hline
\end{tabular}

Notes: Table shows related papers dealing with migrant selection (adopted from Parey et al., 2017). 


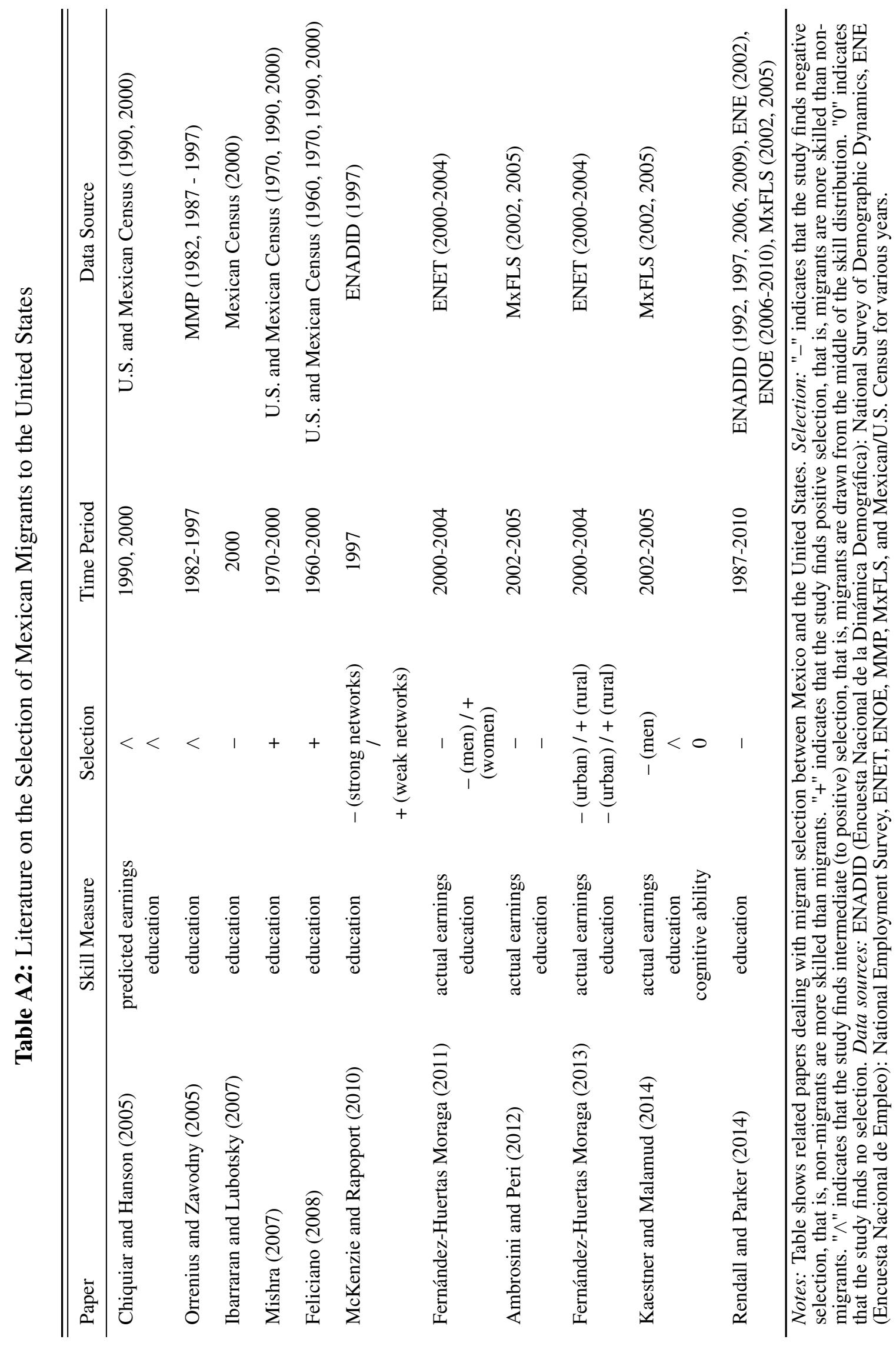


Table A3: Summary Statistics

\begin{tabular}{|c|c|c|c|c|c|}
\hline & (1) & (2) & (3) & (4) & (5) \\
\hline Variable & Mean & SD & Min & $\operatorname{Max}$ & $\mathrm{N}$ \\
\hline \multicolumn{6}{|c|}{ Panel A: ENOE } \\
\hline Cognitive skills (percentile) & 0.3320 & 0.2888 & 0.0006 & 1.0000 & $2,959,528$ \\
\hline Cognitive skills (score) & -0.8695 & 1.4877 & -3.8503 & 3.2256 & $2,959,528$ \\
\hline Manual skills (percentile) & 0.6100 & 0.1332 & 0.2039 & 0.9875 & $2,959,528$ \\
\hline Manual skills (score) & 0.1307 & 0.6175 & -1.8153 & 2.5320 & $2,959,528$ \\
\hline Migrated to the U.S. (quarterly share) & 0.0033 & - & 0 & 1 & $2,959,528$ \\
\hline Years of education & 9.0825 & 4.4436 & 0 & 24 & $2,959,528$ \\
\hline Age & 36.8891 & 12.9577 & 16 & 65 & $2,959,528$ \\
\hline Rural status & 0.2262 & - & 0 & 1 & $2,959,528$ \\
\hline Log real hourly earnings (2010 U.S. dollars) & 0.9613 & 0.7044 & -2.0225 & 3.2797 & $1,950,951$ \\
\hline Travel distance to U.S. border (hours) & 10.269 & 5.3663 & 0.0539 & 26.6936 & $1,950,951$ \\
\hline$\Delta$ basic returns ${ }_{M E X, 2000}^{U S, 2000}$ & -0.4755 & 0.3354 & -1.4323 & 0.1361 & $1,950,951$ \\
\hline$\Delta$ basic returns ${ }_{M E X, 2000}^{U S, 2010}$ & -0.1263 & 0.3106 & -1.1713 & 0.4881 & $1,950,951$ \\
\hline$\Delta$ occupational returns ${ }_{M E X, 2000}^{U S, 2000}$ & 0.1951 & 0.2716 & -0.4192 & 0.6651 & $1,950,951$ \\
\hline$\Delta$ occupational returns ${ }_{M E X, 2000}^{U S, 2010}$ & 0.1782 & 0.2407 & -0.2588 & 0.6287 & $1,950,951$ \\
\hline \multicolumn{6}{|c|}{ Panel B: ENET } \\
\hline Cognitive skills (percentile) & 0.3212 & 0.2887 & 0.0006 & 1.0000 & $2,069,926$ \\
\hline Cognitive skills (score) & -0.9367 & 1.4909 & -3.8503 & 2.9664 & $2,069,926$ \\
\hline Manual skills (percentile) & 0.6147 & 0.1328 & 0.2039 & 0.9875 & $2,069,926$ \\
\hline Manual skills (score) & 0.1528 & 0.6206 & -1.8153 & 2.5320 & $2,069,926$ \\
\hline Migrated to the U.S. (quarterly share) & 0.0068 & - & 0 & 1 & $2,069,926$ \\
\hline Years of education & 7.8243 & 5.3314 & 0 & 22 & $2,069,926$ \\
\hline Age & 35.7065 & 13.0269 & 16 & 65 & $2,069,926$ \\
\hline Rural status & 0.2278 & - & 0 & 1 & $2,069,926$ \\
\hline Log real hourly earnings (2010 U.S. dollars) & 0.8474 & 0.8954 & -2.6531 & 3.3652 & $1,564,772$ \\
\hline Travel distance to U.S. border (hours) & 10.3294 & 5.1784 & 0.0539 & 26.6936 & $1,564,772$ \\
\hline$\Delta$ basic returns ${ }_{M E X, 2000}^{U S, 2000}$ & -0.4146 & 0.3363 & -1.4323 & 0.1361 & $1,564,772$ \\
\hline$\Delta$ basic returns $U_{M E X, 2000}^{U S, 2010}$ & -0.0734 & 0.3049 & -1.1713 & 0.4881 & $1,564,772$ \\
\hline 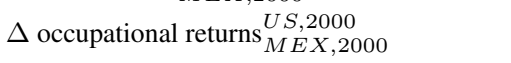 & 0.2073 & 0.2791 & -0.4192 & 0.6651 & $1,564,772$ \\
\hline$\Delta$ occupational returns $\begin{array}{l}U S, 2010 \\
M E X, 2000\end{array}$ & 0.1887 & 0.2489 & -0.2588 & 0.6287 & $1,564,772$ \\
\hline \multicolumn{6}{|c|}{ Panel C: MMP } \\
\hline Cognitive skills (percentile) & 0.2121 & 0.2437 & 0.0155 & 1.0000 & 471,123 \\
\hline Cognitive skills (score) & -1.5300 & 1.3157 & -2.7137 & 2.9664 & 471,123 \\
\hline Manual skills (percentile) & 0.6759 & 0.1338 & 0.1964 & 0.8389 & 471,123 \\
\hline Manual skills (score) & 0.5231 & 0.6785 & -1.7489 & 1.5942 & 471,123 \\
\hline Migrated to the U.S. (annual share) & 0.024 & - & 0 & 1 & 471,123 \\
\hline Years of education & 5.5225 & 4.4830 & 0 & 25 & 471,123 \\
\hline Age & 34.4605 & 12.4148 & 16 & 65 & 471,123 \\
\hline \multicolumn{6}{|c|}{ Panel D: MxFLS } \\
\hline Cognitive skills (percentile) & 0.2868 & 0.2330 & 0.0384 & 0.9598 & 16,164 \\
\hline Cognitive skills (score) & -1.1032 & 1.2121 & -2.5674 & 2.0561 & 16,164 \\
\hline Manual skills (percentile) & 0.6320 & 0.1057 & 0.4005 & 0.7770 & 16,164 \\
\hline Manual skills (score) & 0.2682 & 0.5310 & -0.8926 & 1.0356 & 16,164 \\
\hline Migrated to the U.S. (annual share) & 0.025 & - & 0 & 1 & 16,164 \\
\hline Years of education & 7.6229 & 4.2449 & 0 & 18 & 16,164 \\
\hline Age & 36.4923 & 13.4591 & 16 & 65 & 16,164 \\
\hline
\end{tabular}

Notes: Table contains summary statistics of main variables. See text for the construction of the occupational skill measures (Section III.) and the returns-to-skills measures (Section VII.). Rural status is a dummy variable taking the value 1 if persons lives in a locality with less than 2,500 inhabitants ( 0 otherwise). Observations are weighted by sampling weights. Data sources: CONOCER, ENET, ENOE, MMP, and MxFLS. 
Table A4: Range of Occupational Skills in Main SINCO Categories

\begin{tabular}{|c|c|c|c|}
\hline \multirow[t]{2}{*}{ Occupations } & \multicolumn{2}{|c|}{ Range } & \multirow[t]{2}{*}{ Share } \\
\hline & Manual & Cognitive & \\
\hline \multicolumn{4}{|l|}{ 1-digit level } \\
\hline Officials, directors, and chiefs & 0.420 & 0.718 & 0.045 \\
\hline Professionals and technicians & 0.583 & 0.877 & 0.145 \\
\hline Auxiliary workers in administrative activities & 0.453 & 0.742 & 0.044 \\
\hline Traders, sales clerks, and sales agents & 0.180 & 0.579 & 0.099 \\
\hline Workers in personal services and surveillance & 0.544 & 0.985 & 0.069 \\
\hline Workers in agriculture, livestock, forestry, hunting, and fishing & 0.518 & 0.397 & 0.159 \\
\hline Craft workers & 0.560 & 0.951 & 0.132 \\
\hline Operators of industrial machinery, assemblers, and drivers & 0.397 & 0.733 & 0.129 \\
\hline Workers in elementary and supportive activities & 0.507 & 0.353 & 0.179 \\
\hline Average & 0.476 & 0.663 & \\
\hline \multicolumn{4}{|l|}{ 2-digit level } \\
\hline Average & 0.335 & 0.431 & \\
\hline \multicolumn{4}{|l|}{ 3-digit level } \\
\hline Average & 0.173 & 0.210 & \\
\hline
\end{tabular}

Table A5: Emigrant Selection on Occupational Skills: Functional Form Robustness Results

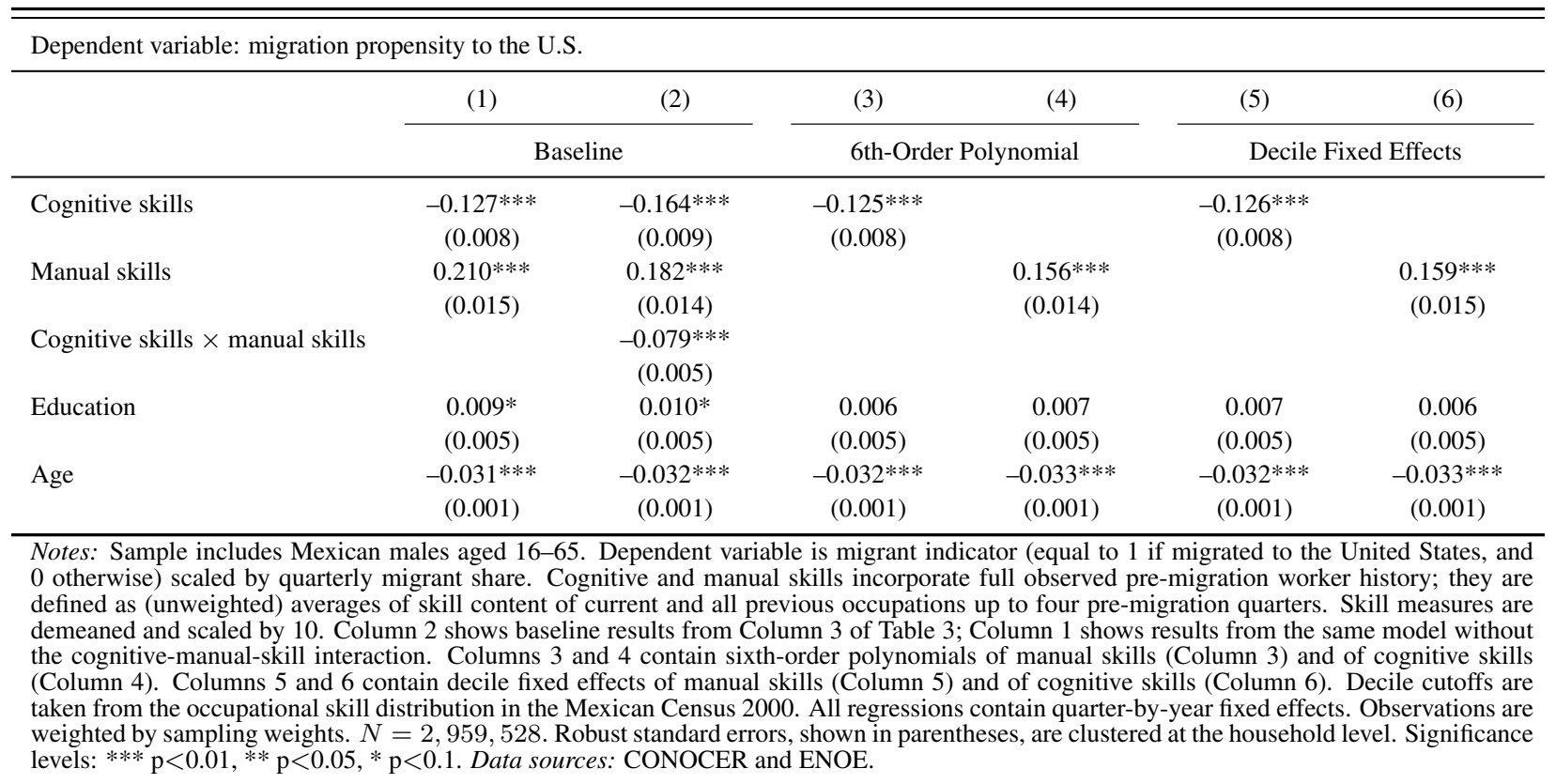


Table A6: Emigrant Selection on Occupational Skills: Results from ENET

\begin{tabular}{|c|c|c|c|c|c|c|c|}
\hline & (1) & (2) & (3) & (4) & (5) & (6) & (7) \\
\hline & \multirow{2}{*}{\multicolumn{3}{|c|}{ Baseline }} & \multicolumn{2}{|c|}{ Urban Status } & \multirow{2}{*}{\multicolumn{2}{|c|}{ Earnings }} \\
\hline & & & & Urban & Rural & & \\
\hline Cognitive skills & $\begin{array}{c}-0.137 * * * \\
(0.005)\end{array}$ & $\begin{array}{c}-0.167 * * * \\
(0.006)\end{array}$ & $\begin{array}{c}-0.161 * * * \\
(0.007)\end{array}$ & $\begin{array}{c}-0.118^{* * * *} \\
(0.008)\end{array}$ & $\begin{array}{c}-0.226^{* * *} \\
(0.029)\end{array}$ & $\begin{array}{c}-0.154 * * * \\
(0.008)\end{array}$ & $\begin{array}{c}-0.159 * * * \\
(0.009)\end{array}$ \\
\hline Manual skills & $\begin{array}{c}0.204 * * * \\
(0.013)\end{array}$ & $\begin{array}{c}0.183 * * * \\
(0.013)\end{array}$ & $\begin{array}{c}0.187 * * * \\
(0.013)\end{array}$ & $\begin{array}{c}0.153^{* * * *} \\
(0.015)\end{array}$ & $\begin{array}{c}0.069 \\
(0.053)\end{array}$ & $\begin{array}{c}0.133 * * * \\
(0.013)\end{array}$ & $\begin{array}{c}0.136 * * * \\
(0.013)\end{array}$ \\
\hline Cognitive skills $\times$ manual skills & & $\begin{array}{c}-0.063^{* * *} \\
(0.004)\end{array}$ & $\begin{array}{c}-0.069 * * * \\
(0.004)\end{array}$ & $\begin{array}{c}-0.051^{* * *} \\
(0.005)\end{array}$ & $\begin{array}{c}-0.039 * * \\
(0.016)\end{array}$ & $\begin{array}{c}-0.063^{* * *} \\
(0.004)\end{array}$ & $\begin{array}{c}-0.065 * * * \\
(0.004)\end{array}$ \\
\hline Education & & & $\begin{array}{l}-0.003 \\
(0.004)\end{array}$ & $\begin{array}{c}-0.007 * \\
(0.004)\end{array}$ & $\begin{array}{c}0.013 \\
(0.013)\end{array}$ & $\begin{array}{c}0.002 \\
(0.004)\end{array}$ & $\begin{array}{l}-0.000 \\
(0.004)\end{array}$ \\
\hline Age & & & $\begin{array}{c}-0.036^{* * * *} \\
(0.001)\end{array}$ & $\begin{array}{c}-0.024 * * * \\
(0.001)\end{array}$ & $\begin{array}{c}-0.069 * * * \\
(0.003)\end{array}$ & $\begin{array}{c}-0.036^{* * *} \\
(0.002)\end{array}$ & $\begin{array}{c}-0.036 * * * \\
(0.002)\end{array}$ \\
\hline Log hourly earnings & & & & & & & $\begin{array}{c}0.045 \\
(0.028)\end{array}$ \\
\hline Observations & $2,069,926$ & $2,069,926$ & $2,069,926$ & $1,816,965$ & 252,961 & $1,564,772$ & $1,564,772$ \\
\hline
\end{tabular}

Table A7: Emigrant Selection on Occupational Skills: Results from MxFLS

\begin{tabular}{|c|c|c|c|c|c|c|}
\hline \multicolumn{7}{|c|}{ Dependent variable: migration propensity to the U.S. } \\
\hline & (1) & (2) & (3) & (4) & (5) & (6) \\
\hline & \multicolumn{3}{|c|}{ Baseline } & Round 1 Only & Last Occupation & Within State \\
\hline Cognitive skills & $\begin{array}{l}-0.048 \\
(0.030)\end{array}$ & $\begin{array}{c}-0.125 * * * \\
(0.046)\end{array}$ & $\begin{array}{c}-0.100 * \\
(0.053)\end{array}$ & $\begin{array}{c}-0.110 * \\
(0.057)\end{array}$ & $\begin{array}{c}-0.119 * * \\
(0.048)\end{array}$ & $\begin{array}{c}-0.092 * \\
(0.054)\end{array}$ \\
\hline Manual skills & $\begin{array}{c}0.323 * * * \\
(0.085)\end{array}$ & $\begin{array}{c}0.196 * * \\
(0.088)\end{array}$ & $\begin{array}{c}0.294 * * * \\
(0.091)\end{array}$ & $\begin{array}{c}0.243^{* *} \\
(0.104)\end{array}$ & $\begin{array}{c}0.169^{* *} \\
(0.085)\end{array}$ & $\begin{array}{c}0.261 * * * \\
(0.091)\end{array}$ \\
\hline Cognitive skills $\times$ manual skills & & $\begin{array}{c}-0.061^{*} \\
(0.032)\end{array}$ & $\begin{array}{c}-0.077 * * \\
(0.032)\end{array}$ & $\begin{array}{c}-0.080^{* *} \\
(0.033)\end{array}$ & $\begin{array}{c}-0.085^{* *} \\
(0.034)\end{array}$ & $\begin{array}{c}-0.058^{*} \\
(0.033)\end{array}$ \\
\hline Education & & & $\begin{array}{l}-0.010 \\
(0.018)\end{array}$ & $\begin{array}{l}-0.003 \\
(0.017)\end{array}$ & $\begin{array}{c}-0.037 * * \\
(0.018)\end{array}$ & $\begin{array}{c}0.005 \\
(0.018)\end{array}$ \\
\hline Age & & & $\begin{array}{c}-0.045^{* * * *} \\
(0.006)\end{array}$ & $\begin{array}{c}-0.043^{* * *} * \\
(0.005)\end{array}$ & $\begin{array}{c}-0.050^{* * * *} \\
(0.007)\end{array}$ & $\begin{array}{c}-0.042 * * * \\
(0.005)\end{array}$ \\
\hline State-of-living fixed effects & & & & & & $\mathrm{X}$ \\
\hline Observations & 16,164 & 16,164 & 16,164 & 7,909 & 12,591 & 16,163 \\
\hline $\begin{array}{l}\text { Notes: Sample includes Mexican } \\
\text { otherwise) scaled by yearly migr } \\
\text { as (unweighted) averages of skil } \\
\text { market entry. Skill measures are } \\
\text { estimation sample. In Column } 5 \text {, } \\
\text { on the current occupation are dro } \\
\text { shown in parentheses, are clustere } \\
\text { MxFLS. }\end{array}$ & $\begin{array}{l}\text { es aged } 16 \\
\text { hare. Cogn } \\
\text { tent of the } \\
\text { aned and s } \\
\text { consider o } \\
\text {. All regre } \\
\text { the househ }\end{array}$ & $\begin{array}{l}\text { ependent vi } \\
\text { nd manual s } \\
\text { t occupatio } \\
\text { y } 10 \text {. In Co } \\
\text { current occ } \\
\text { contain sur } \\
\text { el. Significe }\end{array}$ & $\begin{array}{l}\text { s migrant } \\
\text { corporate } \mathrm{f} \\
\text { ccupation } \\
\text { only parti } \\
\text { to calcula } \\
\text { r fixed effe } \\
\text { els: } * * * \mathrm{p}\end{array}$ & $\begin{array}{l}\text { ator (equal to } 1 \\
\text { oserved pre-mi } \\
\text { years prior to } t \\
\text { ts of round } 1 \mathrm{c} \\
\text { cupational skil } \\
\text { Observations a } \\
\text { l, ** }<<0.05 \text {, * }\end{array}$ & $\begin{array}{l}\text { migrated to the Ur } \\
\text { ion worker history } \\
\text { urvey, and the oc } \\
\text { e MxFLS survey } \\
\text { easures; people w } \\
\text { inweighted. Robu } \\
\text { 0.1. Data sources }\end{array}$ & $\begin{array}{l}\text { ed States, and } \\
\text { hey are definec } \\
\text { pation at labor } \\
\text { included in the } \\
\text { out informatior } \\
\text { standard errors } \\
\text { CONOCER anc }\end{array}$ \\
\hline
\end{tabular}


Table A8: Emigrant Selection on Occupational Skills: Results from MMP

\begin{tabular}{|c|c|c|c|c|c|c|}
\hline \multicolumn{7}{|c|}{ Dependent variable: migration propensity to the U.S. } \\
\hline & (1) & (2) & (3) & (4) & (5) & (6) \\
\hline & \multicolumn{3}{|c|}{ Baseline } & No Return & Last Occupation & Within State \\
\hline Cognitive skills & $\begin{array}{c}-0.097 * * * \\
(0.010)\end{array}$ & $\begin{array}{c}-0.132 * * * \\
(0.013)\end{array}$ & $\begin{array}{c}-0.128 * * * \\
(0.015)\end{array}$ & $\begin{array}{c}-0.123 * * * \\
(0.017)\end{array}$ & $\begin{array}{c}-0.135^{* * *} \\
(0.013)\end{array}$ & $\begin{array}{c}-0.147 * * * \\
(0.015)\end{array}$ \\
\hline Manual skills & $\begin{array}{c}0.069 * * * \\
(0.022)\end{array}$ & $\begin{array}{c}0.057 * * * \\
(0.021)\end{array}$ & $\begin{array}{c}0.087 * * * \\
(0.021)\end{array}$ & $\begin{array}{c}0.056^{* *} \\
(0.024)\end{array}$ & $\begin{array}{c}0.102 * * * \\
(0.018)\end{array}$ & $\begin{array}{c}0.085^{* * * *} \\
(0.021)\end{array}$ \\
\hline Cognitive skills $\times$ manual skills & & $\begin{array}{c}-0.021 * * * \\
(0.005)\end{array}$ & $\begin{array}{c}-0.030 * * * \\
(0.005)\end{array}$ & $\begin{array}{c}-0.032 * * * \\
(0.006)\end{array}$ & $\begin{array}{c}-0.049 * * * \\
(0.005)\end{array}$ & $\begin{array}{c}-0.027 * * * \\
(0.006)\end{array}$ \\
\hline Education & & & $\begin{array}{c}-0.017 * * \\
(0.006)\end{array}$ & $\begin{array}{c}-0.014 * \\
(0.007)\end{array}$ & $\begin{array}{c}-0.019 * * * \\
(0.006)\end{array}$ & $\begin{array}{l}-0.003 \\
(0.007)\end{array}$ \\
\hline Age & & & $\begin{array}{c}-0.043 * * * \\
(0.002)\end{array}$ & $\begin{array}{c}-0.061 * * * \\
(0.002)\end{array}$ & $\begin{array}{c}-0.042 * * * \\
(0.002)\end{array}$ & $\begin{array}{c}-0.046 * * * \\
(0.002)\end{array}$ \\
\hline State-of-birth fixed effects & & & & & & $\mathrm{X}$ \\
\hline Observations & 471,123 & 471,123 & 471,123 & 385,287 & 410,789 & 470,659 \\
\hline $\begin{array}{l}\text { Notes: Sample includes Mexican } \\
\text { is without return migrants). Deper } \\
\text { migrant share. Cognitive and ma } \\
\text { of skill content of current and al } \\
\text { consider only the last pre-migrati } \\
\text { before migration are dropped. All } \\
\text { shown in parentheses, are clustere } \\
\text { MMP. }\end{array}$ & $\begin{array}{l}\text { es aged } 16-6 \\
\text { th variable is } \\
1 \text { skills inco } \\
\text { evious occul } \\
\text { occupation } t \\
\text { ressions con } \\
t \text { the individu }\end{array}$ & $\begin{array}{l}\text { Column 4, } \\
\text { int indicator } \\
\text { full obser } \\
\text { prior to } m \\
\text { ulate occup } \\
\text { ear fixed eff } \\
\text { el. Significe }\end{array}$ & $\begin{array}{l}\text { all observa } \\
1 \text { to } 1 \text { if mig } \\
\text { e-migration } \\
\text { n. Skill m } \\
\text { skill meas } \\
\text { bbservation } \\
\text { vels: } * * \text { p }\end{array}$ & $\begin{array}{l}\text { ter the first } \\
\text { the United } \\
\text { history; } t \\
\text { are demea } \\
\text { ople witho } \\
\text { ighted by } \\
* \text { p }<0.05\end{array}$ & $\begin{array}{l}\text { to the United Stat } \\
\text { s, and } 0 \text { otherwise } \\
\text { e defined as (unw } \\
\text { nd scaled by } 10 \text {. } \\
\text { cupational informa } \\
\text { ng weights. Robu } \\
\text { 0.1. Data sources }\end{array}$ & $\begin{array}{l}\text { i.e., estimation } \\
\text { caled by annual } \\
\text { shted) averages } \\
\text { Column 5, we } \\
\text { on immediately } \\
\text { standard errors, } \\
\text { CONOCER and }\end{array}$ \\
\hline
\end{tabular}


Table A9: Selection on Earnings and Differential Returns: Results for 2010

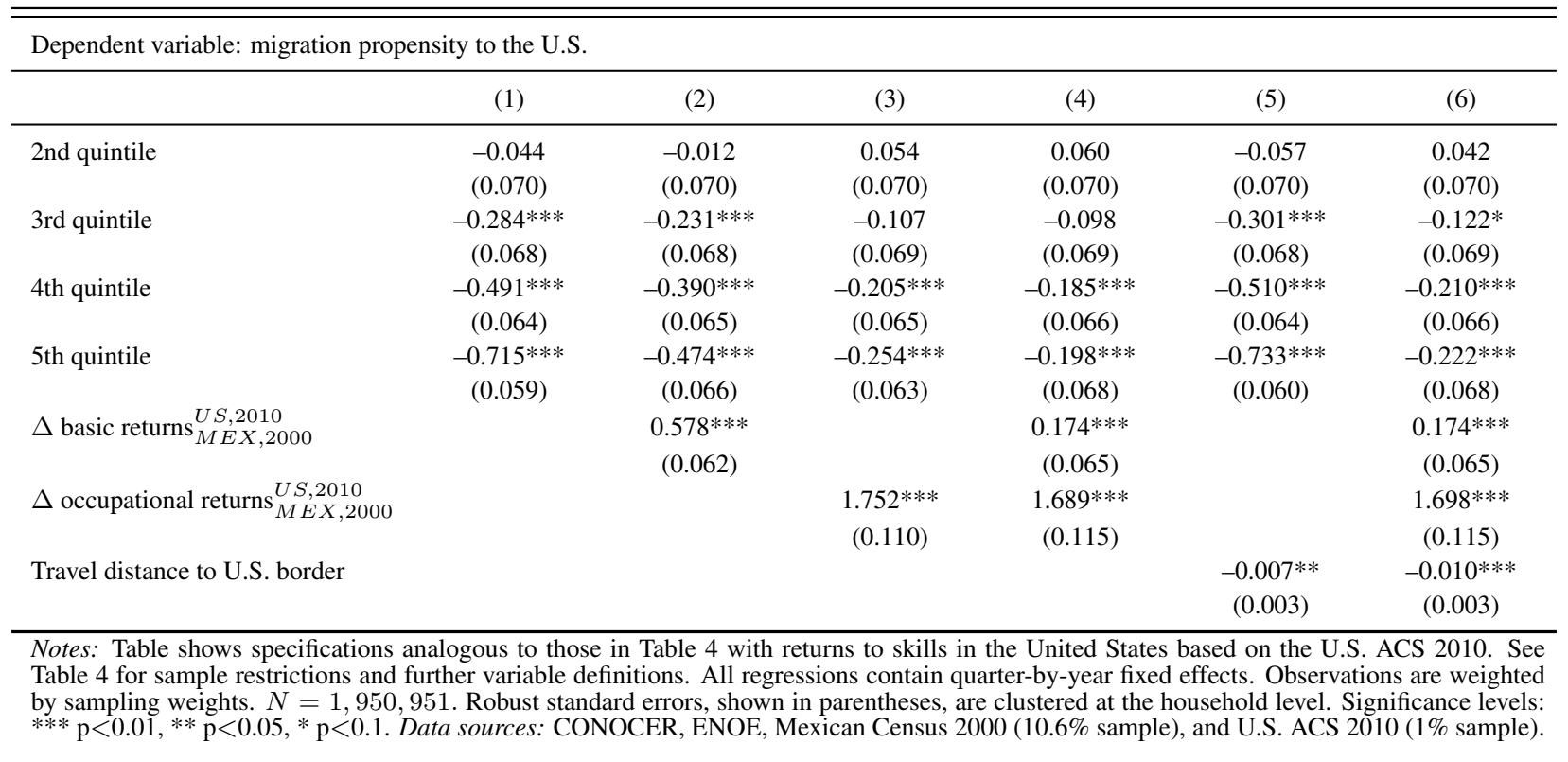

Table A10: Selection on Earnings and Differential Returns: Results from ENET for 2010

\begin{tabular}{|c|c|c|c|c|c|c|}
\hline \multicolumn{7}{|c|}{ Dependent variable: migration propensity to the U.S. } \\
\hline & (1) & (2) & (3) & (4) & (5) & (6) \\
\hline 2nd quintile & $\begin{array}{c}0.037 \\
(0.061)\end{array}$ & $\begin{array}{c}0.078 \\
(0.062)\end{array}$ & $\begin{array}{c}0.227 * * * \\
(0.064)\end{array}$ & $\begin{array}{c}0.232 * * * \\
(0.064)\end{array}$ & $\begin{array}{l}-0.007 \\
(0.062)\end{array}$ & $\begin{array}{c}0.186 * * * \\
(0.065)\end{array}$ \\
\hline 3rd quintile & $\begin{array}{c}-0.216 * * * \\
(0.058)\end{array}$ & $\begin{array}{c}-0.152^{* *} \\
(0.060)\end{array}$ & $\begin{array}{c}0.062 \\
(0.061)\end{array}$ & $\begin{array}{c}0.070 \\
(0.062)\end{array}$ & $\begin{array}{c}-0.282 * * * \\
(0.060)\end{array}$ & $\begin{array}{c}0.002 \\
(0.063)\end{array}$ \\
\hline 4th quintile & $\begin{array}{c}-0.474 * * * \\
(0.054)\end{array}$ & $\begin{array}{l}-0.365^{* * * *} \\
(0.057)\end{array}$ & $\begin{array}{l}-0.092 \\
(0.059)\end{array}$ & $\begin{array}{l}-0.076 \\
(0.061)\end{array}$ & $\begin{array}{c}-0.547 * * * \\
(0.056)\end{array}$ & $\begin{array}{c}-0.152 * * \\
(0.063)\end{array}$ \\
\hline 5th quintile & $\begin{array}{c}-0.766 * * * \\
(0.049)\end{array}$ & $\begin{array}{l}-0.519 * * * \\
(0.060)\end{array}$ & $\begin{array}{l}-0.218 * * * \\
(0.058)\end{array}$ & $\begin{array}{c}-0.176 * * * \\
(0.063)\end{array}$ & $\begin{array}{c}-0.838^{* * * *} \\
(0.051)\end{array}$ & $\begin{array}{l}-0.252^{* * * *} \\
(0.065)\end{array}$ \\
\hline$\Delta$ basic returns ${ }_{M E X, 2000}^{U S, 2010}$ & & $\begin{array}{c}0.524 * * * \\
(0.055)\end{array}$ & & $\begin{array}{c}0.116^{* *} \\
(0.057)\end{array}$ & & $\begin{array}{l}0.107^{*} \\
(0.058)\end{array}$ \\
\hline$\Delta$ occupational returns ${ }_{M E X, 2000}^{U S, 2010}$ & & & $\begin{array}{l}1.703 * * * \\
(0.102)\end{array}$ & $\begin{array}{c}1.664 * * * \\
(0.107)\end{array}$ & & $\begin{array}{c}1.674 * * * \\
(0.107)\end{array}$ \\
\hline Travel distance to U.S. border & & & & & $\begin{array}{l}-0.020^{* * * *} \\
(0.003)\end{array}$ & $\begin{array}{l}-0.022 * * * \\
(0.003)\end{array}$ \\
\hline
\end{tabular}


Table A11: Selection on Earnings and Differential Returns: Using Different Comparison Groups in the United States

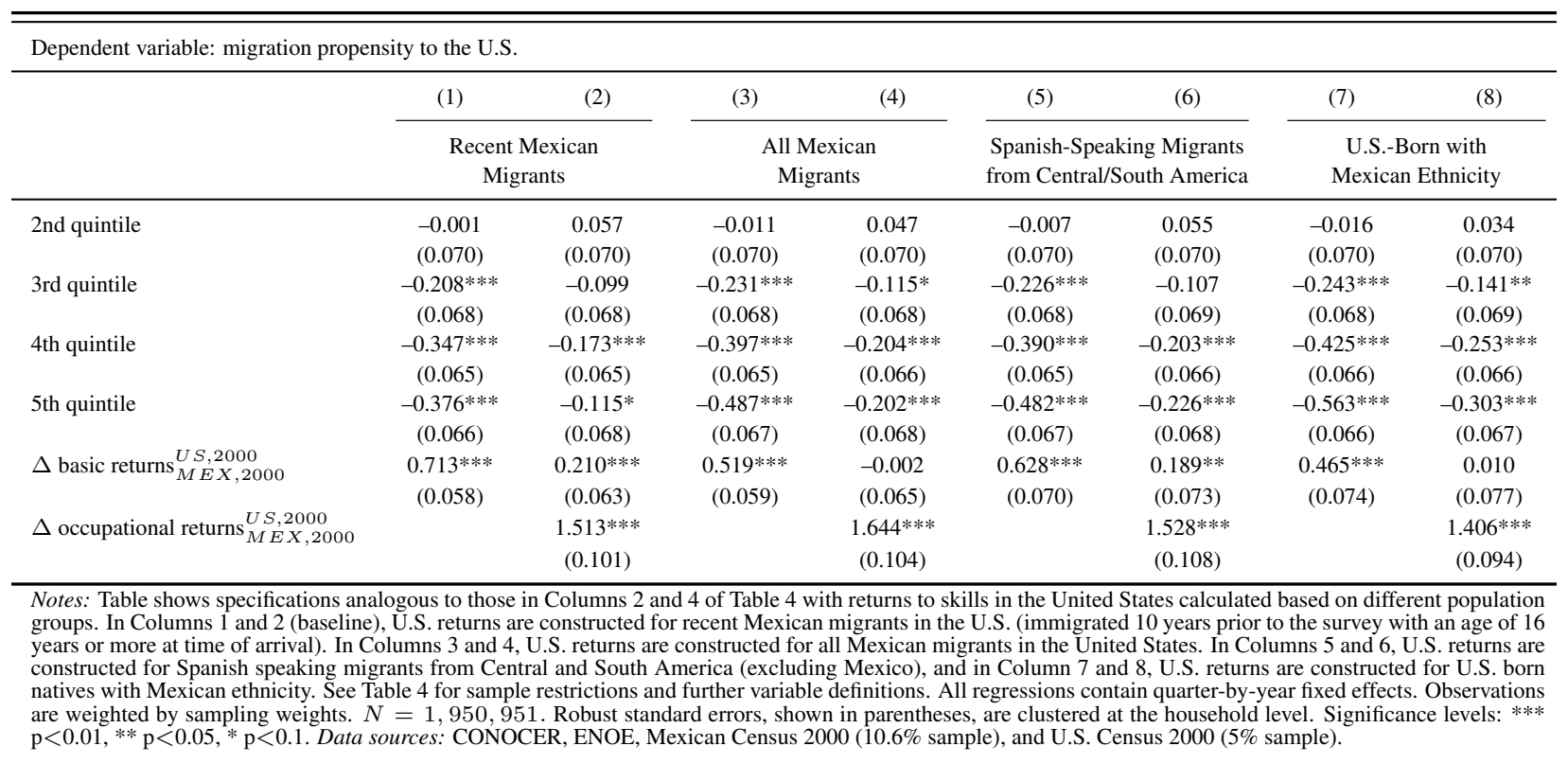

\section{Table A12: Selection on Earnings and Differential Returns: Selected-Corrected U.S. Return Estimates Using Heckman's (1979) Two-Step Estimator}

\begin{tabular}{|c|c|c|c|c|c|c|}
\hline \multicolumn{7}{|c|}{ Dependent variable: migration propensity to the U.S. } \\
\hline & (1) & (2) & (3) & (4) & (5) & (6) \\
\hline 2nd quintile & $\begin{array}{l}-0.044 \\
(0.070)\end{array}$ & $\begin{array}{l}-0.009 \\
(0.070)\end{array}$ & $\begin{array}{l}0.033 \\
(0.070)\end{array}$ & $\begin{array}{c}0.039 \\
(0.070)\end{array}$ & $\begin{array}{l}-0.057 \\
(0.070)\end{array}$ & $\begin{array}{c}0.023 \\
(0.070)\end{array}$ \\
\hline 3rd quintile & $\begin{array}{c}-0.284^{* * * *} \\
(0.068)\end{array}$ & $\begin{array}{c}-0.226 * * * \\
(0.068)\end{array}$ & $\begin{array}{c}-0.138^{* *} \\
(0.069)\end{array}$ & $\begin{array}{c}-0.129^{*} \\
(0.069)\end{array}$ & $\begin{array}{c}-0.301 * * * \\
(0.068)\end{array}$ & $\begin{array}{c}-0.150^{* *} \\
(0.069)\end{array}$ \\
\hline 4th quintile & $\begin{array}{l}-0.491 * * * \\
(0.064)\end{array}$ & $\begin{array}{l}-0.390 * * * * \\
(0.065)\end{array}$ & $\begin{array}{l}-0.245^{* * * *} \\
(0.065)\end{array}$ & $\begin{array}{l}-0.229 * * * \\
(0.066)\end{array}$ & $\begin{array}{l}-0.510 * * * \\
(0.064)\end{array}$ & $\begin{array}{l}-0.251 * * * \\
(0.066)\end{array}$ \\
\hline 5th quintile & $\begin{array}{l}-0.715^{* * *} \\
(0.059)\end{array}$ & $\begin{array}{c}-0.484 * * * \\
(0.067)\end{array}$ & $\begin{array}{l}-0.282 * * * \\
(0.064)\end{array}$ & $\begin{array}{l}-0.240 * * * \\
(0.068)\end{array}$ & $\begin{array}{c}-0.733 * * * \\
(0.060)\end{array}$ & $\begin{array}{l}-0.261^{* * *} \\
(0.069)\end{array}$ \\
\hline$\Delta$ basic returns $\frac{U S, 2000}{M E X, 2000}$ & & $\begin{array}{c}0.561^{* * * *} \\
(0.062)\end{array}$ & & $\begin{array}{c}0.140 * * \\
(0.067)\end{array}$ & & $\begin{array}{c}0.142 * * \\
(0.067)\end{array}$ \\
\hline$\Delta$ occupational returns ${ }_{M E X, 2000}^{U S, 2000}$ & & & $\begin{array}{c}1.705^{* * * *} \\
(0.109)\end{array}$ & $\begin{array}{c}1.645^{* * *} \\
(0.116)\end{array}$ & & $\begin{array}{c}1.650 * * * \\
(0.116)\end{array}$ \\
\hline Travel distance to U.S. border & & & & & $\begin{array}{c}-0.007 * * \\
(0.003)\end{array}$ & $\begin{array}{c}-0.009 * * * \\
(0.003)\end{array}$ \\
\hline \multicolumn{7}{|c|}{$\begin{array}{l}\text { Notes: Table shows specifications analogous to those in Table } 4 \text { using selected-corrected estimates of returns to skills in the United States } \\
\text { Earnings regressions contain a selection correction term (inverse Mills ratio) that is constructed from the parameters of a probit regression } \\
\text { of migration indicator on age categories, education categories, and marital status for basic returns and on occupational skill categories for } \\
\text { occupational returns. Both probit models include the number of children (persons below } 18 \text { years) in the household as the excluded variable in } \\
\text { the earnings regression. See Table } 4 \text { for sample restrictions and further variable definitions. All regressions contain quarter-by-year fixed effects } \\
\text { Observations are weighted by sampling weights. } N=1,950,951 \text {. Robust standard errors, shown in parentheses, are clustered at the household } \\
\text { level. Significance levels: } * * * p<0.01, * * \mathrm{p}<0.05, * \mathrm{p}<0.1 \text {. Data sources: CONOCER, ENOE, Mexican Census } 2000(10.6 \% \text { sample), and } \\
\text { U.S. Census } 2000 \text { (5\% sample). }\end{array}$} \\
\hline
\end{tabular}


Table A13: Emigrant Selection on Occupational Skills: Robustness Results from ENET

\begin{tabular}{|c|c|c|c|c|c|c|c|c|}
\hline & (1) & (2) & (3) & (4) & (5) & (6) & (7) & (8) \\
\hline & Baseline & \multicolumn{4}{|c|}{ Regional labor markets } & \multicolumn{3}{|c|}{ Sectoral labor markets } \\
\hline Cognitive skills & $\begin{array}{c}-0.161 * * * \\
(0.007)\end{array}$ & $\begin{array}{c}-0.156^{* * *} \\
(0.007)\end{array}$ & $\begin{array}{c}-0.150 * * * \\
(0.007)\end{array}$ & $\begin{array}{c}-0.148 * * * \\
(0.007)\end{array}$ & $\begin{array}{c}-0.098 * * * \\
(0.007)\end{array}$ & $\begin{array}{c}-0.110 * * * \\
(0.015)\end{array}$ & $\begin{array}{c}-0.145^{* * *} \\
(0.008)\end{array}$ & $\begin{array}{c}-0.120 * * * \\
(0.008)\end{array}$ \\
\hline Manual skills & $\begin{array}{c}0.187 * * * \\
(0.013)\end{array}$ & $\begin{array}{c}0.175^{* * *} * \\
(0.013)\end{array}$ & $\begin{array}{c}0.170^{* * *} \\
(0.013)\end{array}$ & $\begin{array}{c}0.168 * * * \\
(0.013)\end{array}$ & $\begin{array}{c}0.125 * * * \\
(0.014)\end{array}$ & $\begin{array}{c}0.109 * * * \\
(0.024)\end{array}$ & $\begin{array}{c}0.159 * * * \\
(0.017)\end{array}$ & $\begin{array}{c}0.137 * * * \\
(0.016)\end{array}$ \\
\hline Cognitive skills $\times$ manual skills & $\begin{array}{c}-0.069 * * * \\
(0.004)\end{array}$ & $\begin{array}{c}-0.069 * * * \\
(0.004)\end{array}$ & $\begin{array}{c}-0.065^{* * *} \\
(0.004)\end{array}$ & $\begin{array}{c}-0.064 * * * \\
(0.004)\end{array}$ & $\begin{array}{c}-0.036 * * * \\
(0.004)\end{array}$ & $\begin{array}{c}-0.024 * * * \\
(0.007)\end{array}$ & $\begin{array}{c}-0.046^{* * *} \\
(0.005)\end{array}$ & $\begin{array}{c}-0.037 * * * \\
(0.005)\end{array}$ \\
\hline Education & $\begin{array}{l}-0.003 \\
(0.004)\end{array}$ & $\begin{array}{c}0.004 \\
(0.004)\end{array}$ & $\begin{array}{c}0.003 \\
(0.004)\end{array}$ & $\begin{array}{c}0.004 \\
(0.004)\end{array}$ & $\begin{array}{c}0.011 * * * \\
(0.004)\end{array}$ & $\begin{array}{c}0.000 \\
(0.004)\end{array}$ & $\begin{array}{c}0.020 * * * \\
(0.004)\end{array}$ & $\begin{array}{c}0.022 * * * \\
(0.004)\end{array}$ \\
\hline Age & $\begin{array}{c}-0.036^{* * * *} \\
(0.001)\end{array}$ & $\begin{array}{c}-0.038^{* * *} * \\
(0.001)\end{array}$ & $\begin{array}{c}-0.036^{* * *} * \\
(0.001)\end{array}$ & $\begin{array}{c}-0.036 * * * \\
(0.001)\end{array}$ & $\begin{array}{c}-0.038 * * * \\
(0.001)\end{array}$ & $\begin{array}{c}-0.039 * * * \\
(0.001)\end{array}$ & $\begin{array}{c}-0.035^{* * * *} \\
(0.001)\end{array}$ & $\begin{array}{c}-0.035^{* * * *} \\
(0.001)\end{array}$ \\
\hline \multicolumn{9}{|l|}{ Fixed Effects } \\
\hline Birth state/country [40] & & $\mathrm{X}$ & & & & & & \\
\hline Residence state [32] & & & $\mathrm{X}$ & & & & & \\
\hline Birth-by-residence state $[1,209]$ & & & & $\mathrm{X}$ & & & & \\
\hline Municipality $[1,204]$ & & & & & $\mathrm{X}$ & & & \\
\hline Occupation [143] & & & & & & $\mathrm{X}$ & & \\
\hline Economic sector $[8]$ & & & & & & & $\mathrm{X}$ & \\
\hline Residence state-by-economic sector [246] & & & & & & & & $\mathrm{X}$ \\
\hline
\end{tabular}




\section{Table A14: Emigrant Selection on Occupational Skills: Occupational Tenure and Age Restrictions (MMP)}

\begin{tabular}{|c|c|c|c|c|c|c|c|}
\hline \multicolumn{8}{|c|}{ Dependent variable: migration propensity to the U.S. } \\
\hline & (1) & (2) & (3) & (4) & (5) & (6) & (7) \\
\hline & \multicolumn{3}{|c|}{ Occupational Tenure } & \multicolumn{4}{|c|}{ Age } \\
\hline & $>3$ Years & $>5$ Years & $>10$ Years & $>20$ Years & $>25$ Years & $>30$ Years & $>35$ Years \\
\hline Cognitive skills & $\begin{array}{c}-0.124 * * * \\
(0.013)\end{array}$ & $\begin{array}{c}-0.114 * * * \\
(0.012)\end{array}$ & $\begin{array}{c}-0.101 * * * \\
(0.011)\end{array}$ & $\begin{array}{c}-0.127 * * * \\
(0.015)\end{array}$ & $\begin{array}{c}-0.103 * * * \\
(0.014)\end{array}$ & $\begin{array}{c}-0.090 * * * \\
(0.015)\end{array}$ & $\begin{array}{c}-0.070 * * * \\
(0.016)\end{array}$ \\
\hline Manual skills & $\begin{array}{c}0.103 * * * \\
(0.018)\end{array}$ & $\begin{array}{c}0.107 * * * \\
(0.017)\end{array}$ & $\begin{array}{c}0.091 * * * \\
(0.015)\end{array}$ & $\begin{array}{c}0.089^{* * * *} \\
(0.022)\end{array}$ & $\begin{array}{c}0.098 * * * \\
(0.020)\end{array}$ & $\begin{array}{c}0.095 * * * \\
(0.021)\end{array}$ & $\begin{array}{c}0.111 * * * \\
(0.022)\end{array}$ \\
\hline Cognitive skills $\times$ manual skills & $\begin{array}{c}-0.038^{* * *} \\
(0.005)\end{array}$ & $\begin{array}{c}-0.038^{* * *} \\
(0.005)\end{array}$ & $\begin{array}{c}-0.036^{* * * *} \\
(0.004)\end{array}$ & $\begin{array}{c}-0.032 * * * \\
(0.005)\end{array}$ & $\begin{array}{c}-0.028 * * * \\
(0.005)\end{array}$ & $\begin{array}{c}-0.027 * * * \\
(0.006)\end{array}$ & $\begin{array}{c}-0.029 * * * \\
(0.006)\end{array}$ \\
\hline Education & $\begin{array}{c}-0.019 * * * \\
(0.006)\end{array}$ & $\begin{array}{c}-0.020 * * * \\
(0.005)\end{array}$ & $\begin{array}{c}-0.017 * * * \\
(0.005)\end{array}$ & $\begin{array}{c}-0.018 * * * \\
(0.006)\end{array}$ & $\begin{array}{c}-0.022 * * * \\
(0.006)\end{array}$ & $\begin{array}{c}-0.023 * * * * \\
(0.006)\end{array}$ & $\begin{array}{c}-0.022 * * * \\
(0.006)\end{array}$ \\
\hline Age & $\begin{array}{c}-0.031 * * * \\
(0.002)\end{array}$ & $\begin{array}{c}-0.025 * * * \\
(0.002)\end{array}$ & $\begin{array}{c}-0.018^{* * *} \\
(0.001)\end{array}$ & $\begin{array}{c}-0.045^{* * *} \\
(0.002)\end{array}$ & $\begin{array}{c}-0.039 * * * \\
(0.002)\end{array}$ & $\begin{array}{c}-0.038^{* * *} \\
(0.002)\end{array}$ & $\begin{array}{c}-0.033 * * * \\
(0.002)\end{array}$ \\
\hline Observations & 454,945 & 438,168 & 388,183 & 409,662 & 338,859 & 268,215 & 203,660 \\
\hline
\end{tabular}

Table A15: Emigrant Selection on Occupational Skills: Age Restrictions (ENOE)

\begin{tabular}{|c|c|c|c|c|c|}
\hline \multicolumn{6}{|c|}{ Dependent variable: migration propensity to the U.S. } \\
\hline & (1) & (2) & (3) & (4) & (5) \\
\hline & Baseline & $>20$ Years & $>25$ Years & $>30$ Years & $>35$ Years \\
\hline Cognitive skills & $\begin{array}{c}-0.164 * * * \\
(0.009)\end{array}$ & $\begin{array}{c}-0.152 * * * \\
(0.009)\end{array}$ & $\begin{array}{c}-0.134 * * * \\
(0.009)\end{array}$ & $\begin{array}{c}-0.121 * * * \\
(0.009)\end{array}$ & $\begin{array}{c}-0.108 * * * \\
(0.010)\end{array}$ \\
\hline Manual skills & $\begin{array}{c}0.182 * * * \\
(0.014)\end{array}$ & $\begin{array}{c}0.175 * * * \\
(0.014)\end{array}$ & $\begin{array}{c}0.150 * * * \\
(0.014)\end{array}$ & $\begin{array}{c}0.128 * * * \\
(0.014)\end{array}$ & $\begin{array}{c}0.121 * * * \\
(0.016)\end{array}$ \\
\hline Cognitive skills $\times$ manual skills & $\begin{array}{c}-0.079 * * * \\
(0.005)\end{array}$ & $\begin{array}{c}-0.074 * * * \\
(0.005)\end{array}$ & $\begin{array}{c}-0.060 * * * \\
(0.005)\end{array}$ & $\begin{array}{c}-0.050 * * * \\
(0.005)\end{array}$ & $\begin{array}{c}-0.045 * * * \\
(0.005)\end{array}$ \\
\hline Education & $\begin{array}{l}0.010^{*} \\
(0.005)\end{array}$ & $\begin{array}{c}0.006 \\
(0.005)\end{array}$ & $\begin{array}{c}0.001 \\
(0.005)\end{array}$ & $\begin{array}{l}-0.001 \\
(0.005)\end{array}$ & $\begin{array}{c}0.002 \\
(0.005)\end{array}$ \\
\hline Age & $\begin{array}{c}-0.032 * * * \\
(0.001)\end{array}$ & $\begin{array}{c}-0.034 * * * \\
(0.002)\end{array}$ & $\begin{array}{c}-0.033 * * * \\
(0.002)\end{array}$ & $\begin{array}{c}-0.030 * * * \\
(0.002)\end{array}$ & $\begin{array}{c}-0.032 * * * \\
(0.002)\end{array}$ \\
\hline Observations & $2,959,528$ & $2,631,229$ & $2,241,222$ & $1,869,897$ & $1,513,343$ \\
\hline $\begin{array}{l}\text { Notes: Sample includes Mexica } \\
\text { age 16-65). Dependent variable } \\
\text { quarterly migrant share. Cogniti } \\
\text { as (unweighted) averages of skil } \\
\text { measures are demeaned and scal } \\
\text { sampling weights. Robust standa } \\
\mathrm{p}<0.01, * * \mathrm{p}<0.05,{ }^{*} \mathrm{p}<0.1 . D\end{array}$ & $\begin{array}{l}\text { les up to as } \\
\text { igrant indic } \\
\text { d manual s } \\
\text { tent of curr } \\
10 \text {. All re } \\
\text { rors, showr }\end{array}$ & $\begin{array}{l}\text { ho meet th } \\
\text { qual to } 1 \text { if } \\
\text { corporate fu } \\
\text { all previou } \\
\text { is contain } \mathrm{c} \\
\text { entheses, ar } \\
\text { and ENOE }\end{array}$ & $\begin{array}{l}\text { estriction sp } \\
\text { ed to the U } \\
\text { rved pre-m } \\
\text { pations up } t \\
\text { by-year fixe } \\
\text { red at the } \mathrm{l}\end{array}$ & $\begin{array}{l}\text { in the colu } \\
\text { tates, and } 0 \\
\text { worker his } \\
\text { quarters pri } \\
\text { ts. Observa } \\
\text { ld level. Si }\end{array}$ & $\begin{array}{l}\text { der (Baseline } \\
\text { ise) scaled b } \\
\text { ey are define } \\
\text { igration. Ski } \\
\text { e weighted b } \\
\text { ce levels: ** }\end{array}$ \\
\hline
\end{tabular}




\section{B Details on Constructing Comparable Measures of Skills}

CONOCER and $\mathrm{O} *$ NET both measure the job content in respective populations, but they differ in organization, degree of detail, and emphasis on specific domains, which means that not all questions are of a similar nature in the two surveys. However, despite the differences in design, each variable group in CONOCER can be mapped to one or two variable groups in O*NET, the exception being areas of responsibility, which we do not use (see Table B1). To prevent any inconsistency that could arise from merging questions from conceptually different $\mathrm{O} * \mathrm{NET}$ domains, mapping in such cases is restricted to the domain with most matching questions.

Table B1: Mapping of CONOCER Domains to O*NET Domains.

\begin{tabular}{ccc}
\hline \hline CONOCER Domain & O*NET Domain & Missing Data \\
\hline responsibility & - & \\
knowledge & knowledge & low skilled \\
use of tools & work activities & \\
abilities & skills or abilities & low skilled \\
social skills & work styles & \\
traits & work styles & \\
skills & tasks or knowledge & high skilled \\
physical abilities & abilities & \\
\hline
\end{tabular}

One limitation in the CONOCER survey is that questions on some domains were given only to high-skilled workers, while others were given only to low-skilled workers (see third column in Table B1). Therefore, it is not possible to use all questions that, in principle, could be mapped when constructing the occupational skills measures. We had to drop the domains of knowledge, abilities, and skills altogether because of systematically missing values for a large fraction of population. This is why we restrict the data to the questions on use of tools, social skills, traits, and physical abilities in CONOCER and, correspondingly, to work activities, work styles, and abilities in O*NET. Reassuringly, however, our measure of Mexicans' cognitive skills is highly correlated with the measure derived from the set of variables on cognitive abilities in CONOCER $(r=0.71$ for the sample of high-skilled jobs), so the information loss due to the omission of some CONOCER domains is arguably limited.

We also use only the subset of all questions in every domain that is comparable in CONOCER and $\mathrm{O}^{*}$ NET. Again, our measures retain much of the original information about the jobs because they are strongly correlated with similarly constructed variables on the full set of questions (with a correlation in the range $0.85-0.97)$. When restricting the data so as to have a comparable set of questions, the negative correlation of cognitive and manual scores that appears when using the full 
set of questions is slightly stronger in $\mathrm{O}^{*} \mathrm{NET}$ (from -0.51 up to -0.59) and somewhat weaker in CONOCER (from -0.47 down to -0.24 ), but is still preserved.

Table B2 contains all questions selected from both surveys organized into four groups. Column 1 shows the variable from the CONOCER survey. Column 2 shows the corresponding rotation of the first principal component from the decomposition of the respective group of variables (see main text for details). All rotations have the same sign and are normalized to be positive. Column 3 contains the closest equivalent question from $\mathrm{O}^{*} \mathrm{NET}$; because some questions in CONOCER are more detailed than the corresponding questions in $\mathrm{O}^{*} \mathrm{NET}$, some CONOCER variables are matched to the same $\mathrm{O}^{*}$ NET variable. Column 4 shows the rotation of $\mathrm{O} *$ NET variables. Reassuringly, most rotations for CONOCER variables are in agreement with the rotations of O*NET variables. Hence there is a high degree of external validity of our measures of skills, even though they are based on different populations. Moreover, the measures are characterized by a high degree of reliability: all variable groups have a Cronbach's $\alpha$ in the range of $0.79-0.96$ (the only exception is CONOCER's use of tools, whose Cronbach's $\alpha$ is still reasonably high at 0.69 ). 
Table B2: Correspondence between CONOCER and O*NET Variables

\begin{tabular}{|c|c|c|c|}
\hline \multicolumn{2}{|c|}{ CONOCER } & \multicolumn{2}{|l|}{ O*NET } \\
\hline Variable & Rotation & Variable & Rotation \\
\hline \multicolumn{4}{|l|}{ Use of Tools } \\
\hline Electric Tools & 0.71 & $\begin{array}{l}\text { Repairing and Maintaining Electronic } \\
\text { Equipment }\end{array}$ & 0.38 \\
\hline Agricultural Machinery & 0.20 & $\begin{array}{l}\text { Operating Vehicles, Mechanized } \\
\text { Devices, or Equipment }\end{array}$ & 0.66 \\
\hline Industrial Machinery & 0.44 & $\begin{array}{l}\text { Operating Vehicles, Mechanized } \\
\text { Devices, or Equipment }\end{array}$ & - \\
\hline $\begin{array}{l}\text { Automated Industrial Machinery } \\
\text { (Robots) }\end{array}$ & 0.35 & Controlling Machines and Processes & 0.65 \\
\hline $\begin{array}{l}\text { Transportation Equipment or } \\
\text { Machinery (Vehicles) }\end{array}$ & 0.37 & $\begin{array}{l}\text { Operating Vehicles, Mechanized } \\
\text { Devices, or Equipment }\end{array}$ & - \\
\hline \multicolumn{4}{|l|}{ Physical Skills } \\
\hline Strength & 0.58 & Trunk Strength & 0.55 \\
\hline Coordination and Flexibility & 0.48 & Extent Flexibility & 0.61 \\
\hline Balance & 0.55 & Gross Body Coordination & 0.51 \\
\hline Visual & 0.22 & Far Vision & 0.12 \\
\hline Hearing & 0.29 & Hearing Sensitivity & 0.23 \\
\hline \multicolumn{4}{|l|}{ Cognitive \& Social Skills } \\
\hline Empathy & 0.24 & Concern for Others & 0.26 \\
\hline Assertiveness & 0.30 & Leadership & 0.41 \\
\hline Teamwork & 0.27 & Cooperation & 0.20 \\
\hline Attention & 0.20 & Attention to Detail & 0.17 \\
\hline Active Learning & 0.31 & Adaptability/Flexibility & 0.28 \\
\hline Creativity & 0.28 & Innovation & 0.35 \\
\hline Self-control & 0.35 & Self-control & 0.22 \\
\hline Independence & 0.31 & Independence & 0.25 \\
\hline Flexibility & 0.29 & Adaptability/Flexibility & - \\
\hline Self-motivatedness & 0.28 & Achievement/Effort & 0.30 \\
\hline Proactivity & 0.32 & Initiative & 0.32 \\
\hline Problem Solving & 0.29 & Analytical Thinking & 0.43 \\
\hline \multicolumn{4}{|l|}{ Traits } \\
\hline Cooperation & 0.34 & Cooperation & 0.35 \\
\hline Initiative & 0.36 & Initiative & 0.38 \\
\hline Thoroughness & 0.38 & Attention to Detail & 0.23 \\
\hline Responsibility & 0.24 & Dependability & 0.28 \\
\hline Toleration & 0.44 & Stress Tolerance & 0.48 \\
\hline Kindness & 0.42 & Concern for Others & 0.49 \\
\hline Perseverance & 0.42 & Achievement/Effort & 0.36 \\
\hline \multicolumn{4}{|l|}{ Use of Office Equipment } \\
\hline Office Equipment & 0.78 & Interacting with Computers & 1.00 \\
\hline Software & 0.63 & Interacting with Computers & - \\
\hline
\end{tabular}




\section{Occupation Crosswalks}

Before Q2-2012, ENET and ENOE used the four-digit Mexican Classification of Occupations (Clasificación Mexicana de Ocupaciones-CMO) to classify occupations. Afterward, ENOE started to report occupations in the four-digit National Occupation Classification System (Sistema Nacional de Clasificación de Ocupaciones-SINCO) (for details on SINCO, see INEGI, 2011a). SINCO was introduced to make the occupational classification more comparable with other international classification systems and with classification systems of Mexico's main trading partners (i.e., USA and Canada). CONOCER, which we use to construct our skill measures, also reports occupational information using the SINCO classification at the four-digit level.

We use a crosswalk between SINCO and CMO (provided by INEGI, 2011b) to convert CMO occupations into SINCO occupations for periods before Q2-2012. Out of 448 CMO occupational codes, 373 occupations (83\%) have a direct and unique equivalent in SINCO. For the remaining 75 CMO occupations, we use the SINCO occupation with the largest weight, calculated as the share of workers for each occupational code within a given CMO occupation (based on ENOE Q3-2012 to Q2-2013). This weight is on average 74\%, meaning that there is mostly one large SINCO occupation corresponding to the respective CMO occupation. We also experimented with using skill score averages over the multiple SINCO occupations that relate to one specific CMO occupation (instead of picking the one with the largest weight). This procedure yields very similar skill measures ( $r>0.99$ for manual and cognitive skills).

The MMP provides occupational information at the three-digit level, also reported using the $\mathrm{CMO}$ classification. Here, we use skill averages over the CMO occupations based on the four-digit SINCO occupations to construct occupational skill measures. Skill scores are weighted by the share of workers in each SINCO occupation within a given CMO occupation (based on ENOE Q3-2012 to Q2-2013). We apply the same procedure to construct skill measures in the MxFLS data, where occupational information is provided in the CMO classification at the two-digit level.

\section{Returns to Occupational Skills}

The model specified in Section IV.A. predicts that the main drivers of emigrant selection are the differential returns to occupational skills between Mexico and the United States. To test this prediction, we estimate returns to occupational skills from Mincer-type earnings regressions for Mexican residents and recent Mexican immigrants in the United States (Ambrosini and Peri, 2012; Kaestner and Malamud, 2014). For Mexican residents, we use data from the 2000 Mexican Census taken from the Integrated Public Use Microdata Series (IPUMS) International database (Minnesota Population Center, 2015, Mexican National Institute of Statistics, Geography, and Informatics). For recent Mexican migrants, we draw on data from the 2000 U.S. Census and the 2010 U.S. American 
Community Survey (ACS) taken from the IPUMS USA database (Ruggles et al., 2015). ${ }^{66}$

It is important to note that returns to specific tasks or skills are not easily retrieved from Mincertype earnings models because the tasks that a worker performs on the job are a bundle of activities that require multiple skills to be carried out (Heckman and Scheinkman, 1987; Autor and Handel, 2013). However, to provide intuition regarding the model's predictions in the context of Mexicoto-U.S. migration, we follow the common approach in the literature to estimate returns to specific skills in a Mincer-type framework (e.g., Autor and Handel, 2013; Hanushek et al., 2015), holding constant the other skill level. In particular, separately for each skill domain (i.e., cognitive or manual skills), we regress log hourly earnings on this skill domain and control flexibly for the other domain by including skill decile fixed effects. The resulting returns-to-skills estimate is to be interpreted as the average return over the entire distribution of the other skill. For comparison, we also estimate models that include cognitive and manual skills linearly. Importantly, when we assess the role of differential returns to skills for the migration decision and the selection on earnings (Section VII.), we account for the fact that workers are rewarded for applying bundles of skills by slicing the cognitive and manual skill distributions into cells and calculating returns within these cells.

We begin by providing visual evidence on the distribution of hourly earnings (conditional on control variables) by skill percentiles for Mexicans in the Mexican Census 2000 (Figure D1a) and for the recent Mexican migrants in the U.S. Census 2000 (Figure D1b). The figures aid our understanding of the earnings situation of Mexican residents and recent Mexican migrants in the United States in several ways. First, as expected, the average wage level (expressed in purchasing power parities) is higher in the United States than in Mexico. Second, most Mexican workers in the United States cluster in high-manual, low-cognitive occupations. Interestingly, most of them work in occupations that require manual skills above the 80th percentile of manual skills-a percentile that does not even exist in Mexico. In contrast, Mexican migrants in the United States typically do not work in occupations requiring high levels of cognitive skills, even though there are Mexican residents who do work in such occupations in Mexico. Third, in both countries, hourly wages increase strongly with cognitive skills, while the pattern is less clear for manual skills.

Tables D1 and D2 show the results of the earnings regressions. All specifications control for years of completed education (five categories), age (six categories), martial status, urban status, and state of residence. For Mexican residents, returns to manual skills are close to zero (and even

\footnotetext{
${ }^{66}$ Samples contain males aged between 16 and 65 who are not currently enrolled in school. We restrict samples to those who have reported working between 10 and 80 hours per week and drop the top and bottom $0.5 \%$ of the data. For the 2000 Mexico Census, samples are further restricted to individuals born in Mexico. Hourly earnings are constructed by dividing reported monthly earnings by 4.5 times hours worked per week (see also Chiquiar and Hanson, 2005; Fernández-Huertas Moraga, 2011). Hourly earnings in the 2000 U.S. Census and the 2010 ACS are constructed by dividing reported yearly earnings by the number of reported weeks worked per year (using the respective mean of the reported intervals of the number of weeks) times hours worked per week.
} 
slightly negative). A one-decile increase in manual skills is associated with $0.4 \%$ lower hourly earnings (Table D1, Column 2). ${ }^{67}$ This is not implausible given that the supply of manual skills is very large in Mexico (see also Figure 1). Recent Mexican migrants in the United States have considerably larger returns to manual skills than Mexican residents. They receive 2.3\% higher hourly earnings for an increase of one decile in manual skills (Table D2, Column 2). For cognitive skills, we find the opposite picture. Returns are higher for Mexican residents in Mexico (5.0\%; Table D1, Column 3) than for recent Mexican migrants (4.1\%; Table D2, Column 3). Given these differences in the returns, the Roy/Borjas model developed in Section IV.A. predicts that Mexican migrants are positively selected on manual skills and negatively selected on cognitive skills. ${ }^{68}$

To put the estimated returns for recent Mexican migrants into perspective, Table D2 provides return estimates for Mexicans who migrated before 1990 (Panel B), non-Mexican migrants (Panel C), and for natives (Panel D). We find that returns for Mexican migrants increase with time spent in the United States, possibly due to integration or skill upgrading (following a potential skill downgrading, as documented in Dustmann et al., 2013, 2016). However, the increase in returns is rather modest. In particular, the returns to cognitive skills for other Mexican migrants (4.7\%) still do not exceed those earned in Mexico. Natives exhibit rather low returns from manual skills (2.2\%) and rather high returns from cognitive skills (5.7\%). This may be the result of skill specialization driven by comparative advantage of Mexicans in manual-skill-intensive occupations (Peri and Sparber, 2009; Peri, 2012). For other migrants, we document very low returns to manual skills $(0.6 \%)$, but very high returns to cognitive skills $(7.3 \%)$. One potential explanation for this finding is the rather restrictive U.S. immigration policy that permits residence and work visas mainly to high-skilled migrants (e.g., via the H1B visa program).

\footnotetext{
${ }^{67}$ Even though the estimate is almost zero, it is highly significant due to the very large sample size $(N=$ $1,430,922)$.

${ }^{68}$ For comparison, Columns 4-6 of Table D2 provide return estimates based on the ACS 2010 instead of the U.S. Census 2000. Returns are generally slightly higher. However, returns to cognitive skills for Mexican migrants are still higher in Mexico than in the United States, so the model predictions remain unchanged.
} 
Figure D1: Average Hourly Earnings in the Year 2000 by Skill Percentiles

(a) Mexican Residents

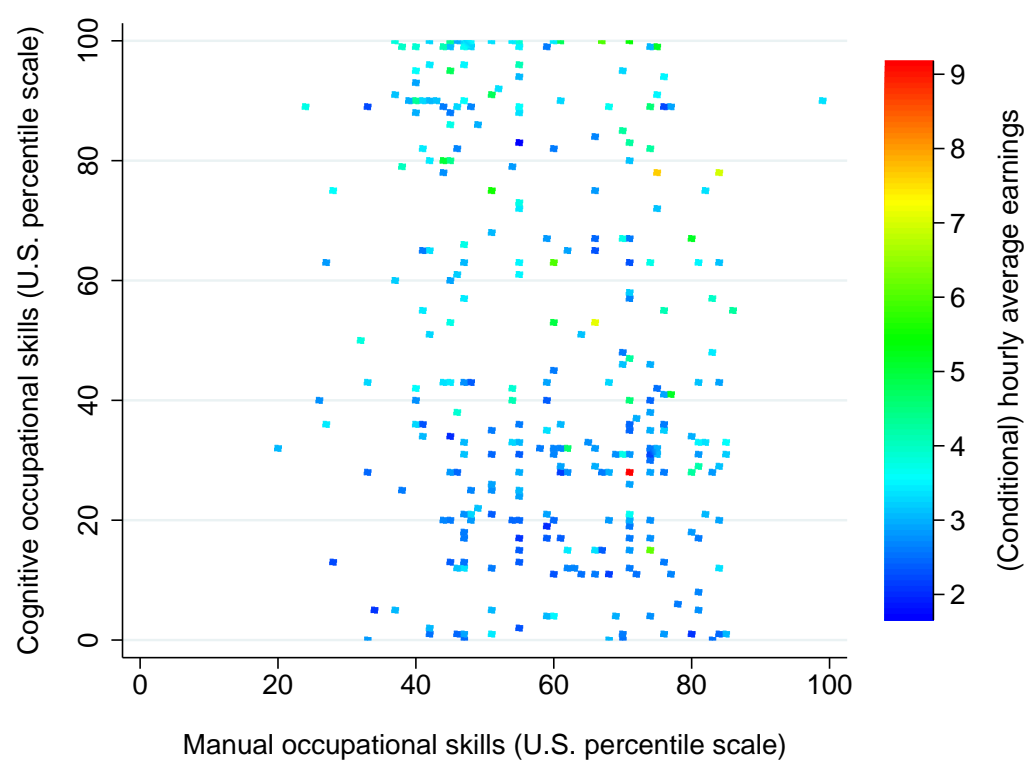

(b) Recent Mexican Migrants

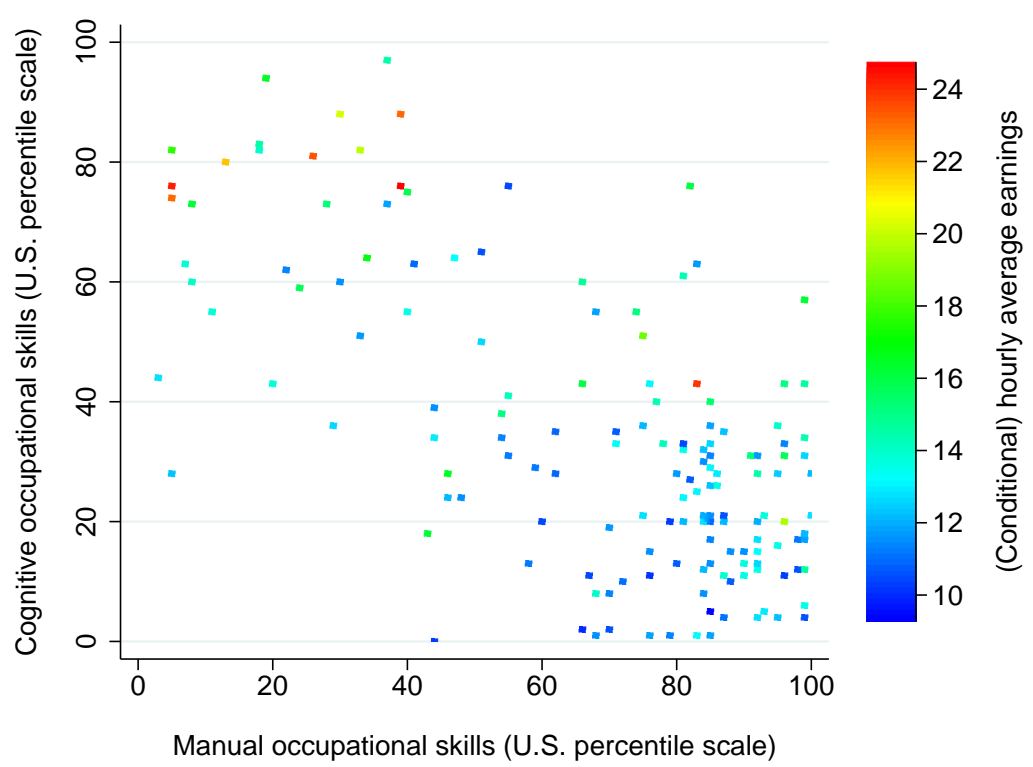

Notes: Figures show average hourly earnings by skill percentiles for Mexican residents (Figure D1a) and for Mexican migrants in the United States who immigrated between 1990 and 2000 (Figure D1b). Sample consists of males aged 16-65. Earnings are expressed in constant 2010 U.S. dollars. For Mexico, earnings are adjusted for PPP. Hourly earnings are conditional on education (five categories), age (six categories), marital status, urban (metro status for the United States), and state fixed effects. Cells with less than 20 observations are dropped. Data sources: CONOCER, Mexican Census 2000 (Figure D1a), and U.S. Census 2000 (Figure D1b). 
Table D1: Returns to Occupational Skills in Mexico

\begin{tabular}{|c|c|c|c|}
\hline \multicolumn{4}{|c|}{ Dependent variable: log hourly earnings } \\
\hline & (1) & (2) & (3) \\
\hline & Linear & \multicolumn{2}{|c|}{ Decile Fixed Effects } \\
\hline Manual skills & $\begin{array}{c}-0.0034 * * * \\
(0.0006)\end{array}$ & $\begin{array}{c}-0.0039 * * * \\
(0.0006)\end{array}$ & \\
\hline Cognitive skills & $\begin{array}{c}0.0482 * * * \\
(0.0003)\end{array}$ & & $\begin{array}{c}0.0498^{* * *} \\
(0.0004)\end{array}$ \\
\hline Control variables & $\mathrm{X}$ & $\mathrm{X}$ & $\mathrm{X}$ \\
\hline Cognitive skill decile fixed effects & & $X$ & \\
\hline Manual skill decile fixed effects & & & $\mathrm{X}$ \\
\hline R-squared & 0.418 & 0.423 & 0.424 \\
\hline
\end{tabular}

Median manual skills $=0.612$, median cognitive skills $=0.284$.

Notes: Table shows returns to cognitive and manual occupational skills in the Mexican Census 2000. Sample restricted to Mexican-born males aged 16-65 who are not in school and work between 10 and 80 hours per week. Dependent variable is log hourly earnings, constructed by dividing monthly earnings by $4.5 \times$ hours worked per week. The largest and smallest $0.5 \%$ of hourly earnings are dropped. Cognitive and manual skills are based on the occupation held when the Mexican Census was conducted. Skill measures are scaled by 10 to allow for interpretation in decile changes and are denoted in 2010 U.S. deciles. All regressions condition on a full set of control variables: education (five categories), age (six categories), marital status, state-of-living fixed effects, and urban status. Columns 2 and 3 contain decile fixed effects of cognitive skills (Column 2) and of manual skills (Column 3 ). Decile cutoffs are taken from the occupational skill distribution in the Mexican Census 2000. $N=1,430,922$. Robust standard errors, shown in parentheses, are clustered at the household level. Significance levels: $* * * \mathrm{p}<0.01$, $* * \mathrm{p}<0.05, * \mathrm{p}<0.1$. Data sources: CONOCER and Mexican Census 2000 (10.6\% sample). 
Table D2: Returns to Occupational Skills in the United States

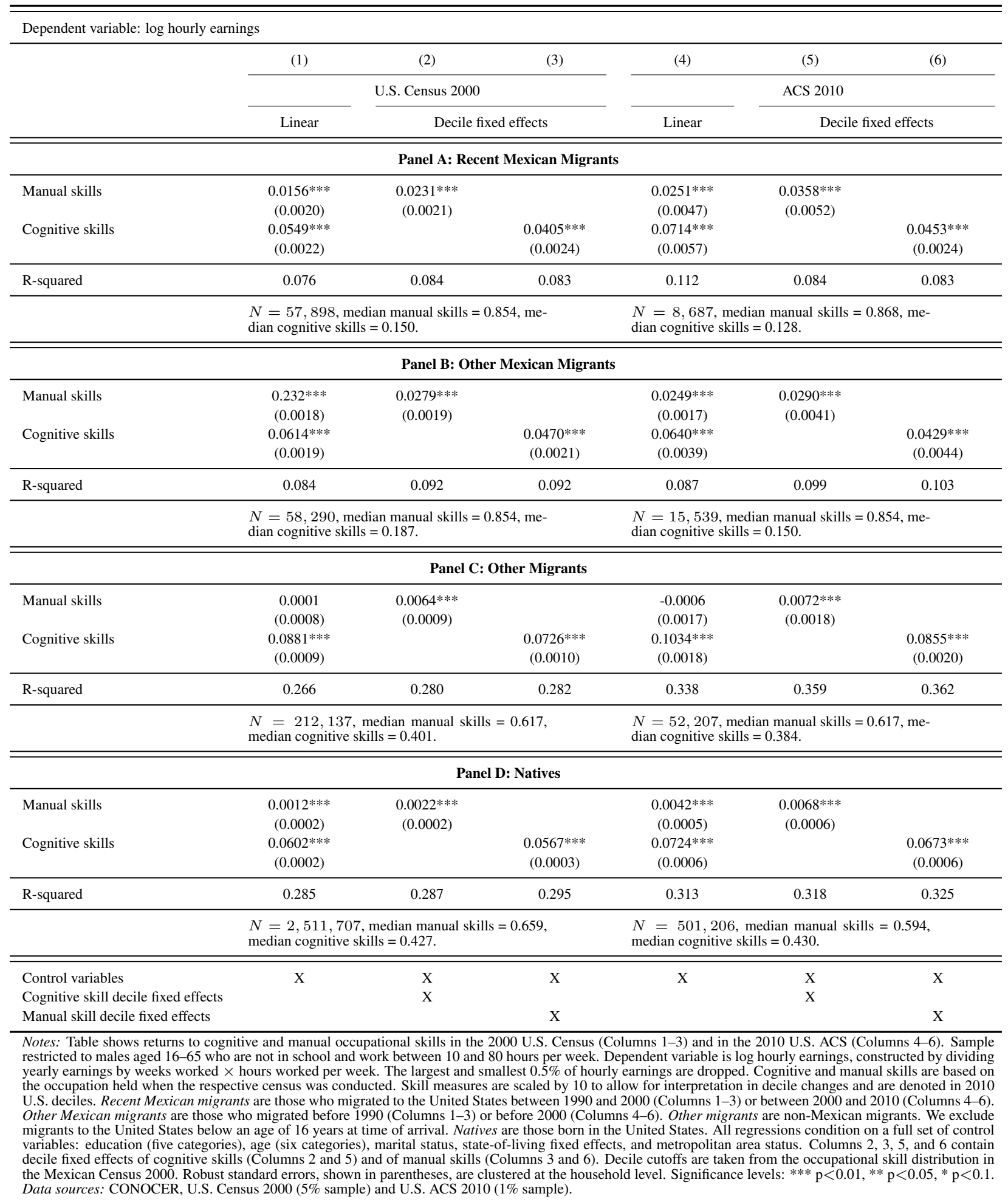




\section{Appendix References}

Abramitzky, R., Boustan, L. P., and Eriksson, K. (2012). Europe's Tired, Poor, Huddled Masses: Self-Selection and Economic Outcomes in the Age of Mass Migration. American Economic Review, 102(5):1832-1856.

Ambrosini, J. W. and Peri, G. (2012). The Determinants and the Selection of Mexico-US Migrants. World Economy, 35(2):111-151.

Autor, D. and Handel, M. (2013). Putting Tasks to the Test: Human Capital, Job Tasks, and Wages. Journal of Labor Economics, 31(2):S59-S96.

Belot, M. V. K. and Hatton, T. J. (2012). Immigrant Selection in the OECD. Scandinavian Journal of Economics, 114(4):1105-1128.

Borjas, G. J. (1987). Self-Selection and the Earnings of Immigrants. American Economic Review, 77(4):531-553.

Borjas, G. J. (2008). Labor Outflows and Labor Inflows in Puerto Rico. Journal of Human Capital, 2(1):32-68.

Borjas, G. J., Kauppinen, I., and Poutvaara, P. (2015). Self-Selection of Emigrants: Theory and Evidence on Stochastic Dominance in Observable and Unobservable Characteristics. NBER Working Paper No. 21649.

Borjas, George, J. (2014). Immigration Economics. Harvard University Press.

Chiquiar, D. and Hanson, G. H. (2005). International Migration, Self-Selection, and the Distribution of Wages: Evidence from Mexico and the United States. Journal of Political Economy, 113(2):239-281.

Dustmann, C., Frattini, T., and Preston, I. P. (2013). The Effect of Immigration Along the Distribution of Wages. Review of Economic Studies, 80(1):145-173.

Dustmann, C., Schönberg, U., and Stuhler, J. (2016). The Impact of Immigration: Why Do Studies Reach Such Different Results? Journal of Economic Perspectives, 30(4):31-56.

Feliciano, C. (2005). Educational Selectivity in U.S. Immigration: How Do Immigrants Compare to Those Left Behind? Demography, 42(1):131-152.

Feliciano, C. (2008). Gendered Selectivity: U.S. Mexican Immigrants and Mexican Nonmigrants, 1960-2000. Latin American Research Review, 43(1):139-160. 
Fernández-Huertas Moraga, J. (2011). New Evidence on Emigrant Selection. Review of Economics and Statistics, 93(1):72-96.

Fernández-Huertas Moraga, J. (2013). Understanding Different Migrant Selection Patterns in Rural and Urban Mexico. Journal of Development Economics, 103(1):182-201.

Gould, E. D. and Moav, O. (2016). Does High Inequality Attract High Skilled Immigrants? Economic Journal, 126(593):1055-1091.

Grogger, J. and Hanson, G. H. (2011). Income Maximization and the Selection and Sorting of International Migrants. Journal of Development Economics, 95(1):42-57.

Hanushek, E. A., Schwerdt, G., Wiederhold, S., and Woessmann, L. (2015). Returns to Skills Around the World: Evidence from PIAAC. European Economic Review, 73(C):103-130.

Heckman, J. J. (1979). Sample Selection Bias as a Specification Error. Econometrica, 47(1):153161.

Heckman, J. J. and Scheinkman, J. (1987). The Importance of Bundling in a Gorman-Lancaster Model of Earnings. Review of Economic Studies, 54(2):243-255.

Ibarraran, P. and Lubotsky, D. (2007). Mexican Immigration and Self-Selection: New Evidence from the 2000 Mexican Census. In Borjas, G. J., editor, Mexican Immigration to the United States, chapter 5, pages 159-192. Chicago, IL: University of Chicago Press.

INEGI (2011a). Sistema Nacional de Clasificación de Ocupaciones (SINCO). http: //www . inegi.org.mx/est/contenidos/proyectos/aspectosmetodologicos/ clasificadoresycatalogos/sinco.aspx.

INEGI (2011b). Sistema Nacional de Clasificación de Ocupaciones (SINCO): Crosswalk Between SINCO and CMO. http://www.inegi.org.mx/est/contenidos/ proyectos/aspectosmetodologicos/clasificadoresycatalogos/doc/ sinco_tablas_comparativas.xls.

Kaestner, R. and Malamud, O. (2014). Self-Selection and International Migration: New Evidence from Mexico. Review of Economics and Statistics, 96(1):78-91.

McKenzie, D. and Rapoport, H. (2010). Self-Selection Patterns in Mexico-U.S. Migration: The Role of Migration Networks. Review of Economics and Statistics, 92(4):811-821.

Minnesota Population Center (2015). Integrated Public Use Microdata Series, International: Version 6.4 [Machine-readable database]. Minneapolis, MN: University of Minnesota. 
Mishra, P. (2007). Emigration and Wages in Source Countries: Evidence from Mexico. Journal of Development Economics, 82(1):180-199.

Orrenius, P. M. and Zavodny, M. (2005). Self-Selection Among Undocumented Immigrants from Mexico. Journal of Development Economics, 78(1):215-240.

Parey, M., Ruhose, J., Waldinger, F., and Netz, N. (2017). The Selection of High-Skilled Emigrants. Review of Economics and Statistics, forthcoming.

Peri, G. (2012). The Effect of Immigration on Productivity: Evidence from U.S. States. Review of Economics and Statistics, 94(1):348-358.

Peri, G. and Sparber, C. (2009). Task Specialization, Immigration, and Wages. American Economic Journal: Applied Economics, 1(3):135-169.

Ramos, F. A. (1992). Outmigration and Return Migration of Puerto Ricans. In Borjas, G. J. and Freeman, R. B., editors, Immigration and the Workforce: Economic Consequences for the United States and Source Areas, chapter 2, pages 49-66. Chicago, IL: University of Chicago Press.

Rendall, M. S. and Parker, S. W. (2014). Two Decades of Negative Educational Selectivity of Mexican Migrants to the United States. Population and Development Review, 40(3):421-446.

Ruggles, S., Genadek, K., Goeken, R., Grover, J., and Sobeku, M. (2015). Integrated Public Use Microdata Series: Version 6.0 [Machine-readable database]. Minneapolis, MN: University of Minnesota.

Stolz, Y. and Baten, J. (2012). Brain Drain in the Age of Mass Migration: Does Relative Inequality Explain Migrant Selectivity? Explorations in Economic History, 49(2):205-220. 